\title{
IT governance transparency : an empirical assessment of information disclosure on IT governance
}

Citation for published version (APA):

Joshi, A. S. (2013). IT governance transparency : an empirical assessment of information disclosure on IT governance. [Doctoral Thesis, Maastricht University]. Maastricht University. https://doi.org/10.26481/dis.20130704aj

Document status and date:

Published: 01/01/2013

DOI:

10.26481/dis.20130704aj

Document Version:

Publisher's PDF, also known as Version of record

\section{Please check the document version of this publication:}

- A submitted manuscript is the version of the article upon submission and before peer-review. There can be important differences between the submitted version and the official published version of record.

People interested in the research are advised to contact the author for the final version of the publication, or visit the DOI to the publisher's website.

- The final author version and the galley proof are versions of the publication after peer review.

- The final published version features the final layout of the paper including the volume, issue and page numbers.

Link to publication

\footnotetext{
General rights rights.

- You may freely distribute the URL identifying the publication in the public portal. please follow below link for the End User Agreement:

www.umlib.nl/taverne-license

Take down policy

If you believe that this document breaches copyright please contact us at:

repository@maastrichtuniversity.nl

providing details and we will investigate your claim.
}

Copyright and moral rights for the publications made accessible in the public portal are retained by the authors and/or other copyright owners and it is a condition of accessing publications that users recognise and abide by the legal requirements associated with these

- Users may download and print one copy of any publication from the public portal for the purpose of private study or research.

- You may not further distribute the material or use it for any profit-making activity or commercial gain

If the publication is distributed under the terms of Article $25 \mathrm{fa}$ of the Dutch Copyright Act, indicated by the "Taverne" license above, 


\section{IT Governance Transparency}

An Empirical Assessment of Information Disclosure on IT Governance

Anant Joshi 
C Copyright Anant Joshi, Maastricht 2013.

All rights reserved. No part of this thesis may be reproduced or transmitted in any form or by any means, electronic or mechanical, including photocopying, recording, or any information storage or retrieval system without permission from the author, or when appropriate, from the publishers of the publications.

Cover Design: Shailesh Newalkar

ISBN 9789461592415 


\section{IT Governance Transparency}

\section{An Empirical Assessment of Information Disclosure on IT Governance}

\section{DISSERTATION}

to obtain the degree of Doctor at Maastricht University, on the authority of the Rector Magnificus, Prof.dr. L.L.G Soete in accordance with the decision of the Board of Deans, to be defended in public

on Thursday July 4, 2013, at 16:00 hours

by

Anant Joshi 


\section{Promoter}

Prof.dr. Harold Hassink

\section{Co-promoter}

Dr. Laury Bollen

\section{Evaluation Committee}

Prof.dr. Roger Meuwissen RA (Chair)

Prof.dr. Wim Van Grembergen (University of Antwerp)

Prof.dr. Frank Harmsen

Prof.dr. Steven De Haes (University of Antwerp)

This research is funded by the Graduate School of Business and Economics (GSBE), formerly known by Maastricht Research School of Economics of Technology and Organization (METEOR). 


\section{Acknowledgements}

For the past several years, working on my $\mathrm{PhD}$ dissertation was an enriching journey in many ways. It has provided me with plenty of opportunities to learn and develop myself as a researcher. It has introduced me to new eye opening knowledge, brilliant academic scholars, new cultures, new colleagues, and some great friends. All of this gives me a great sense of contentment and a feeling of gratitude toward all those who made this journey a memorable one.

First and foremost, I am deeply indebted to my co-promoter dr. Laury Bollen for his invaluable supervision. My journey as a $\mathrm{PhD}$ student would have been impossible without his helpful guidance, suggestions, and critical views. I was fortunate to have Laury as my supervisor. Not only did I learn a lot from him, but also received great encouragement to explore my own research ideas. I am also extremely grateful to my promoter prof. dr. Harold Hassink for his motivation, valuable inputs, and strong support since the beginning of my $\mathrm{PhD}$ project. He has always encouraged me in my efforts to improve the quality of my research.

I would like to thank the members of the assessment committee, prof. dr. Roger Meuwissen, prof. dr. Wim Van Grembergen, prof. dr. Frank Harmsen, and prof. dr. Steven De Haes, for their prompt assessment of the dissertation.

I want to extend my gratitude to each of my former colleagues of the Department of Accounting and Information Management. I especially thank dr. Rita Walczuch, under whose coordination I embarked on my PhD journey. I learned a lot about management information systems from her in the initial year of my $\mathrm{PhD}$, and she has remained a strong source of encouragement and support through all these years. It is my pleasure to thank dr. Mark Vluggen for his invaluable support. From reading my first research proposal, providing critical and constructive feedback on the final draft of the dissertation, and finally drafting the Dutch summary of this dissertation. dr. Vluggen has been instrumental in many ways in my $\mathrm{PhD}$ journey. Likewise, I will remain thankful to him and Sylvia for developing my taste for cinema and reading. I sincerely thank dr. Thomas Thijssens for his tremendous help while walking through this challenging research journey and providing constructive feedback on the initial draft of the dissertation. I was also lucky to have him as my roommate. Over all these years, I have enjoyed his company and our laughter.

I further like to thank my other former roommates: Falko, Jorg, Nadine for her sheer cheerfulness, and Reka for her invaluable help on countless occasions. I extend my thanks to Julius, Mona, Jeroen, Ronny, Isabell, Thomas, Abiot, Patrick, Jonas, and Christoph, Judith, Britt, Lars, Golam, Nick, Miel, Femke, Nina, Leon, Meinderd, and Frans Volmer for their great company during, and after my AIM days! My special thanks to prof. Frank Moers, prof. Ann Vanstraelen, prof. Philip Vergauwen, prof. Erik Peek, dr. Rogier Deumes, dr. Caren Schelleman, dr. Brent Furneaux, dr. Alexander Bruggen, dr. Rick Cuijpers, dr.Jeroen Derwall, dr. An- 
nelies Renders, and dr. Isabella Grabner. Also, I am grateful to the staff at the secretary's office for their great support. Thanks Tanja, Marjo, Sabine, Sacha, Miranda, and Juliëtte!

I would like to express my gratitude to all the colleagues of the Department of Organization and Strategy who have welcomed me so warmly. My special thanks to dr. Wilko Letterie, prof. Martin Carree, dr. Peter Bollen, Gabri, Harold, Thijs, Christopher, Martijn, and Bas. I extend my thanks to Anita and Adela at the secretary's office for their kind support.

On my PhD voyage, I found some gem of a friend like Bossy and GM. I cannot imagine my journey without their advice, affection, hospitality, humour, and support. I am also grateful to dr.Höppe for his great friendship. It was great fun to explore my cooking skills together with Bossy and dr.Höppe. I am also thankful to them, along with David, for grooming me as a reliable goalkeeper! Moreover, I extend my sincere thanks to Andrea, Anka, Charlotte, Daniela, David, Myrthe, dr. Julio, Li Jia, Katrin, Dicku, Sebastian, Amaresh Bhai, Maarten, Sjir, Hannes, Sarah, Sovik, Michael, Omar, Paulo, dr. Motta, Tom, Iraz, Jessica, Mukul, Abhimanyu, and Silja for their great friendship! A special thanks to a good friend dr.Mirjam Schönert for her great help in my first year.

Moreover, I am deeply indebted to Akhil and Laura for their great friendship, care, and hospitality. I extend my gratitude to Dhiraj, Sonia, Siddharth, Namrata, Mehul, Kanchan, Mayank, Ashish, Garima, and Sachin who offered me a MiniIndia in the form of festivity, bollywood, and cricket in Maastricht. I am grateful to your hospitality, love, and support. I like to extend my gratitude to some of my very close friends: Prasanna, Parag, Ashish, Pravin, Santosh, Aniket, Shruti, and Jaideep. Although most of them live in different continents and time zones, their friendship has remained invaluable and a great source of strength.

Without a doubt I have missed many to whom I owe a great gratitude. For all those I also would like to extend a sincere thanks. I hope you can forgive me for the omission.

In this educational pursuit, my greatest debt is to my father, my elder brother dr. Prashant, my sister-in-law Devika, and my niece Pragati. Their unconditional support has given me copious freedom to complete my dissertation. I finally dedicate the dissertation to my late mother, who always appreciated education over all material things. I will remain indebted to my parents for their sacrifices and giving me an opportunity to study abroad.

\section{Anant Joshi}

May, 2013 


\section{Table of Contents}

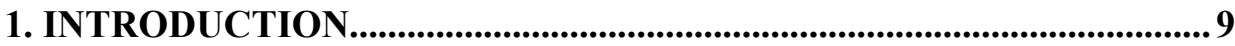

1.1. Scope and objective .......................................................................................... 9

1.2. Significance of IT governance transparency ...................................................12

1.3. Dissertation outline ...............................................................................................13

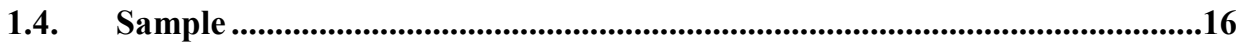

1.5. Dissertation Structure ...........................................................................................17

2. AN EMPIRICAL ASSESSMENT OF IT GOVERNANCE

TRANSPARENCY: EVIDENCE FROM COMMERCIAL BANKING' ...19

2.1. Introduction .....................................................................................................20

2.2. Background............................................................................................................22

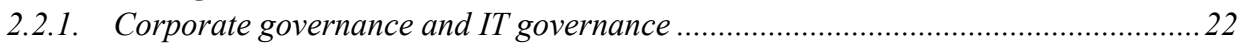

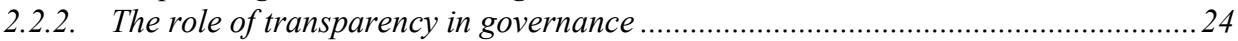

2.3. Research Questions ................................................................................................25

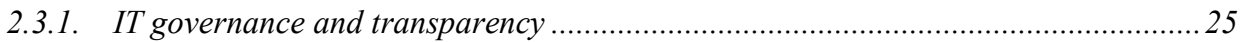

2.3.2. Influence of corporate governance environment ……….....................................26

2.3.3. External corporate governance environment ……………………………….......26

2.3.4. Internal corporate governance environment ………………………………......2 28

2.4. A Framework for IT Governance Disclosure …….......................................28

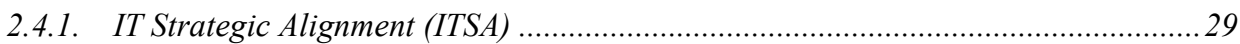

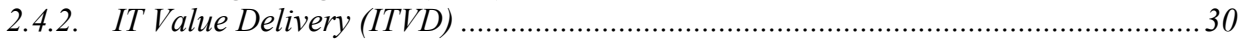

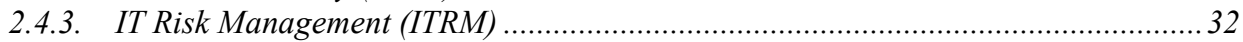

2.4.4. IT Performance Measurement (ITPM) .................................................................... 33

2.5. Research Methodology ....................................................................................33

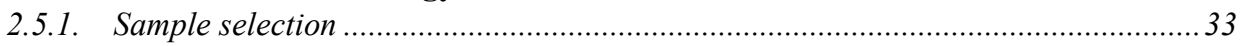

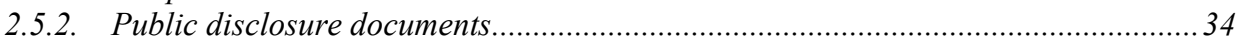

2.5.3. Categories of the IT governance disclosure framework …......................................... 34

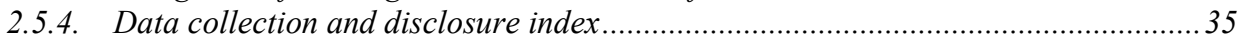

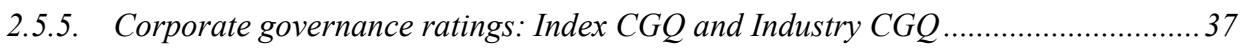

2.5.6. Data classification: Country groups and CGQ groups...........................................37

2.6. Results and Discussion ...........................................................................................38

2.6.1. IT governance disclosure framework: Item-level analysis......................................38

2.6.2. IT governance disclosure framework: Category-level analysis ............................40

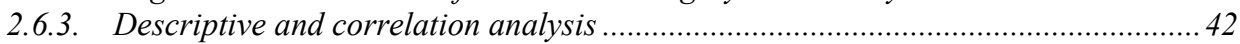

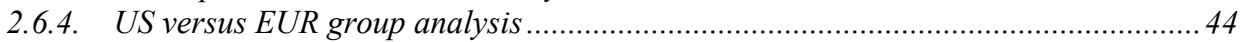

2.6.5. The effect of the corporate governance rating ………………………………........4 45

2.7. Summary, contribution, limitations and future research .................................47

3. BOARD OF DIRECTORS, OWNERSHIP STRUCTURE, AND IT GOVERNANCE TRANSPARENCY......................................................51

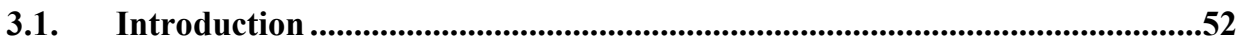

3.2. Background and Hypotheses ................................................................................54 


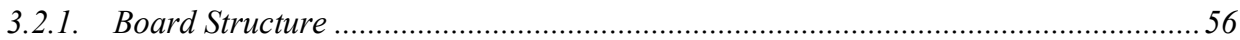

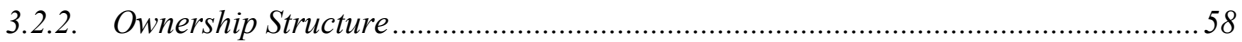

3.3. Research Methodology .....................................................................................60

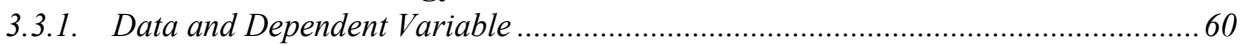

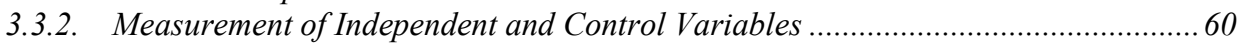

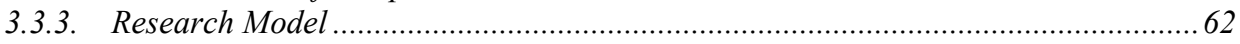

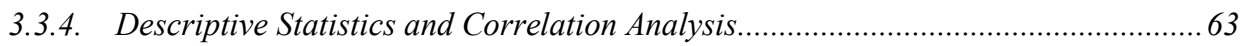

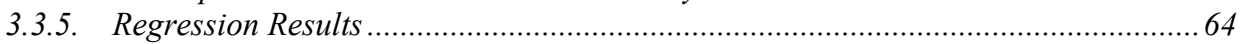

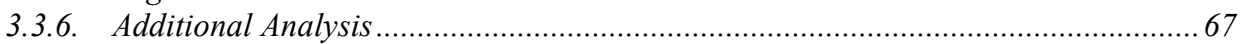

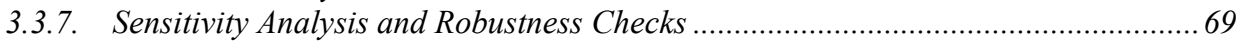

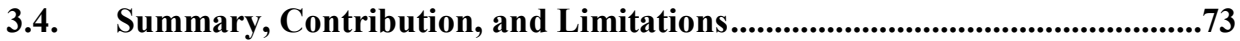

\section{IT GOVERNANCE MATURITY, INDUSTRY IT STRATEGIC} ROLE, AND IT GOVERNANCE DISCLOSURE......................................75

4.1. Introduction ...............................................................................................................76

4.2. Background and Hypotheses ........................................................................78

4.2.1. COBIT as IT governance framework ...................................................................... 78

4.2.2. The association between IT governance maturity and IT governance disclosure.....81

4.2.3. Industry IT strategic role and IT governance disclosure ............................................ 84

4.2.4. Moderating effect of Industry IT strategic role ................................................... 87

4.3. Research Method ................................................................................................88

4.3.1. Sample, data, and variable measurement ................................................................. 88

4.3.2. Dependent, independent and control variables.................................................. 90

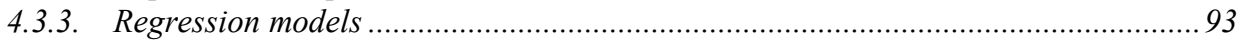

4.4. Results ................................................................................................93

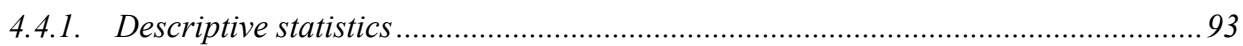

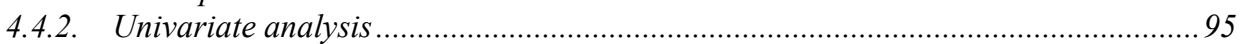

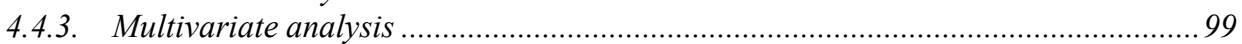

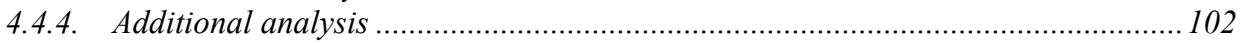

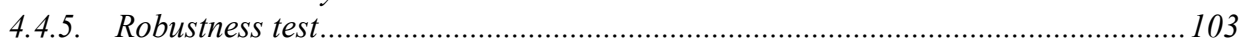

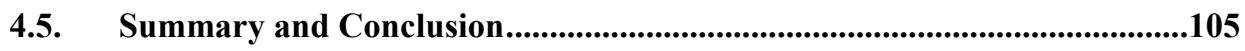

5. SUMMARY AND CONCLUSION........................................................109

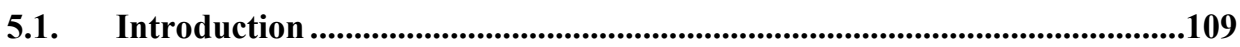

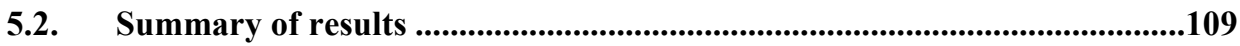

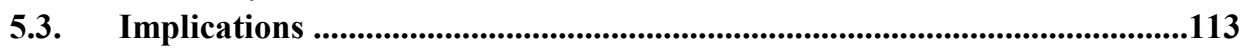

5.4. Limitations and recommendations for future research .............................114

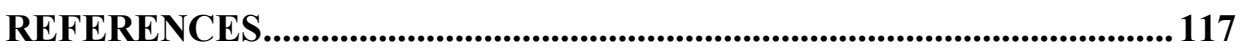

APPENDIX A: IT GOVERNANCE DISCLOSURE FRAMEWORK ..... 125

APPENDIX B: EXAMPLES OF IT GOVERNANCE DISCLOSURE .... 129

APPENDIX C: COBIT DOMAINS AND IT PROCESSES ......................133

APPENDIX D: COBIT FRAMEWORK SURVEY .................................... 135

SAMENVATTING (SUMMARY IN DUTCH).....................................137

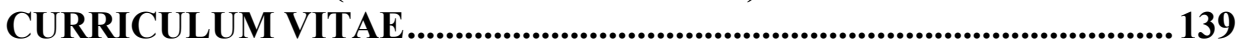




\section{1.}

\section{INTRODUCTION}

\subsection{Scope and objective}

In today's business environment, firms rely heavily on Information Technology (IT) to manage their business operations and to offer products and services to customers. Accordingly, firms are spending heavily on strengthening their IT capabilities to compete in the marketplace and sustain their position. Gartner, a leading IT research and advisory firm, notes that worldwide spending on IT is expected to reach $\$ 2.679$ trillion in 2013; this is a $2.5 \%$ increase over spending in 2012 (Gartner, 2012). Data from the U.S. Department of Commerce show that on average $3 \%-4 \%$ of a firm's capital revenue is spent on IT investments (US Commerce, 2003). In the last two decades, information systems research has extensively investigated the association between IT spending and its contribution to firm performance. As this research shows wide variance in the association between the two constructs (Brynjolfsson \& Hitt, 1996; Davis, Dehning, \& Stratopoulos, 2003), the proper governance of IT is seen as an important determinant of returns on IT investments. Weill and Ross (2004) show that firms with superior IT governance have outperformed poorly governed firms, and that the former reported $25 \%$ higher profits, by comparison. According to a recent global status report on IT governance by the IT Governance Institute (ITGI, 2011), firms are increasingly focusing on IT governance to ensure better returns on IT investments, to lower IT costs, and manage IT risks.

The concept of IT governance entails broader principles and mechanisms of corporate governance - a system by which a firm and its key resources are directed and controlled. IT governance is defined as "the subset of corporate governance that provides IT structures, processes, and relational mechanisms to 
sustain and extend organization's strategy and objectives" (Van Grembergen \& De Haes, 2009, p. 3). Over the last two decades, IT governance scholars have made significant contributions to our theoretical understanding of how different variables (e.g. organizational culture, competitive strategy, firm size) influence IT governance in firms. In the late nineties, researchers were interested in understanding the role and influence of different IT decision-making arrangements in firms. Later on, the focus was extended to, for example, IT risk management, IT performance evaluation, and IT business alignment. This extension of the focus could be attributed in large part to the growing impact of IT on business functions as well as to the introduction of the Sarbanes-Oxley Act (SOX). In response to the major accounting scandals of the last decade (e.g. Enron and WorldCom), the SOX provided guidelines for improving corporate governance mechanisms, including the reliability of financial reporting and effectiveness of the audit. Since IT-enabled infrastructure in firms has served as the backbone for assimilating financial and non-financial information for almost two decades now, the internal control and governance of management information systems has become a top priority for firms. Consequently, the practical and managerial implications of IT governance have come to the forefront. To help practitioners and firms, specific frameworks and standards have been developed to establish IT governance. For example, today, the IT Governance Institute's Control Objectives for Information and Related Technologies (COBIT) is one of the most widely implemented IT governance frameworks across different industries. Deploying such a framework, firms are now better able to establish effective and efficient IT governance practices to monitor and evaluate their information and IT assets.

A review of current IT governance literature suggests that the scope of IT governance research has been oriented predominately towards the internal environment of firms. Drawing on organization theory and corporate governance literature, this research has enriched our understanding of how firms allocate IT decision rights and accountabilities, manage IT risks, measure IT performance, and align their IT strategy with the firm's overall business strategy (Wilkin \& Chenhall, 2010). However, transparency - a key corporate governance mechanism to uphold stakeholder confidence - is still not fully instilled and understood in IT governance research. From a corporate governance view, firms are also responsible for taking into account the interests of external stakeholders while managing and governing key assets like IT. Recognizing that firms are becoming increasingly dependent on IT assets to achieve operational and strategic goals, it can also raise important issues, such as effective IT decision making and management control, IT investment priorities, and IT risk management. 
Consequently, a review of the traditional models of IT governance and the communication of IT governance to uphold stakeholder confidence are important topics in ensuring effective IT governance. Information disclosure on IT governance can help the different stakeholders of a firm (for example, customers, investors, analysts) to assess the quality of IT governance activities. However, extant literature has largely ignored IT governance disclosure. To alleviate this scarcity of research on IT governance transparency, in this dissertation I focus on: (1) exploring how firms disclose their IT governance practices, (2) how corporate governance relates to IT governance transparency and (3) whether the adoption of best practices on IT governance and the strategic role of IT are associated with IT governance transparency. More specifically, drawing on economic theory, I examine the association of corporate governance, IT governance, and the strategic role of IT with the level of IT governance disclosure. Accordingly, the principal objective of the dissertation is to evaluate the fundamental definition of IT governance, which portends that the governance of IT is an integral part of corporate governance. I propose that these research questions are relevant and important in advancing the current understanding of IT governance. While current IT governance literature does not provide any single instrument for assessing a firm's disclosure of IT governance, this dissertation helps to develop a comprehensive disclosure framework for addressing this issue. It also helps to further understand the role of corporate governance in IT governance, which is largely unexplored in the information systems literature.

This dissertation makes several important theoretical contributions to the existing body of research. First, it introduces the concept of transparency to the IT governance literature. Until now, IT governance studies have focused mainly on topics such as IT decision control, IT investment, and IT risk management, paying little attention to the significance and role of IT governance disclosure. This dissertation presents one of the first studies for developing an independent IT governance disclosure framework to examine the association between transparency and IT governance. Second, this dissertation advances our understanding of the role of corporate governance mechanisms and their impact on IT governance transparency. Third, this dissertation further examines the effects of IT governance maturity via the adoption of an IT governance framework based on best practices. In this way, the results presented add to our understanding of how IT governance initiatives at the firm level improve opportunities for IT governance disclosure. Moreover, this dissertation indicates that the strategic role IT serves at the industry level in which firms operate is associated with IT governance transparency. This finding extends and corroborates prior research, 
which states that IT information disclosure is systematically associated with the strategic role of IT.

This dissertation has some important managerial implications. For senior managers of firms (such as CIOs or CFOs), this dissertation provides a comprehensive IT governance reporting instrument. Using the IT governance disclosure framework, I expect that managers can formulate, extend, and improve IT reporting practices in public documents. Recognizing that there is IT attention deficit at the board level, the proposed framework can also be used by boards of directors to assess executive management's approach in the use of IT. The framework can also be used effectively by analysts, investors, and IT consultants to benchmark the IT governance practices of individual firms. Currently, the existing IT governance frameworks (e.g., COBIT and ITIL) do not cover exclusive guidelines on the IT governance disclosure behaviour of organizations. I therefore expect that the IT governance disclosure framework can prove to be a suitable reporting instrument, together with frameworks based on best practice, for improving external communication on IT topics.

\subsection{Significance of IT governance transparency}

In the context of this dissertation, the term IT governance transparency essentially implies the extent to which firms provide IT governance information in their corporate disclosure ${ }^{1}$. The disclosure in public documents of information about IT-related activities is voluntary for firms. Thus, voluntary disclosure literature offers a useful theoretical framework for explaining under which conditions firms are willing to provide more information on IT governance. Voluntary disclosure and agency theory predicts that firms can improve their liquidity and firm valuation through better information intermediation, thus enhancing market reputation, reducing litigation costs, and reducing the cost of capital (Diamond \& Verrecchia, 1991; Healy \& Palepu, 2001; Jensen \& Meckling, 1976; Narayanan, Pinches, Kelm, \& Lander, 2000). Consistent with this, some notable studies in the information systems literature have provided strong empirical evidence on the relevant value of voluntary IT information in corporate disclosure, and thereby confirmed the importance of IT disclosure in public documents (Gordon, Loeb, \& Lucyshyn, 2003; Gordon, Loeb, \& Sohail, 2010). Drawing on these studies, I identify that voluntary disclosure literature and

\footnotetext{
${ }^{1}$ The term IT governance transparency is used interchangeably with IT governance disclosure in this dissertation.
} 
agency theory provide theoretical frameworks with which to address the research questions of this dissertation.

\subsection{Dissertation outline}

In this dissertation, I present three distinct but related studies. In Chapter Two, I first develop an IT governance disclosure framework. This framework provides a comprehensive measurement instrument for assessing firms' transparency regarding IT governance in all three studies presented in this dissertation. In Chapter Two, I examine the association of external and internal corporate governance to the level of IT governance disclosure. Specifically, I examine the association of 1) external corporate governance by contrasting US firms with European firms on the basis of their corporate governance, and 2) internal corporate governance as characterized by taking into account the quality of corporate governance at the firm level.

Previous corporate governance studies suggest that the US and continental European countries differ in their corporate governance (Aguilera \& Jackson, 2003; Millar, Eldomiaty, Choi, \& Hilton, 2005). The US corporate governance model is characterized by dispersed ownership structures, an active market for corporate control, and financing through equity. On the other hand, the European corporate governance model is subjected to ownership by large block holders, a weak market for corporate control, and reliance on long term debt financing (Becht \& Rodl, 1999; Berglof, 1991; Hall \& Soskice, 2001). I assume that this fundamental difference offers a useful insight into the effect of the external corporate governance environment on IT governance transparency. Specifically, I hypothesize that differences in the external corporate governance environment will induce different sets of expectations on IT governance disclosure. In the second research question, I focus on the association between IT governance transparency and the internal corporate governance environment of the firm. An underlying assumption in testing this association is that a superior quality of the internal corporate governance environment can induce effective IT governance practices across different layers of the firm. In theory, IT governance is the responsibility of the board of directors and executive management of the firm. A number of studies in the information systems literature report the significance of the role of the board of directors, chief information officers, IT steering or technology committees in IT governance (e.g., Andriole, 2009; Jewer \& McKay, 2012; Merhout \& Havelka, 2008; Premuroso \& Bhattacharya, 2007). Drawing on these existing theoretical insights, I predict that the quality of internal corporate governance has a direct influence on IT governance. This, in turn, is likely 
to affect the level of IT governance disclosure. I measure the quality of internal corporate governance using the Corporate Governance Quotient (CGQ) from Institutional Shareholder Services (ISS). The CGQ represents a ranking system designed specifically to evaluate the quality of corporate governance using 65 different rating criteria across eight core categories for US firms and 55 rating criteria for non-US firms.

In Chapter Three I extend my focus further on the internal and external corporate governance environment. I investigate the impact of board structure and ownership structure of firms on IT governance transparency. From an IT governance perspective, IT is a strategic asset for firms - it has direct implications for firms' long and short term firm performance as well as for operational risk. I therefore argue that IT governance information is critical for shareholders and the board of directors in assessing management's approach to the use of IT. Also, as noted earlier, IT governance is assumed to be the responsibility of the board of directors and executive management of the firm. In theory, the fundamental role of the corporate board is to mitigate agency problems that arise because of information asymmetry between the shareholders and managers of the firm. In this view, prior literature has examined the influence of ownership structure and board structure as mechanisms of corporate governance on a firm's voluntary disclosure behavior (Eng \& Mak, 2003; Kelton \& Yang, 2008; Lim, Matolcsy, \& Chow, 2007). An assumption underlying this stream of literature is that voluntary disclosure helps to alleviate agency problems. Since IT governance disclosure is voluntary, I apply these theoretical insights to develop hypotheses regarding the influence of ownership and board structure on the level of IT governance disclosure. In the study, ownership structure is characterized by managerial ownership and blockholder ownership. I characterize board structure by measuring board independence and the board size of firms.

In Chapter Four, I shift the focus to the IT governance initiatives of firms and the strategic role of IT at the industry level. In Chapter Four, I empirically explore the impact of: (1) the maturity of IT governance practices and (2) the strategic role of IT at the industry level on the level of IT governance disclosure. An underlying assumption in the chapter is that firm's information on ITrelated topics will be enriched because of the adoption of the IT governance framework based on best practices. This, in turn, is likely to increase firms' opportunities to disseminate IT governance disclosure to enhance stakeholder confidence. I test the hypothesis that a higher level of IT governance maturity is associated with more IT governance disclosure. Chapter Four also examines the strategic role of IT at the industry level in relation to IT governance transparency. Numerous studies exploring the role of IT at the industry level suggest that 
the strategic influence of IT at industry level can be classified into three categories, namely: automate, informate, and transform (Chatterjee, Richardson, \& Zmud, 2001; Dehning, Richardson, \& Zmud, 2003; Kobelsky, Richardson, Smith, \& Zmud, 2008). The automated category of industries is associated with the notion that IT replaces human labor in automating business processes in such an industry. IT is said to be informative when it helps firms in creating efficient and effective information flows for decision making across upper and lower levels of the firm. In its transforming role, IT is deployed to "fundamentally redefine business and industry processes and relationships" (Dehning, et al., 2003, p. 639). Drawing on this characterization, I address the question of whether the strategic role of IT in an industry induces systematic variation in IT governance disclosure. Previous studies examining the relevant value of IT disclosure report that transformative industries are associated with higher IT disclosure in comparison with automate industries. These results suggest that the economic consequences of IT disclosure for firms that operate in transforming industry groups are higher than for firms operating in informative or automated industries. However, these findings are limited to specific types of IT disclosure (e.g., IT investment announcements). I extend these findings to the context of IT governance. I assume that transforming and informative industries will be subjected to a higher dependency on IT resources as well as to scrutiny from a corporate governance view. I predict that the level of IT governance disclosure differs across industries, depending on the strategic role of IT in the respective industry. I expect that the strategic role of IT in transforming and informative industries is associated with a higher level of IT governance disclosure in comparison with automated industries. While studying the relevance and significance of different IT governance frameworks from the reference literature, I note that, in comparison with other industry groups, transformative industries are largely implementing best practices-based IT governance frameworks. Therefore, in Chapter Four, I also hypothesize that the association between the maturity of IT governance and the level of IT governance disclosure is moderated by the strategic role of IT at the industry level. Figure 1 illustrates the hypothesized associations of this dissertation. The dotted rectangle represents the scope of corporate governance considered for this dissertation. Within this scope, each of the solid rectangles lists various constructs employed in Chapters Two, Three, and Four. The associations that are the subject of this dissertation are represented by the solid lines. For example, the scope of Chapter Two is represented by connecting the solid rectangle labeled 'internal and external corporate governance' to the rectangle named 'IT governance disclosure' with a solid line. Similarly, the scope of other chapters is also depicted in 
Figure 1.1. Recognizing that the construct 'strategic role of IT in industry' is outside the scope of corporate governance, I represent this construct outside the dotted rectangle.

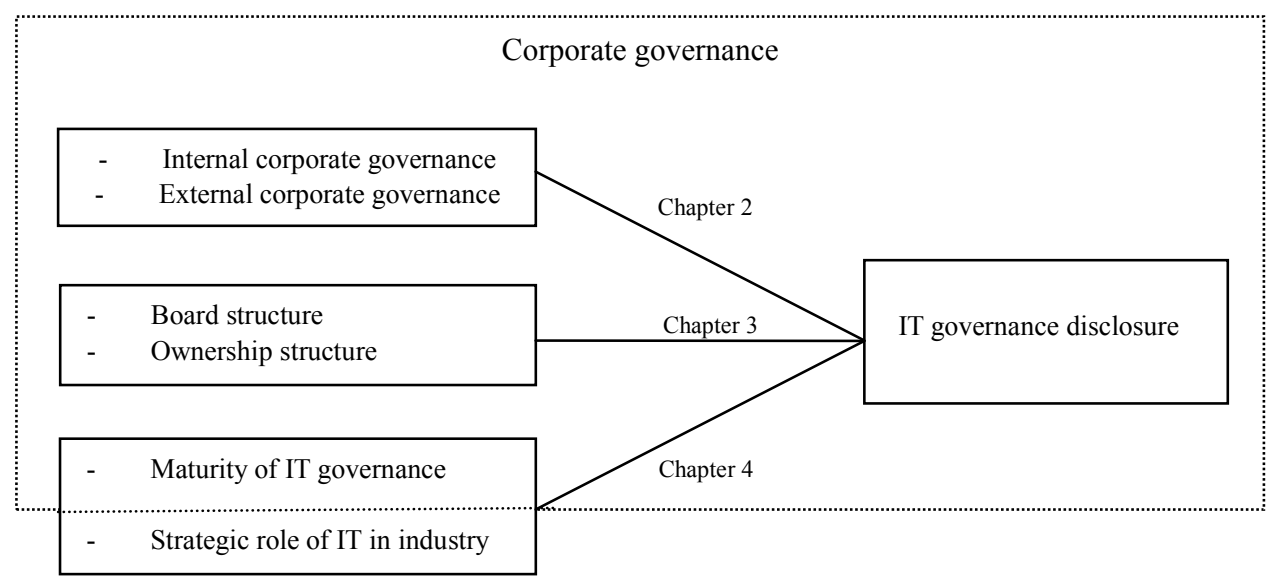

Figure 1.1. Overview of hypothesized associations of the dissertation

\subsection{Sample}

For all three studies in the dissertation, I used a cross-sectional research design. As noted earlier, the focus of Chapters Two and Three is on commercial banks. I selected samples of publicly listed commercial banks, both European and US, from the Morgan Stanley Capital International (MSCI) Barra index. I focused specifically on the biggest commercial banks in terms of market capitalization. The final sample contains 73 banks from 15 European countries and 127 banks from the US. Using content analysis (Weber, 1985), the data on IT governance disclosure are gathered via different sources of public disclosure such as annual reports, SEC filings, company websites, corporate governance documents, press releases, and corporate social responsibility (CSR) reports. Using content analysis, I studied all the aforementioned sources of public disclosure to examine whether each item on the IT governance disclosure framework (developed in Chapter Two) is reported or not. Data was collected from October 2008 to March 2009. To ensure the reliability of the coding procedure, I examined public documents with another coder on a limited sample of data to attain the sufficient level of inter-coder reliability. To study the impact of internal corporate governance, the Corporate Governance Quotient (CGQ) of the Institutional Shareholder Services (ISS) is used as a proxy. For Chapter Three, the additional data on ownership structure, board structure, and relevant firm accounting and financial information is obtained from the SEC filings, COMPUSTAT Global, 
and the DataStream. In Chapter Four, the empirical analysis is based on two data sources: 1) survey data on the self-assessment, by executives and managers of firms, of the maturity of IT governance, and 2) annual reports in a crosssectional setting for the year 2008. I obtained the survey data from a prior study conducted in 2008 to assess the implementation level of 34 COBIT processes.

\subsection{Dissertation Structure}

The remainder of this dissertation is arranged as follows. In Chapter Two, I present the study on the development of the IT governance disclosure framework and its association with internal and external corporate governance. In Chapter Three, I study the association of board structure and ownership structure with the level of IT governance disclosure. Chapter Four investigates the association of the maturity of IT governance and the strategic role of IT at the industry level with the disclosure of IT governance. In Chapter Five, I provide a conclusion and summary, contributions and limitations of this dissertation, and suggestions for future research. 



\title{
2.
}

\section{AN EMPIRICAL ASSESSMENT OF IT GOVERNANCE TRANSPARENCY: EVIDENCE FROM COMMERCIAL BANKING ${ }^{2,3}$}

\begin{abstract}
In this chapter, I develop an IT governance disclosure framework to examine how firms communicate their IT governance activities. Using this framework for a sample of 200 commercial banking firms, my empirical assessment indicates that differences in the level of disclosure are systematically related to differences in institutional settings. I also find that firms with relatively good corporate governance practices consider IT performance measurement matters to be highly important when informing and communicating with shareholders.

\footnotetext{
${ }^{2}$ This study is co-authored with Laury Bollen and Harold Hassink, and has been accepted for publication in Information Systems Management.

${ }^{3}$ I thank Frank Moers, Robin Braun, Jeroen Derwall, and Michael Viehs of the ECCE of Maastricht University for providing access to the corporate governance rating database of Institutional Shareholder Services. I would also like to thank the participants of the doctoral consortium of the Pacific Asia International conference on Information Systems (PACIS) 2009.
} 


\subsection{Introduction}

In trying to identify effective IT governance arrangements, many studies have documented the significance of various mechanisms of IT governance (for example, Andriole, 2009; Huang, Zmud, \& Price, 2010; Kambil \& Lucas, 2002; Sambamurthy \& Zmud, 1999; Trites, 2004; Weill \& Ross, 2004; Xue, Ray, \& $\mathrm{Gu}, 2011)$. In this body of literature, some specific mechanisms of corporate governance - such as decision rights, control, accountability, risk management - have been fully incorporated in the concept of IT governance. However, even though it has been recognised that transparency is also an important mechanism to ensure good governance (Millar, et al., 2005), the issue of transparency in IT governance has received little attention. Still, Davies (1999, p. vii) argues that "the foundation of all these governance codes is disclosure. Transparency is the key to the governance of any organization. Openness is also the basis of public confidence in institutions [. . .] openness and accountability are the governance watchwords and ethical standards are the basis on which lasting governance systems are built." Following a similar line of argumentation in the context of IT governance, Raghupathi (2007, p.98) emphasizes that "the transparency and accountability in IT governance can serve as a mechanism for firms to retain stakeholder confidence and create a positive image with the general public." While IT has emerged as a strategic resource in today's complex business environment, it can also raise critical issues, such as effective IT decision making and management control, IT investment priorities, and IT risk management. Therefore, a review of the traditional models of IT governance and the communication of IT governance to uphold stakeholder confidence are important topics in ensuring effective IT governance. However, existing research on IT governance has scarcely explored disclosure as a mechanism for improving IT governance practices. Therefore, the aim of this study is to examine (a) how firms communicate about their IT governance activities and (b) whether these communication activities (i.e., the level of IT governance disclosure) are associated with their environment of internal and external corporate governance.

It is important to understand that IT governance transparency can encompass the interest of internal as well as external stakeholders of an organization. While the communication of IT governance policies and guidelines to different levels of management and users as a whole within the organization addresses the internal stakeholder environment (Huang, et al., 2010), the dissemination of IT governance information in public corporate disclosure serves the interest of the external stakeholders of the organization. As far as the scope of this study is 
concerned, I am focusing especially on public corporate disclosure of IT governance practices in addressing the interests of external stakeholders.

In order to investigate IT governance transparency, I have developed a descriptive framework of IT governance disclosure. Using this disclosure framework, I conducted a content analysis to examine the level of IT governance disclosure across 200 commercial banking firms from European countries and the US. I specifically focused on the banking industry as the extant literature shows that the banking sector is heavily dependent on IT to improve operating efficiency (for example, Banker, Chen, Liu, \& Ou, 2009; Berger, 2003; Chiasson \& Davidson, 2005; Chowdhury, 2003; Fuß, Gmeiner, Schiereck, \& Strahringer, 2007; Zhu, Kraemer, Xu, \& Dedrick, 2004). Accordingly, a recent survey of the IT Governance Institute indicates that $47 \%$ of the financial sector firms in their study sample are in the process of implementing IT governance (ITGI, 2008; Van Grembergen \& De Haes, 2009). Thus, the commercial banking industry is regarded as an appropriate example for this study.

Next, the IT governance disclosure framework is used to address two research questions. First, the current literature on corporate governance suggests that the US and European corporate governance models differ from each other (Aguilera \& Jackson, 2003; Millar, et al., 2005). Given that IT governance is a subset of corporate governance, I investigate whether these institutional differences are reflected in the level of IT governance transparency. In this study, I posit these institutional differences as the influence of the external corporate governance environment on IT governance transparency. Second, the existing IT governance literature suggests that the quality of corporate governance practices is closely linked to the quality of IT governance (Gray, 2004; Heroux, 2010; ITGI, 2003; Parent \& Reich, 2009; Trites, 2004; Weill \& Ross, 2004). Consistent with the extant literature, I assume that the quality of corporate governance practices is positively related to the quality of IT governance practices, which subsequently encourages IT governance transparency. To verify this assumption, I examine whether there is an association between the quality of corporate governance practices and the level of IT governance disclosure.

This study contributes to the existing IT governance literature in several ways. First, it makes an important theoretical contribution by enriching the concept of transparency in the IT governance literature. Second, this paper advances our understanding of the role of the corporate governance environment and its impact on IT governance transparency. Third, I link the current IT governance literature with that on corporate disclosure, specifically with the voluntary disclosure literature. By doing so, this study not only introduces some new in- 
sights into IT governance, but also contributes to the interdisciplinary research between accounting, finance, and information systems.

The remainder of the paper is organized as follows: Section 2 provides the background of the research, including prior literature. Section 3 discusses the development of the research questions. The IT governance disclosure framework is described in Section 4. Section 5 describes the sample collection and research methodology. The results and discussion are presented in Section 6 . Finally, Section 7 presents the summary, contributions, and suggestions for future research.

\subsection{Background}

\subsubsection{Corporate governance and IT governance}

Most of the current literature in information systems indicates that the evolution of IT governance is based primarily on the principles and guidelines of corporate governance (Heart, Maoz, \& Pliskin, 2010; ITGI, 2003; Jordan \& Musson, 2004; Korac-Kakabadse \& Kakabadse, 2001; Mähring, 2006; Raghupathi, 2007; Van Grembergen \& De Haes, 2009; Weill \& Ross, 2004). Larcker, Richardson, \& Tuna (2007, p. 964) refer to "corporate governance as the set of mechanisms that influence the decisions made by managers when there is a separation of ownership and control". The board of directors, corporate disclosure, and institutional ownership are a few examples of these monitoring mechanisms that align the actions of managers with the interest of stakeholders.

In the early nineties, Henderson \& Venkatraman (1993) introduced the term IT governance in relation to the strategic alignment of business and IT. In their view, it is the selection and use of mechanisms (for example, collaboration with one or more vendors) to obtain the IT competence necessary to align business and IT. From then on, the concept of IT governance has been emerging gradually, specifically encompassing the mechanisms of corporate governance. Drawing an analogy to the principles of corporate governance, IT governance provides structures, processes and relational mechanisms to control and monitor the effectiveness of IT (De Haes \& Van Grembergen, 2009; Peterson, 2004; Willson \& Pollard, 2009). It ensures that "the organization's IT sustains and extends the organization's strategy and objectives" (ITGI, 2003, p. 10). Weill and Ross $(2004$, p. 8) define IT governance as "the decision rights and accountability framework to encourage desirable behavior in using IT". A study by Webb, Pollard and Ridley (2006, p. 7) to derive a definitive definition of IT governance concludes that "IT governance is the strategic alignment of IT with 
business such that maximum business value is achieved through the development and maintenance of effective IT control and accountability, performance management and risk management." In this study, I adhere to the definition on IT governance put forward by the IT Governance Institute (2003, p.11), which states that IT governance "consists of the leadership and organizational structures and processes that ensure that the organization's IT sustains and extends the organization's strategies and objectives". This definition is particularly useful in the context of my research, as it points towards areas on which companies should be transparent on.

IT governance is an important topic for two reasons. First of all, most organizations in today's complex and competitive business environment rely heavily on IT to improve operating efficiency and sustain competitive advantage (Mata, Fuerst, \& Barney, 1995). The effective governance of IT can support organizations in generating value-adding objectives from IT, thereby contributing to the broader objectives of corporate governance (Weill \& Ross, 2004). Second, IT governance can help organizations to arrange and specify an efficient IT decision making structure for a range of IT-related topics, such as IT investment, IT principles, and IT infrastructure management (Sambamurthy \& Zmud, 1999; Weill \& Ross, 2004; Xue, Liang, \& Boulton, 2008; Xue, et al., 2011).

As noted, a majority of the information systems literature has been influenced by corporate governance principles in conceptualizing IT governance and its mechanisms (for example, Peterson, 2004; Van Grembergen \& De Haes, 2009; Weill \& Ross, 2004). Some tightly linked mechanisms include decision rights, accountability, and risk management (for example, Brown, 1997; Huang, et al., 2010; Parent \& Reich, 2009; Sambamurthy \& Zmud, 1999; Weill \& Ross, 2004). A closer examination of this literature reveals that IT governance research has mainly concentrated on IT management and IT decision making (i.e., centralized, decentralized, and hybrid IT decision structures). Brown and Grant (2005) specify that such IT decision structures are one form of IT governance. Focusing only on this particular IT governance form, contemporary IT governance literature has explored many different facets of IT governance, such as the role of the board of directors, the effectiveness of the IT steering committee, IT control and firm performance, IT investment performance, and IT audit issues (Boritz \& Lim, 2008; Gu, Xue, \& Ray, 2008; Huff, Maher, \& Munro, 2006; Mähring, 2006; Merhout \& Havelka, 2008; Prasad, Heales, \& Green, 2009; Trites, 2004). 


\subsubsection{The role of transparency in governance}

Beyond financial transparency, many of the principles and guidelines on corporate governance advocate the disclosure of non-financial issues (for example: OECD, 2004; UNCTAD, 2006). Disclosure focusing on various non-financial topics (for example, IT governance, corporate social responsibility, intellectual capital) might address the interest of different stakeholders. In making disclosures on these topics firms can reduce information asymmetry and improve the firm's valuation (Botosan, 1997; Healy \& Palepu, 2001). Transparency, therefore, has evolved as one of the mechanisms to safeguard the interest of different stakeholders of a firm (Hsiang-Tsai \& Li-Jen, 2010; Jiang, Raghupathi, \& Raghupathi, 2009; Millar, et al., 2005; Patel \& Dallas, 2002) and recently empirical studies have specifically examined the influence of corporate governance on transparency to exemplify this claim (Eldomiaty \& Choi, 2006; Eng \& Mak, 2003; Hermalin \& Weisbach, 2007). These studies, for example, show that higher board independence and outside ownership have a positive impact on reporting behaviour of firms.

Surprisingly, while most of the principles of corporate governance are well incorporated into current IT governance literature, very little attention has been given to IT governance transparency. Following the corporate governance transparency literature, I define IT governance transparency as the extent to which firms provide adequate and relevant IT governance information in a timely and effective manner to their stakeholders, such as investors, policy makers, and regulatory bodies, so that they can assess management's behaviour in using IT (Eldomiaty \& Choi, 2006; Millar, et al., 2005).

In recent years specific IT governance standards, such as the ISO/IEC 38500 (2008), have been introduced to guide the directors of firms on the effective, efficient, and acceptable use of IT within their organisation. In order to initiate an effective IT governance program, the IT Governance Institute's board briefing (2003) has laid out principles and guidelines to help the top management of firms. While most of these standards and guidelines encourage the use of communication policies and practices as an effective control mechanism of IT governance, extant IT governance research has not provided any evidence on how firms practice it. Accordingly, the purpose of the study is to increase our understanding of how firms exhibit their competence in effective governance of IT. 


\subsection{Research Questions}

\subsubsection{IT governance and transparency}

Disclosure of information on IT governance activities is voluntary. I therefore propose that the literature on voluntary disclosure (for example, voluntary disclosure of corporate governance, intellectual capital) offers useful insights into the circumstances under which firms are willing to provide more information on IT governance than is required. From an economic perspective, the existing literature suggests that firms' voluntary disclosures may lead to capital market benefits. Such benefits include reduced cost of capital (Barry \& Brown, 1984, 1985; Barry \& Brown, 1986; Easley \& O’Hara, 2004; Vanstraelen, Zarzeski, \& Robb, 2003), improvement in liquidity (Diamond \& Verrecchia, 1991; Kim \& Verrecchia, 1994), and better information intermediation (Bhushan, 1989; Lang \& Lundholm, 1996). Thus, firms with average-to-better performance have an incentive to disclose more information to improve firm valuation, in comparison with underperforming firms (Clarkson, Li, \& Richardson, 2004; Lang \& Lundholm, 1996).

Using this theoretical framework, I suggest that firms with better IT performance due to their effective IT governance practices have an incentive to inform their stakeholders. In doing so, firms will enable stakeholders to distinguish between firms with high and low quality of IT governance practices. As a result, better performing firms can improve their firm's valuation. Based on the above theoretical premise, I developed an IT governance disclosure framework in order to observe how and where firms are reporting on their IT governance initiatives. The first two research questions in this study are therefore oriented towards examining the disclosure of IT governance activities through public disclosure. Under the first question, I investigate what main topics of IT governance are included in public disclosure.

RQ 1: What topics of IT governance are reported in public disclosures?

In addition, I assume that firms may use various public disclosure mediums such as the annual report, press releases, company website - to convey information on IT governance topics. Therefore, the second question examines what different public disclosure mediums are being used to communicate IT governance activities. 
RQ 2: In what public disclosure media can information on IT governance topics be found?

\subsubsection{Influence of corporate governance environment}

In a comprehensive review of existing corporate governance literature, Gillan (2006) proposes a broad framework of corporate governance mechanisms through two distinct categories - internal governance and external governance. According to his classification, internal governance includes monitoring mechanisms such as the board of directors, managerial incentives, capital structure, bylaws and charter provisions, and the internal control system (which includes information systems). These mechanisms exist to protect the interest of different stakeholders within the operating environment of firms. On the other hand, the external corporate governance mechanisms exist outside of the operating environment of firms. Some of these external monitoring mechanisms include laws and regulations (for example, the Sarbanes Oxley Act, 2002; UK Combined Code), the political environment, different markets and private sources of external oversight. As IT governance reflects the broader principles of corporate governance (Weill \& Ross, 2004), I therefore anticipate that both the internal and external corporate governance environment will influence IT governance mechanisms. In this study, I specifically focus on IT governance transparency as one of the mechanisms of IT governance, and on how this particular mechanism is influenced by these two distinct corporate governance environments.

Using Gillan's (2006) classification of internal and external corporate governance, I develop two specific research questions (RQ3 and RQ4). In the third research question (RQ3), I examine how the external corporate governance environment of a firm influences IT governance disclosure. I posit the difference between the US versus the European corporate governance model as an influence of the external corporate governance environment. The fourth research question (RQ4) examines the influence of the internal corporate governance of a firm on IT governance disclosure by looking at the impact of corporate governance practices on IT governance disclosure.

\subsubsection{External corporate governance environment}

Existing literature on corporate disclosure and corporate governance posits that the US and European countries differ in their approach to both these issues (Aguilera \& Jackson, 2003; Millar, et al., 2005). While evaluating US versus European models of corporate governance, researchers have characterized the 
former in terms of dispersed ownership, an active market for corporate control, flexible labor markets, and financing through equity, and the latter in terms of ownership by holders of large blocks, a weak market for corporate control, rigid labor laws and being subject to long-term debt financing (Aguilera \& Jackson, 2003; Becht \& Rodl, 1999; Berglof, 1991; Hall \& Soskice, 2001; Millar, et al., 2005; Shleifer \& Vishny, 1997). In the European business system, there are close links between industry and banking, and considerable emphasis is placed on the group orientation of society and on communitarian values (Eldomiaty \& Choi, 2006). Millar et al. (2005) suggest that these differences influence corporate practices of corporate governance. Considering transparency as a key mechanism of corporate governance, governance disclosure is also influenced by these different business systems. Therefore, I hypothesize that differences in the external corporate governance environment will induce different sets of expectations on disclosure requirements. Accordingly, there is likely to be a difference in IT governance disclosure across these two continents.

To support my proposition, I also refer to existing studies on the relationship between voluntary disclosure and corporate governance mechanisms. These studies specifically examine the link between voluntary disclosure and ownership structure as a mechanism of corporate governance (for example, Baek, Johnson, \& Kim, 2009; Chau \& Gray, 2002; Eng \& Mak, 2003; Forker, 1992; Kelton \& Yang, 2008; Makhija \& Patton, 2004; Xiao \& Yuan, 2007). Given that IT governance disclosure is voluntary, these studies are also applicable in examining the association between different arrangements for corporate governance and the transparency of IT governance. The findings of these studies indicate that the level of voluntary disclosure is positively associated with outside ownership, negatively related to managerial ownership and that results are mixed for blockholder ownership. I extend and apply these findings to the prior discussion on the dissimilarity between US versus European models for corporate governance. Given that the US corporate governance model is dispersed in terms of ownership structure and that the European model is more influenced by blockholder ownership, I anticipate that the US corporate governance arrangement will effect higher disclosure in comparison with the European model of corporate governance. When this theoretical premise is applied to IT governance disclosure, the following research question can be developed:

RQ3: To what extent does the US corporate governance arrangement encourage more extensive IT governance disclosure in comparison with European countries? 


\subsubsection{Internal corporate governance environment}

The internal corporate governance environment of a firm consists of the board of directors, managerial incentives, bylaw and charter provisions, capital structure, and an internal control system (Gillan, 2006). To enhance the level of IT governance, a number of studies have suggested several mechanisms, including structure, processes, relational aspects, and internal policies and procedures for governing IT (Ali \& Green, 2009; Huang, et al., 2010; Prasad, et al., 2009; Raghupathi, 2007; Van Grembergen \& De Haes, 2004). Based on these existing insights into the association between corporate and IT governance, I suggest that the development of IT governance and its mechanisms (including IT governance transparency) is associated with the quality of internal corporate governance practices of a firm. In other words, internal corporate governance structures help to shape efficient IT decision-making and control mechanisms, and better accountability and transparency on of information and IT assets. Therefore, I expect that the quality of internal corporate governance is positively associated with the level of IT governance transparency. To examine this assumption, I formulate the fourth research question of the study:

RQ4: To what extent is the quality of internal corporate governance practices positively associated with the level of IT governance disclosure?

\subsection{A Framework for IT Governance Disclosure}

Corporate disclosures of IT governance do not adhere to any standardized or mandatory reporting format which could be used by reporting firms to structure their disclosures. Although various IT governance frameworks are available (for example, COBIT, ITIL), few of these provide guidance on external reporting issues ${ }^{4}$. COBIT, under one of its key domains termed as 'monitor and evaluate', encourages board reporting to stakeholders as a key IT goal in providing effective IT governance (McFarlane, 2005). However, guidance is not offered on its implementation in external reporting practices. Also, the existing IT governance literature does not propose any single standard framework to assess the IT governance disclosure behaviour of organizations. As described earlier in the back-

\footnotetext{
${ }^{4}$ Information Technology Infrastructure Library (ITIL) is a comprehensive documentation of best practices for IT Service Management, whereas Control Objectives for Information and related Technology (COBIT) enables clear policy development and best practices for IT control throughout organizations.
} 
ground section, the present literature provides various definitions, and subsequently a range of constructs to describe the concept of IT governance (For example, ITGI, 2003; Van Grembergen \& De Haes, 2004; Webb, et al., 2006; Willson \& Pollard, 2009). This literature typically describes IT governance in the form of different structures, processes, domains, facets, and elements, which potentially could all be used to provide a reporting framework on IT governance issues. For example, Van Grembergen and De Haes (2004) argue that IT governance can be deployed using a mixture of various structures, processes, and relational mechanisms. However, Willson and Pollard (2009) argue that these terms - although important concepts - do not define IT governance, and they identify six IT governance facets which determine the scope of IT governance. Similarly, ITGI (2003) describe five distinct focus areas of IT governance, each of which is driven by stakeholder values. "Sustaining the current business and growing into new business models are certainly stakeholder expectations and can be achieved only with adequate governance of the enterprise's IT infrastructure" (ITGI, 2003, p. 10). Reporting on each of these focus areas is relevant in order for stakeholders to evaluate to what extent their expectations in the context of IT governance are met by company practice.

For this reason, I adopt all the focus areas from the ITGI (2003) framework, including: IT strategic alignment, IT value delivery, IT risk management, IT resource management, and IT performance measurement, as a basis for the IT governance disclosure framework. While IT value delivery and IT risk management areas are supposedly driven by IT strategic alignment and IT performance measurement, the IT resource management area overlays all other focus areas (ITGI, 2003). It enables each of the focus areas to retain all necessary IT resources, including people, applications, technology, facilities, and data (Buckby, Best, \& Stewart, 2008; ITGI, 2003). Therefore, rather than specifying IT resource management as a separate category of the disclosure framework, I incorporate all essential issues of IT resource allocation across all the remaining focus areas. The following subsections describe the theoretical underpinning of each of the categories in more detail.

\subsubsection{IT Strategic Alignment (ITSA)}

IT strategic alignment typically refers to "the fit and integration among IT strategy, business strategy, IT structures, and business structures" (Van Grembergen \& De Haes, 2009, p. 6). From the point of view of IT governance disclosure, I do not expect that firms will disclose and describe guidelines or procedures related to IT-business alignment under the strategic alignment category. In fact, 
I anticipate that firms will actually report what specific structural mechanisms are in place to achieve IT-business strategic alignment. For example, an organization might disclose that it has a technology committee to align IT strategy with business strategy, or a Chief Information Officer position (CIO) to take care of IT assets at the top level in order to support the overall business goals of the firm. Ultimately, the dissemination of such information can assure stakeholders that the organization has an IT governance structure, and that policies and procedures are in place to achieve IT-business alignment.

With respect to the role of information systems leadership, a considerable body of literature has examined the association between such factors as the board of directors, chief information officer (CIO) and different IT committees, and how these correspond to the firm's value (Armstrong \& Sambamurthy, 1999; Bhattacherjee, 1998; Jarvenpaa \& Ives, 1991; Karahanna \& Watson, 2006; Ranganathan \& Jha, 2008; Read, 2004). In their study on the effectiveness of IT governance, Prasad et al. (2009) show that an IT steering committee that is composed of top level executives is positively associated with firm-level performance and with the performance of the customer services process. While exploring the relationship between IT and the board of directors, Nolan and McFarlan (2005) suggest four modes under a strategic IT impact grid for directing and controlling IT within firms at the board level. They argue that there is less understanding about IT's operational as well as strategic role at the board level. IT governance ensures the involvement of senior leadership in the operational as well as strategic orientation of IT in the firm. This could be observed in several forms of IT governance mechanisms, such as an IT steering committee, technology committee, and promoting the CIO to the board (De Haes \& Van Grembergen, 2009; Huang, et al., 2010; Van Grembergen \& De Haes, 2009).

Taken as a whole, an underlying view of much of this literature is that the involvement of the board of directors and executive management is positively associated with the effective governance of IT and information assets. I suggest that the disclosure of such mechanisms can promote transparency on IT issues, which is one of the desirable features of IT governance. I expect that firms which disclose their IT governance structure and competence appropriately can improve stakeholder confidence.

\subsubsection{IT Value Delivery (ITVD)}

According to ITGI (2003), the notion of IT value delivery is related to the optimization of IT expenses and providing IT products and services on time, within budget, and with appropriate quality. Under the category of value delivery I 
anticipate that firms will report on identifying different IT value-adding issues, such as the significant role of IT in fulfilling business objectives, and its strategic importance in creating competitive advantage. I also argue that effective IT value delivery is possible only when the utilization of IT resources is optimized. Therefore, I cover the issues related to IT resource management along with the aspect of value delivery. These issues include reporting on productive, progressive and effective value-adding practices - for example, IT training, Green IT, in-sourcing or outsourcing of IT.

Today, many firms spend a major portion of their revenue on IT-related activities (Andriole, 2009; Benko \& McFarlan, 2003). A study by Weill, Woerner, Aral, and Johnson (2007) shows that a majority of IT investment occurs in IT infrastructure, typically including network, helpdesk, middleware, database, and IT management. From a shareholder perspective, it is worthwhile for a firm to provide disclosure on its ongoing and future IT activities. This enables shareholders to make a better assessment of the firm's financial health as well as its current and future plans regarding IT and information assets. While investigating the disclosure choices related to enterprise resource planning systems (ERP) in the annual report, Muldin and Richtermeyer (2004) suggest that management may wish to signal to the shareholders that they are undertaking value adding IT projects that will make them more productive, competitive and in turn more profitable.

Under the ITVD category, I analyze to what extent a firm discloses information about new or existing IT projects, the role of IT in achieving business goals, information about IT outsourcing, IT performance evaluation, and IT training. I also examine emerging value-adding practices, such as 'Green IT', to encompass awareness and attention concerning the optimal use of IT resources. Prior literature suggests that IT resources can create a competitive advantage for firms (Bharadwaj, 2000; Byrd, 2001; Davis, et al., 2003; Mata, et al., 1995). As a result, I can assume that, due to competitive pressures, a firm may limit full disclosure of its strategic approach to IT assets (Darrough, 1993; Darrough \& Stoughton, 1990; Eldomiaty \& Choi, 2006). However, in the ITVD category I attempt to explore those IT governance practices which can be considered to be more widespread across firms in creating business value. Examples of such practices include Green IT initiatives or the implementation of IT governance frameworks and standards (also see Appendix A). 


\subsubsection{IT Risk Management (ITRM)}

An IT risk is something that can go wrong with IT and cause a negative impact on the business (Jordan \& Silcock, 2005). From an IT governance perspective, Parent and Reich (2009) identify several types of IT risks such as IT project risk, IT competence risk, IT infrastructure risk, business continuity, and information risk, which can have an adverse impact on business. A study by Bharadwaj, Keil, \& Mähring (2009) reports that IT failures, such as the implementation failure of new systems and the operational failure of existing systems, resulted in an abnormal drop in stock price over a 2-day event window. This indicates that these types of IT failures have a significant impact on shareholder value. As a consequence, firms must not only take care of financial risks, but they also need to manage technology associated risks and security related issues. According to the IT Governance Institute (2003), the regulatory institutions are most concerned about system and operational risk, in particular technology risk.

Referring to the fact that IT resources consume $50 \%$ of capital expenditure in leading organizations (Benko \& McFarlan, 2003; Read, 2004; US Commerce, 2003), Jordon and Silcock (2005) suggest that senior management and the board of directors are therefore expected to pay more attention to IT risk issues. With regard to IT risk transparency, the IT Governance Institute (2003) indicates that top management is responsible for planning and making IT risk policies, and for clarifying all the IT-related business risks. An example of a typical voluntary disclosure of IT system security policy, one of the aspects of IT risk management, can be found in the corporate social responsibility (CSR) report (2007, p. 26-27) of the National Bank of Greece, which states:

"[ . . ] the Bank has developed an IT Systems Security Policy, which applies to all its systems, as well as other specific policies, such as:

Organizational Structure: aiming at allocating responsibilities and designating duties to the heads of corporate units.

Asset Classification: aiming at recording all sensitive data and maintaining appropriate records at each corporate unit. Any information stored in computers is deemed to form part of the Bank's IT assets and is classified on the basis of its security requirements.

Business Continuity Management: aiming at protecting the Bank from unforeseen or disastrous events, so that each unit can continue to operate unobstructed. In order to deal with problems more efficiently, IT systems frequently undergo testing. 
Access Control: this policy enables the Bank to restrict unauthorized access to its system

$[\ldots] "$

In the ITRM category of the disclosure framework, I focus specifically on transparency pertaining to the IT risk management activities of firms. I anticipate that disclosure on IT risk can help all the stakeholders concerned to assess the firm's potential for managing risk issues.

\subsubsection{IT Performance Measurement (ITPM)}

IT performance measurement is specifically related to transparency on matters concerning the IT budget and IT investments. Expenditure on IT resources and its association to firm value have always been a topic of interest to many information systems researchers. In the past two decades, the economics of information systems research has focused extensively on this topic and has come up with considerable evidence (For example, Dehning, et al., 2003; Kobelsky, et al., 2008; Xue, et al., 2008). Dos Santos, Peffers, \& Mauer (1993), and Im, Dow, \& Grover (2001) find that the announcement of IT investment decisions results in an increase in market value. A study by Anderson, Banker, \& $\mathrm{Hu}$ (2003) reports a strong relationship between future earnings and IT spending, especially for firms which are technology intensive. Many of these studies suggest that communication and reporting of IT financial matters have economic benefits. Given that IT budgeting and expenditure are a matter for top management under IT governance (ITGI, 2003; Weill \& Ross, 2004), this can be also seen as transparency of IT financial matters.

Thus, I expect that better IT governance practices will provide investors with clearer information on IT cost allocations and thereby assist them in assessing the business value of IT. Taking into account that firms often include IT expenses under administrative costs or intangible assets costs in their financial reporting, I thoroughly examine how and where firms are providing details on IT expenditure.

\subsection{Research Methodology}

\subsubsection{Sample selection}

Firms included in this study are in the Morgan Stanley Capital International (MSCI) Barra index, which represents publicly traded firms. Within this index, 
I focus particularly on the biggest commercial banks in terms of market capitalization. The final sample data are from 73 banks across 15 European countries and 127 banks from the US, making an overall sample of 200 firms. The main reason for using commercial banks is that these are highly technology-driven, information technology is critical to the success of their business goals (Banker, et al., 2009; Chiasson \& Davidson, 2005; Parent \& Reich, 2009). A study by Sohal \& Fitzpatrick (2002) examines IT governance and management in firms from an information intensity perspective. They propose a classification of firms into three groups based on the intensity of IT usage: high-tier, mediumtier and low-tier firms. Among these three groups, commercial banking firms are placed in the high-tier group, signifying that IT is among the most important factors in influencing the core business of a firm. Correspondingly, I assume that IT governance transparency is highly important to this industry group.

\subsubsection{Public disclosure documents}

The study deals with examining IT governance activities through public disclosure. To ensure the completeness and reliability of the IT governance disclosure framework, I recorded the data from different sources of public disclosure. For the European firms, I examined the annual report, website, corporate governance documents, and press releases, and I also examined other disclosures, such as the corporate social responsibility (CSR) report/ sustainability report, corporate presentations and supplementary documents. In addition to these types of disclosure, for US firms I examined two additional documents: the 10-K report and DEF 14A filings. In the US, the annual report to shareholders is distributed before the annual shareholders meeting, whereas the $10-\mathrm{K}$ annual report is required by the US Securities and Exchange Commission (SEC) as a mandatory disclosure filing. In addition, I included the DEF 14A filing, which is also known as "efinitive proxy statement". This is a mandatory filing required by the SEC to ensure that shareholder rights are upheld.

\subsubsection{Categories of the IT governance disclosure framework}

The disclosure framework consists of four broad categories of IT governance (see Appendix A). The first category (C1) contains 11 items. It focuses on disclosure related to IT strategic alignment (ITSA). For example, a firm whose board or executive management initiated a technology committee or included an IT expert on the board is expected to inform their stakeholders of such provisions. The second category $(\mathrm{C} 2)$ relates to a firm's disclosure about value deliv- 
ery on IT matters (ITVD). A firm that implemented a large scale IT project, or initiated an IT governance framework such as ITIL or COBIT is likely to share such developments with its shareholders. I register 13 disclosure items under this category. The third category (C3) observes the level to which firms disclose specific IT risk management issues (ITRM). It consists of the disclosures of their existing IT vulnerabilities, risk assessment, and risk mitigation efforts. Specifically, this category helps to understand different risks related to IT and how firms plan to address these risks. The final category in the framework deals with disclosure of IT performance measurement (C4). In this category, I look at how firms disclose details on IT-related expenditures. This information can be both subjective and objective; for instance, a firm can disclose information about its IT expenses in percentage of revenue or operational budget in the nonfinancial section, whereas another firm can provide accounting ratios on IT in the consolidated balance sheet. The IT performance measurement category consists of eight disclosure items.

\subsubsection{Data collection and disclosure index}

The primary focus of the study is to investigate the current state of IT governance disclosures; hence I chose a cross-sectional setting and recorded the data for the year 2007. Information retrieved from websites (HTML pages) might be more recent as firms may update webpage information on a regular basis (data was collected between October 2008 and March 2009). In this study, I use content analysis to create the dataset for empirical analysis (Weber, 1985). I conducted a pilot study with a limited sample size to test how and where firms are reporting their IT governance related activities. Based on prior literature and the pilot study, I confirmed the IT governance disclosure categories as well as items under those categories for the final content analysis. This exercise was useful in improving and validating the items in different categories of IT governance disclosure. The relevant literature used to formulate the items is indicated in Appendix A.

To carry out the content analysis, I developed a set of keywords related to IT governance. However, this set of keywords was based not only on the current literature, but also included terms which emerged from the initial pilot study. The exercise ensured that the set is comprehensive and complementary. For instance, Chief Information Officer (CIO) is the most prevalent term in the academic literature for a person responsible for information technology at top management level. However, in the analysis, I found other complementary terms, which are equivalent to this position. These include: head information technol- 
ogy; director of information technology; vice-president information systems and operations; chief technology officer. Accordingly, I searched through the rest of the items in the disclosure framework to note down possible keywords associated with these terms.

I examined each firm's website to obtain the relevant documents and information. All public disclosure documents were retrieved from the archive folders provided on the firms' websites. Using the set of keywords, I inspected each document manually to record the data on a relevant item. I examined whether or not each item on the IT governance disclosure framework is reported $(1=$ reported, $0=$ not reported). I applied this dichotomous coding technique across all public disclosure documents included in the study. This approach resulted in an individual data set for each disclosure type. From the point of view of transparency, I assume that the presence of the item on any of the public disclosure documents is sufficient. With this in mind, I next developed an overall data set to carry out a univariate analysis.

I inspected each individual dataset to observe whether each item on the disclosure framework is present or absent. For example, if I record a CIO position on at least one individual datasets out of five, then a firm will receive an overall score of one on that particular item. In other words, I recorded a score of one if the item is present on any of the individual data sets, and zero otherwise. Last, I computed the disclosure index score for each category of the IT governance disclosure framework as well as an overall IT governance disclosure index (ITGDI), which is the average score on all the items for a firm. A number of studies have computed a disclosure index within the context of their study (for example: environmental disclosure (Wiseman, 1982), (Clarkson, Li, Richardson, \& Vasvari, 2008); Internet financial reporting (Bollen, Hassink, \& Bozic, 2006), (Kelton \& Yang, 2008); voluntary disclosure (Eng \& Mak, 2003)). I constructed the IT governance disclosure index based on Bollen et al. (2006). The only difference is that they obtained the disclosure index by simply adding the scores on a category, while my index is the sum of the score divided by the number of items in the category (see model 1).

$$
I T G D I=\frac{1}{n} \times \sum_{i=1}^{n} x_{i}
$$

Where,

ITGDI $=$ IT governance disclosure index score of a firm

$\mathrm{x}_{\mathrm{i}}=$ Sum of the item scores

$\mathrm{n}=$ Number of items 


\subsubsection{Corporate governance ratings: Index $C G Q$ and Industry $C G Q$}

In order to estimate the quality of internal corporate governance, I use the Corporate Governance Quotient (CGQ) from Institutional Shareholder Services (ISS). CGQ is a ranking system designed specifically to evaluate the quality of a company's corporate governance and board of directors (http://www.riskmetrics.com/cgq). I recorded the CGQ for each company as of December 31, 2007. There are two types of possible CGQ scores: the Index CGQ and the Industry CGQ. When calculating CGQs for firms, ISS looks at 65 different rating criteria across eight core categories for US and 55 rating criteria for non-US firms. The core categories are board of directors, audit, charter and bylaw provisions, anti-takeover provisions, executive and director compensation, progressive practices, ownership, and director education. Based on governance practice structure, each firm can achieve a certain number of points on these criteria; the sum of these points is termed a row score. Further, ISS compares this row score to a relative index such as the S\&P 500, S\&P 400, S\&P 600 and the Russell 3000 to form the 'Index CGQ score'. Similarly, to obtain the 'Industry CGQ score', the row score is compared on a relative basis within an industry group. For this calculation, ISS uses Standard \& Poor's and MSCI's GICS industry grouping system across 23 sectors.

\subsubsection{Data classification: Country groups and CGQ groups}

Initially, 73 commercial banking firms were included from 15 European countries, but nine banking firms were excluded due to the absence of any of the disclosure documents or unavailability of information in English. The initial U.S. sample size was 127 ; this dropped to 119 , since some firms provided only $10-\mathrm{K}$ reports and did not publish an annual report to shareholders. In all, the univariate analysis contained 64 firms from the European country group (EUR) and 119 from the US. Out of 183 firms for the CGQ analysis, I could register Index and Industry CGQs for 169 firms, as 14 firms were missing from the CGQ data set.

Panel A of Table 2.1 presents the two company groups of the continent into which firms were classified. For the European country group (EUR), Table 2.1 also indicates the country and number of sample firms included in the study. In addition, I was interested in examining the association between corporate governance rating and categories of IT governance disclosure using the Index CGQ and Industry CGQ. For this purpose, I divided firms into three groups on the basis of their Index CGQ rankings (see panel B): those with an Index CGQ be- 
low 36.5\% (group "Low"); between 36.7\% and 62.5\% (group "Medium"); and above $62.5 \%$ (group "High"). Similarly, I also formed three groups for the Industry CGQ. During the univariate analysis, I compared the "Low" group with "High" group, skipping the "Medium" group. Following Jiang et al. (2009), I tried several group specifications as there is no standard on the cutoff point of CGQ. The specifications included: (1) splitting firms into two groups (with 50\% as the cutoff point); (2) trying different sets of cutoff points (for example, $60 \%$, $80 \%$ ). All these specifications yielded quite similar results. Therefore, I opted to present the one with three groups, where the groups are formed based on CGQ rankings.

Table 2.1: Grouping of Sample: Continent and CGQ

\begin{tabular}{|c|c|c|c|}
\hline \multicolumn{4}{|l|}{ Panel A } \\
\hline Continent & Code & Group & $\mathrm{N}$ \\
\hline European countries & 1 & EUR* & 64 \\
\hline Unites States & 2 & US & 119 \\
\hline Total & & & 183 \\
\hline \multicolumn{4}{|l|}{ Panel B } \\
\hline \multicolumn{4}{|l|}{ Index CGQ Grouping (\%) } \\
\hline Below 36\% & 1 & Low & 57 \\
\hline Between $36.5 \%$ to $62.5 \%$ & 2 & Medium & 55 \\
\hline Above $62.5 \%$ & 3 & High & 57 \\
\hline Total & & & 169 \\
\hline \multicolumn{4}{|l|}{ Industry CGQ Grouping (\%) } \\
\hline Below $40.9 \%$ & 1 & Low & 57 \\
\hline Between $42 \%$ to $70.1 \%$ & 2 & Medium & 55 \\
\hline Above $70.1 \%$ & 3 & High & 57 \\
\hline Total & & & 169 \\
\hline
\end{tabular}

* EUR sample contains following countries [Country = number of firms]:

$[$ Ausria $=2] ;[$ Belgium $=2] ;[$ Denmark $=3] ;[$ France $=4] ;[$ Germany $=8] ;[$ Greece $=7] ;[$ Ireland $=4] ;[$ Italy $=5] ;[$ Netherlands $=1]$; $[$ Norway $=1] ;[$ Portugal $=4] ;[$ Spain $=6] ;[$ Sweden $=4] ;[$ Switzerland $=4] ;[$ UK=9]

\subsection{Results and Discussion}

\subsubsection{IT governance disclosure framework: Item-level analysis}

Table 2.2 reports the percentage of firms that disclose the items of the IT governance framework. For Panel A - IT strategic alignment, the result shows that the existence of a $\mathrm{CIO}$ or an equivalent position in firms is disclosed by $88 \%$ of EUR firms and $71 \%$ of US firms. Panel B exhibits results for the category IT 
value delivery of the disclosure framework. For the EUR group, the majority of the firms reported IT as a strategic business issue (70\%), followed by the role of IT in achieving business objectives (69\%). The disclosure on items under the $I T$ risk management category is included in Panel C. Information technology is considered to be an operational risk by most of the firms in the sample ( $91 \%$ for the EUR group and $63 \%$ for the US). Panel D reports on the IT performance measurement category of the disclosure framework. The findings indicate that many firms reported their IT expenditure (EUR group: 67\%; US: 49\%). The overall reporting percentage for the EUR group on all categories of the IT governance disclosure framework is far higher than the US, thus, firms in the EUR group appear to be more informative than the US firms of their IT governance.

Table 2.2: Percentage of Firms Disclosing IT Governance Items

\begin{tabular}{lll}
\hline Items & EUR* & US \\
& $(\mathrm{N}=64)$ & $(\mathrm{N}=119)$ \\
\hline
\end{tabular}

Panel A: (C1) IT Strategic Alignment (ITSA)

IT expert on the board

IT expert with experience on the board

$\mathrm{A} \mathrm{CIO}$ or an equivalent position in the firm

IT committee

IT risk is part of audit committee or risk committee

IT is part of audit committee

IT steering committee

IT planning committee

Technology committee

IT committee at an executive level

$\mathrm{CIO}$ or equivalent is on the board

$\begin{array}{ll}27 \% & 16 \% \\ 23 \% & 16 \% \\ 88 \% & 71 \% \\ 2 \% & 0 \% \\ 19 \% & 28 \% \\ 14 \% & 3 \% \\ 5 \% & 3 \% \\ 0 \% & 1 \% \\ 8 \% & 2 \% \\ 6 \% & 3 \% \\ 6 \% & 8 \%\end{array}$

Panel B: (C2) IT Value Delivery (ITVD)

\begin{tabular}{lll}
\hline IT governance framework/standard: ITIL/COBIT/ISO etc. & $1 \%$ \\
IT as an issue in the board meeting & $19 \%$ & $10 \%$ \\
Suggestion/decision/advise by the board on IT & $34 \%$ & $2 \%$ \\
Special report/section on IT/ IT projects in annual report & $17 \%$ & $3 \%$ \\
IT mentioned as a strategic business issue & $39 \%$ & $43 \%$ \\
IT projected as strength & $70 \%$ & $49 \%$ \\
IT projected as opportunity & $66 \%$ & $36 \%$ \\
Project updates or comments & $67 \%$ & $28 \%$ \\
IT is explicitly mentioned for achieving specific business objectives & $66 \%$ & $62 \%$ \\
Comments/Updates on IT performance & $69 \%$ & $12 \%$ \\
IT training & $39 \%$ & $1 \%$
\end{tabular}




\begin{tabular}{lll}
\hline Items & EUR* & US \\
& $(\mathrm{N}=64)$ & $(\mathrm{N}=119)$ \\
\hline Green IT & $39 \%$ & $8 \%$ \\
Direction and status about IT outsourcing and in-sourcing & $23 \%$ & $18 \%$
\end{tabular}

Panel C: (C3) IT Risk Management (ITRM)

\begin{tabular}{lll}
\hline IT is referred under the operational risk & $61 \%$ \\
Special IT risk management program & $27 \%$ & $8 \%$ \\
Use of IT for regulation and compliance & $58 \%$ & $4 \%$ \\
IT/ Electronic Data Processing (EDP) audit & $39 \%$ & $7 \%$ \\
Information and security policy/plan (IT security) & $61 \%$ & $1 \%$ \\
The role of IT in accounting and the reporting standards (IAS) & $56 \%$ & $23 \%$ \\
Operations continuity plan & $48 \%$ & $49 \%$ \\
Panel D: (C4) IT Performance Measurement (ITPM) & & $0 \%$ \\
\hline Explicit information on IT expenditure & & \\
IT budget & $67 \%$ & $0 \%$ \\
IT hardware cost & $3 \%$ & $34 \%$ \\
IT software cost & & $0 \%$ \\
Explicit IT manpower cost is mentioned & $9 \%$ & $3 \%$ \\
IT expenses are mentioned under administrative cost & $52 \%$ & $3 \%$ \\
IT related assets are mentioned under intangible assets & $2 \%$ & $0 \%$ \\
Direct cost on IT is mentioned in currency or percentage & $39 \%$ & $75 \%$ \\
\hline
\end{tabular}

\subsubsection{IT governance disclosure framework: Category-level analysis}

Table 2.3 presents the descriptive statistics at the level of categories of the IT governance disclosure framework. The table lists the disclosure of each category across the various types of public disclosure documents examined in this study. Of the four categories of the disclosure framework, IT risk management is the most reported category (Overall: 54\%). The annual report seems to be the preferred medium for sharing information. The press release is the least preferred medium when it comes to disclosing an IT performance measurement category $(0.2 \%)$. When interpreting these results, it is important to understand that these findings indicate only the propensity of firms to prefer a particular disclosure channel; these preferences are not necessarily those of the readers of these channels. 


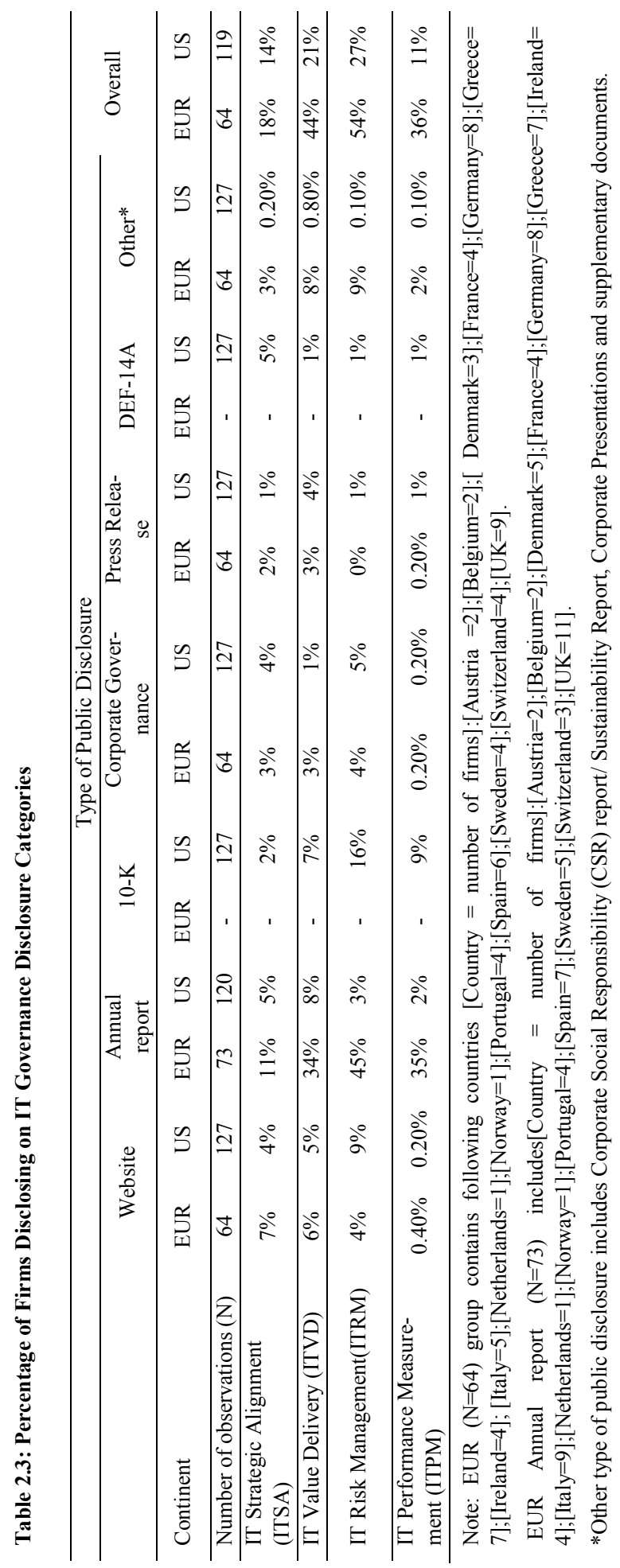




\subsubsection{Descriptive and correlation analysis}

Table 2.4 provides descriptive statistics for the variables employed in the study. The mean for the overall IT governance disclosure index $(\mathrm{N}=183)$ is 0.24 , representing that on average a firm reports on 9 out of 39 items of the IT governance disclosure framework. However, the range of the overall IT governance disclosure index is broad. Based on a theoretical maximum score of 1, the maximum score is 0.69 and the minimum is 0.03 . This indicates that the firm scoring highest on the IT governance disclosure framework has reported on 27 items, and the firm with the lowest score has reported on a single disclosure item.

Table 2.4: Descriptive Statistics

\begin{tabular}{lcccccc}
\hline Variable & N & Mean & Median & $\begin{array}{c}\text { Standard } \\
\text { Deviation }\end{array}$ & Minimum & Maximum \\
\hline IT Strategic Alignment (ITSA) & 183 & 0.15 & 0.09 & 0.10 & 0.03 & 0.69 \\
IT Value Delivery (ITVD) & 183 & 0.29 & 0.23 & 0.21 & 0.00 & 0.92 \\
IT Risk management (ITRM) & 183 & 0.36 & 0.29 & 0.25 & 0.00 & 1.00 \\
IT Performance Measurement (ITPM) & 183 & 0.20 & 0.13 & 0.17 & 0.00 & 0.75 \\
Overall IT Governance Disclosure & 183 & 0.24 & 0.21 & 0.14 & 0.03 & 0.69 \\
Index(ITGDI) & 169 & 47.38 & 49.90 & 28.07 & 1.20 & 99.70 \\
Index CGQ & 169 & 52.70 & 55.20 & 29.81 & 0.70 & 100.00 \\
Industry CGQ & & & & & & \\
\hline
\end{tabular}

Table 2.5 presents the correlation analysis between the categories of IT governance disclosure. Drawing on the IT Governance Institute's (ITGI, 2003) notion that the focus areas of IT governance are interlinked in a continuous cycle, I test this theoretical premise by analyzing the correlation between each of the categories in the disclosure framework. The results indicate a significant correlation between categories. Specifically, the categories of IT strategic alignment (ITSA) and IT performance management (ITPM) are significantly correlated with the categories of IT value delivery (ITVD) and IT risk management (ITRM). The IT governance continuous lifecycle (ITGI, 2003) approach states that the ITSA and ITPM focus areas are the drivers of the ITVD and ITRM areas. Interestingly, the above significant correlations, although tested in relation to disclosure of these categories, show a consistency with the theoretical premise mentioned. Nevertheless, it is important to note that I cannot infer a causal relationship between the categories through a correlation analysis. 


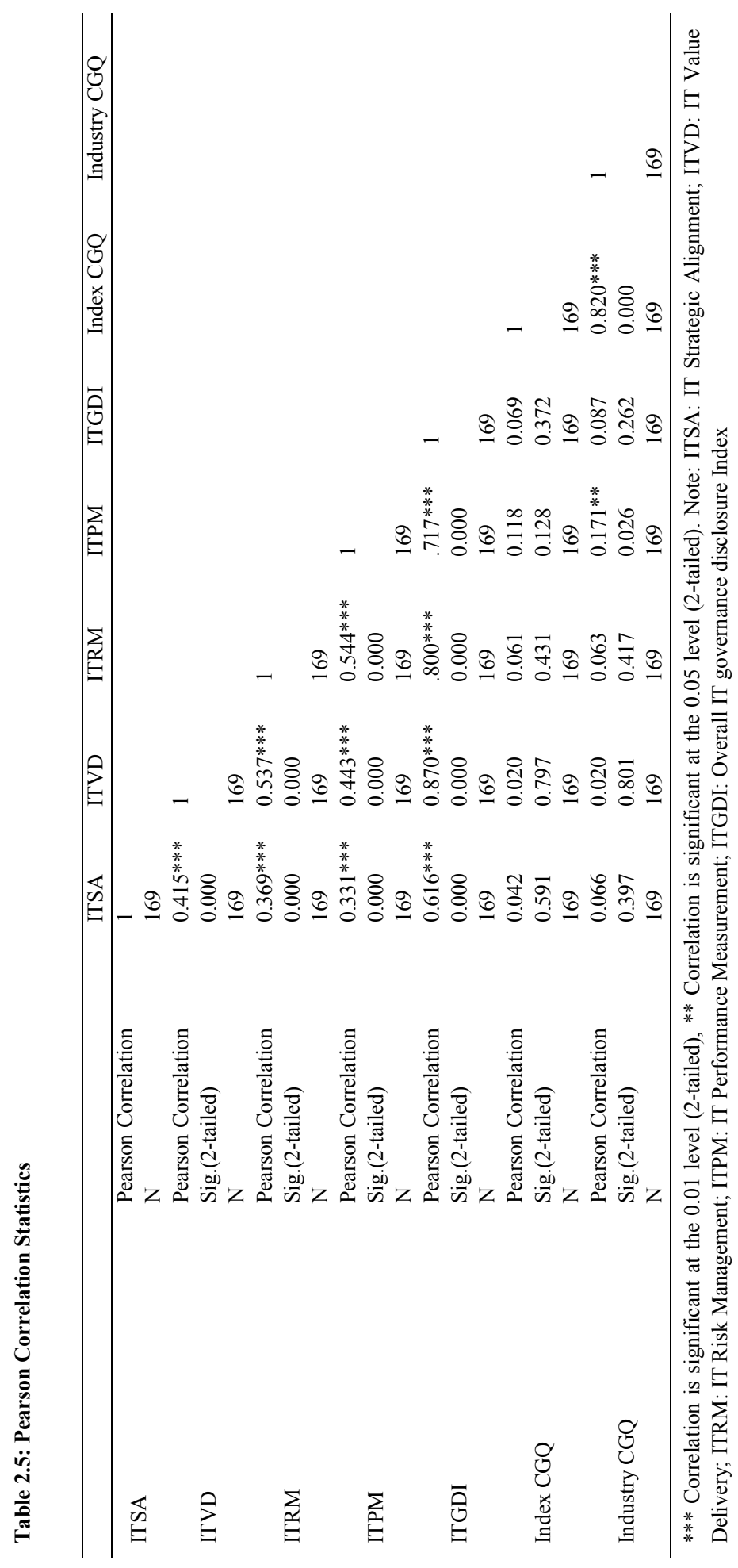


The correlation analysis also includes Index and Industry CGQ variables. The CGQ index or CGQ industry are not correlated with most of the categories of the disclosure framework. However, the category of IT performance measurement and the CGQ industry variable are positively and significantly correlated. This finding implies that technology intensive firms with appropriate corporate governance mechanisms are more informative on IT performance measurement.

\subsubsection{US versus EUR group analysis}

The results of the analysis at the category level (see Table 2.3) indicate that the US firms provide less information in comparison with their EUR counterparts. Interestingly, these findings are contrary to my assumption that US firms are more informative on overall IT governance practices, due to their shareholder driven corporate governance environment. To verify this argument and to address the third research question (RQ3), I performed a univariate analysis. I classified the data into two groups, the EUR country group and the US group (see Table 1). The analysis shows a significant difference between the two groups in all categories of the disclosure framework (see Table 2.6).

Table 2.6: T-test for EUR and US Differences

\begin{tabular}{llcccc}
\hline Category & Country & $\mathrm{N}$ & Mean & $\begin{array}{c}\text { Standard } \\
\text { Deviation }\end{array}$ & t-statistics \\
\hline IT Strategic Alignment (ITSA) & EUR & 64 & 0.18 & 0.11 & $2.626^{* * * *}$ \\
& US & 119 & 0.14 & 0.10 & \\
IT Value Delivery (ITVD) & EUR & 64 & 0.44 & 0.25 & $6.871^{* * *}$ \\
& US & 119 & 0.20 & 0.14 & \\
IT Risk Management (ITRM) & EUR & 64 & 0.54 & 0.29 & $7.028^{* * *}$ \\
& US & 119 & 0.27 & 0.17 & \\
IT Performance Measurement (ITPM) & EUR & 64 & 0.36 & 0.18 & $10.17^{* * *}$ \\
& US & 119 & 0.11 & 0.10 & \\
Overall IT Governance Disclosure Index (ITGDI) & EUR & 64 & 0.37 & 0.15 & $9.374 * * *$ \\
\hline
\end{tabular}

The Significance levels is for $* * * p<0.01$ (2-tailed).

The results of the univariate analysis indicate a strong effect of the country difference on the reporting patterns across all the categories of the disclosure framework. Drawing on the existing literature, I expected that the US firms would be more informative than the EUR group on IT governance disclosure. However, the results reveal that the EUR group consistently reported more extensively than did US firms. A potential explanation for this finding could be that the US firms in the sample have paid less attention to IT governance practices in recent years, or perhaps even fewer firms developed IT governance 
practices, and consequently, there was less attention given to voluntary disclosure on this topic.

An alternative explanation could be that US firms' focus more on compliance and regulations in comparison with the European countries, which could have contributed to an "attention deficit" with respect to unregulated issues such as IT governance reporting. From an economic point of view, Ghose (2006) provides some intuitive insights into the trade-offs involved for firms with respect to the disclosure of IT governance. The study argues that regulatory compliance can have broader ramifications on firm profitability, market structure and social welfare. Drawing on this, it is argued that firms may avoid disclosing more than is required by regulatory arrangements, to hold the perceived costs of reporting and litigation at an optimum level. The fact that financial reporting and corporate governance are heavily regulated in the US thus may lead to an attitude to report only what is specifically required by law. This overall attitude to reporting consequently might result in less disclosure in areas which are not extensively regulated, such as IT governance. In contrast, European countries adhere to a regulatory environment where firms have more discretion in how much information to disclose. Therefore, European firms are more inclined to stimulate or discourage more IT governance transparency depending on their appetite for cost and competitive risk.

In conclusion, although the original argumentation with respect to RQ3 may still hold in the context of IT governance disclosure, this effect may be overshadowed by the desire of firms to optimize their reporting and litigation costs. This finding could be related to the fact that this study particularly focuses on the commercial banking industry where the strategic and competitive role of IT generally is perceived to be particularly high (Banker, et al., 2009; Zmud, Shaft, Zheng, \& Croes, 2010). In such an industry environment, voluntary disclosures on IT related topics might result in particularly high reporting cost.

\subsubsection{The effect of the corporate governance rating}

I examined the effect of internal corporate governance on the categories of IT governance disclosure. First, I looked at corporate governance rating on a global level, for which the CGQ index score was used as a proxy. Second, I investigated the effect of corporate governance performance at the industry level with the CGQ industry score as a proxy. Panel B of Table 2.1 shows the classification of the groups according to the CGQ scores. Table 2.7 shows the result of the analysis, Panel A gives the results for the CGQ index groups and Panel B for the CGQ industry groups. The findings do not show a significant difference be- 
tween the high and low CGQ firms for the majority of IT governance disclosure categories, on either level of the analysis. However, I find a significant difference between the high CGQ and low CGQ group in the category of IT performance measurement. This indicates that firms with a high corporate governance rating are more informative on IT performance measurement matters in comparison with those which have a relatively low corporate governance rating.

Table 2.7: Panel A: T-test for Index CGQ Effect

\begin{tabular}{|c|c|c|c|c|c|}
\hline Category & Group & $\mathrm{N}$ & Mean & $\begin{array}{l}\text { Standard } \\
\text { Deviation }\end{array}$ & $\begin{array}{c}\mathrm{t}- \\
\text { statistics }\end{array}$ \\
\hline \multirow{2}{*}{ IT Strategic Alignment (ITSA) } & Low & 57 & 0.15 & 0.10 & \multirow{2}{*}{-0.402} \\
\hline & High & 57 & 0.16 & 0.11 & \\
\hline \multirow{2}{*}{ IT Value Delivery (ITVD) } & Low & 57 & 0.27 & 0.20 & \multirow{2}{*}{-1.108} \\
\hline & High & 57 & 0.31 & 0.25 & \\
\hline \multirow{2}{*}{ IT Risk management (ITRM) } & Low & 57 & 0.34 & 0.24 & \multirow[t]{2}{*}{-0.904} \\
\hline & High & 57 & 0.38 & 0.26 & \\
\hline \multirow{2}{*}{ IT Performance Measurement (ITPM) } & Low & 57 & 0.15 & 0.15 & \multirow[t]{2}{*}{$-2.050 * *$} \\
\hline & High & 57 & 0.22 & 0.18 & \\
\hline \multirow{2}{*}{ Overall IT Governance Disclosure Index (ITGDI) } & Low & 57 & 0.22 & 0.12 & \multirow{2}{*}{-1.427} \\
\hline & High & 57 & 0.26 & 0.17 & \\
\hline \multicolumn{6}{|l|}{ Panel B: T-test for Industry CGQ Effect } \\
\hline Category & Group & $\mathrm{N}$ & Mean & $\begin{array}{l}\text { Standard } \\
\text { Deviation }\end{array}$ & $\begin{array}{c}\mathrm{t}- \\
\text { statistics }\end{array}$ \\
\hline \multirow{2}{*}{ IT Strategic Alignment (ITSA) } & Low & 57 & 0.15 & 0.10 & \multirow{2}{*}{-1.451} \\
\hline & High & 57 & 0.18 & 0.12 & \\
\hline \multirow{2}{*}{ IT Value Delivery (ITVD) } & Low & 57 & 0.28 & 0.20 & \multirow{2}{*}{-0.955} \\
\hline & High & 57 & 0.32 & 0.26 & \\
\hline \multirow{2}{*}{ IT Risk management (ITRM) } & Low & 57 & 0.32 & 0.24 & \multirow{2}{*}{-1.276} \\
\hline & High & 57 & 0.39 & 0.28 & \\
\hline \multirow{2}{*}{ IT Performance Measurement (ITPM) } & Low & 57 & 0.15 & 0.15 & \multirow{2}{*}{$-2.527 * *$} \\
\hline & High & 57 & 0.23 & 0.19 & \\
\hline \multirow{2}{*}{ Overall IT Governance Disclosure Index (ITGDI) } & Low & 57 & 0.22 & 0.13 & \multirow{2}{*}{$-1.740 *$} \\
\hline & High & 57 & 0.27 & 0.18 & \\
\hline
\end{tabular}

The Significance levels is for $* * \mathrm{p}<0.05, * \mathrm{p}<0.10$ (2-tailed).

In addition, the univariate analysis shows a significant difference in the overall IT governance disclosure index within the industry CGQ groups. This is probably because there are significant differences in the category for IT performance measurement, which can further drive the overall results. Although the results in 
the other three categories appear to be insignificant, it does not signify that they are less important or that they are irrelevant from the perspective of corporate governance. It is plausible that in the case of IT governance transparency, firms might perceive IT performance measurement matters to be a top priority. Given that IT entails a large portion of capital investment, and shareholders may react strongly to IT expenditure decisions, firms with high quality corporate governance practices consider disclosure on IT performance measurement matters to be of highly important. Another possible explanation for this finding is that technology intensive firms (the banking industry), understand that a certain level of IT governance transparency is required. In other words, it could be commonly accepted across the sample firms that, irrespective of their firm's mechanisms for corporate governance, they must establish a minimum level of IT governance transparency.

\subsection{Summary, contribution, limitations and future research}

While addressing the first two research questions, this study reveals that there is no single source of public disclosure where information on IT governance activities can be acquired. Investors have to look into multiple public documents to gather the required information. The annual report appears to be the medium most preferred by firms for communicating information on IT governance topics. Contrary to my assumption, I find that the level of IT governance disclosure for the EUR group of countries is higher than for the US. From this finding, I infer that US firms could have less developed IT governance practices and therefore pay less attention to IT governance disclosure. An alternative explanation for this finding could be that US firms are subject to more unique and standardized reporting frameworks in comparison with EUR firms. In an attempt to hold reporting costs at an optimum level, US firms might have adhered to the stipulated disclosure requirements. As IT governance disclosure is voluntary in nature, less attention might have been paid to it.

This study also advances our understanding of the role of the internal corporate governance environment in IT governance transparency (RQ3 and RQ4). The findings suggest that firms with a high corporate governance rating are more informative on IT performance measurement matters. Specifically, firms with high quality corporate governance consider IT performance measurement matters to be highly important when informing and communicating with shareholders. On the other hand, other categories of the disclosure framework are found to be insignificant. Interestingly, this finding is contrary to the descriptive literature, which advocates a strong role for corporate governance in shaping IT 
governance practices. However, further research can focus on new approaches for investigating the determinants of IT governance transparency. For instance, prior literature on transparency and accountability in IT governance, ownership structure, board composition, and voluntary disclosure can be useful in explaining the association with the level of IT governance disclosure (Ajinkya, Bhojraj, \& Sengupta, 2005; Eng \& Mak, 2003; Raghupathi, 2007).

To my knowledge, this study is the first to explicitly shed light on the link between the corporate governance environment and IT governance transparency. This research offers several contributions to the existing literature in the IT governance area. First, this research offers a descriptive framework for IT governance disclosure. I also provide empirical evidence for this disclosure framework by focusing on a technology intensive industry. While several studies suggest that corporate communications systems, accountability, and transparency are important for effective IT governance (Ali \& Green, 2009; Raghupathi, 2007), my study contributes to the IT governance literature and extends it further on the importance of IT governance transparency. Second, I apply the literature on voluntary disclosure, corporate governance quality (e.g., CGQ), crossnational diversity of corporate governance, and the business value of IT to the IT governance literature. In doing so, this study not only introduces some new insights into the IT governance topic, but also contributes to the interdisciplinary research between accounting, finance, and information systems.

This study has some limitations that should be considered when interpreting the results. First, the focus of the study is on technology intensive organizations. Within this sector, I have included only banking firms; this may limit the external validity of the results. Also, sample data focuses on large firms, which also may limit the applicability of my results. Second, the goal of this study is to examine the level of IT governance transparency, which is a voluntary activity. This may lead to the potential limitation that for items in the IT governance framework which are applicable to a particular firm, the firm may choose not to disclose this information item. Consequently, it is hard to distinguish between firms that deliberately do not disclose particular IT governance issues even though the items are applicable (i.e., lack of transparency with respect to such items) and firms for which such items are not applicable. As a result, my measure of transparency might be an underestimation of the actual level of transparency. Third, although I validated the reliability of items through measuring inter-coder agreement on a limited sample of data, it is important to note that the process of coding data from public disclosure is inevitably subjective. Moreover, my coding scheme only records the presence or absence of the items without giving any weights to them in the disclosure framework. Therefore, if the 
same item is found to be disclosed by two firms, it is difficult to differentiate whether it implies a minimal disclosure for one firm, but a considerable disclosure for the other.

There are several ways to extend the current study. First, future research could investigate whether actual IT governance practices differ from reported practices. Second, research could be done on whether actual IT governance practices are associated with corporate governance and cross-national differences, and to what extent this affects the business value of a firm. One of the primary aims of the study is to investigate the current status of IT and information governance activities in corporate disclosure. Keeping this in mind, I opted for a cross-sectional setting. However, an event-based longitudinal setting, such as the introduction of the Sarbanes Oxley Act and its impact on IT governance disclosure, can shed some more light on this rich topic.

I expect that academic researchers can further validate this disclosure framework. In addition, practitioners such as managers can make use of the proposed framework to strengthen their mechanisms for formal communications - such as the firm's website, annual report, and CSR report with regard to IT governance. In doing so, they can further improve stakeholder confidence. IT governance is an increasingly essential yet complicated topic in research on information systems. Therefore, I expect that in the future both academic and practice oriented research will revise, extend, illustrate, investigate, and critique the current disclosure framework to make it more concrete. 



\title{
3.
}

\section{BOARD OF DIRECTORS, OWNERSHIP STRUCTURE, AND IT GOVERNANCE TRANSPARENCY ${ }^{5}$}

\begin{abstract}
In this chapter, I empirically investigate the effect of board attributes and ownership structure of firms on the decision to disseminate IT governance information in corporate disclosure. Considering the growing importance and value implications of IT information from an IT governance view, I argue that the board of directors and ownership structure of firms are dominant corporate governance mechanisms, which are related to the level of IT governance disclosure. The empirical analysis reveals that blockholder ownership is associated with higher disclosure on IT governance topics. The proportion of independent directors is correlated with lower information dissemination on IT governance. The study offers an important theoretical contribution in understanding the relationship between corporate governance and IT governance. Further, the evidence produced in the chapter will help investors, investment analysts, customers, and
\end{abstract}

\footnotetext{
${ }^{5}$ I would like to thank the participants of the doctoral consortium of the International conference on Information Systems (ICIS) 2010, the 34th European Accounting Association Annual Congress, and the 4th Annual Doctoral Colloquium at Indian Institute of Management (IIM) Ahmedabad for their comments. Special thanks to Robert Zmud, Vallabh Sambamurthy, Michael Davern, and Brian Fitzgerald for their valuable comments.
} 
policy makers to better understand the role of corporate governance in formulating IT governance communication practices.

\subsection{Introduction}

In this study, I empirically examine to what extent board attributes such as board size and board independence, and ownership structure characterized by managerial ownership and blockholder ownership influence the level of IT governance disclosure in public documents. In theory, monitoring and control of IT assets is the responsibility of the board of directors of the firm (Jewer \& McKay, 2012; Karake, 1992; Nolan \& McFarlan, 2005). In this view, the important duties of corporate boards in IT governance are to assign responsibilities to mangers to control and manage IT resources, and to provide IT oversight on behalf of the external stakeholders of the firm (Trites, 2004). Previous literature also shows that the ownership structure in the form of managerial ownership and outside ownership is associated with IT control in firms (Karake, 1992, 1995). Despite the relevance of IT governance, empirical and theoretical work aimed at understanding the complex role of the board of directors and ownership structure in IT governance is still very limited. Specifically, research on the role of corporate boards and ownership structure, and their association with information transparency on IT governance practices in corporate disclosure is nonexistent. From an IT governance perspective, communication on IT governance practices to stakeholders is an essential mechanism to maintain stakeholder confidence (Raghupathi, 2007). While the corporate board is responsible for monitoring and controlling strategic assets including, IT, its role is also instrumental in communication of IT related practices to external stakeholders, to mitigate agency problems, which occur primarily because of information asymmetry between stakeholders and firm management (Jensen \& Meckling, 1976; Karake, 1992). In this view, disclosure of IT governance information might serve as an important mechanism for the board of directors and stakeholders in firms to assess the behavior of management in the use of IT.

Drawing on agency theory prior literature shows that board attributes and ownership structure of firms are dominant corporate governance mechanisms in relation to voluntary disclosure of financial as well as non-financial information (e.g., Eng \& Mak, 2003; Forker, 1992; Lim, Matolcsy, \& Chow, 2007). Moreover, some notable studies have also explored the impact of corporate governance on specific voluntary disclosure practices, which include intellectual capital disclosure (Cerbioni \& Parbonetti, 2007; Hidalgo, García-Meca, \& Martínez, 2011), and corporate social responsibility disclosure (Haniffa \& 
Cooke, 2005). However, the current IT governance literature has not undertaken systematic analysis of factors influencing the choice whether to disseminate IT governance related information in corporate disclosure, nor more importantly the influence of the board of directors and ownership structure of the firm.

In relation to IT related disclosure, a review of current strategic information systems literature suggests that IT information dissemination has value implications for capital markets and is a major area for future research (Davis, et al., 2003; Gordon, et al., 2010; Zmud, et al., 2010). Also, from an IT compliance and audit view, there is a demand for better transparency on IT controls to ensure the reliability of financial reporting practices. Moreover, organizational literature suggests that stakeholders are increasingly looking beyond the financial information in corporate disclosure to assess firm value (Hidalgo, et al., 2011). Next, it is also important to note that the IT capability of firms has an explicit or implicit influence on firm related risk factors, knowledge competence, strategic direction, innovation, and managerial decision abilities, which are important information criteria for capital markets to assess the value of intangible assets (Eccles, Herz, Keegan, \& Phillips, 2001).

Based on the above discussion, the question addressed in this study is how corporate governance mechanisms help to improve IT governance transparency. More specifically, the study undertakes a systematic analysis of how board structure and ownership structure are related to extensiveness of IT governance disclosure in public documents ${ }^{6}$. I focus on board structure by analyzing two attributes: (1) board size; and (2) the proportion of independent directors, as pervious literature has illustrated that board structure provides a control mechanism at an internal level of the firm to monitor managers (Fama, 1980; Jensen \& Meckling, 1976; Jewer \& McKay, 2012). I also analyze ownership structure by focusing on: (1) managerial ownership; and (2) blockholder ownership. Corporate governance literature indicates that the level of corporate disclosure varies depending on the ownership held by outside shareholders or inside managers of firms (Eng \& Mak, 2003).

I use a study sample of 180 commercial banks from the US and European countries. The choice to focus exclusively on banking firms is explained by the fact that firms operating in banking and financial industries are heavily dependent on IT to (re)design and improve their business processes, products, and services (e.g., Banker, et al., 2009; Chiasson \& Davidson, 2005). Given this trans-

\footnotetext{
${ }^{6}$ Note that IT governance disclosure is voluntary. In this study, I use the terms IT governance disclosure and IT governance transparency interchangeably. The term IT governance transparency is defined as the extent to which firms provide adequate and relevant IT governance information in a timely and effective manner to their stakeholders (See Chapter Two).
} 
formative role of IT in commercial banks, this study regards the commercial banking industry as an appropriate sample to examine the relationship between board of attributes, ownership structure, and IT governance transparency. The results of the study suggest that higher blockholder ownership is associated with an increase in the level of IT governance disclosure. In percentage terms, the result shows that a $1 \%$-point increase in blockholder ownership enhances IT governance transparency by approximately $1.5 \%$-point. Contrary to my assumption, the study shows a negative association between board independence and the level of IT governance disclosure, suggesting that higher independence leads to a substitutive mechanism for disclosure practices. Besides these explanatory variables, I find that firm size has a significant impact on IT governance disclosure. More detailed analysis for each of the disclosure categories shows that blockholder ownership stimulates transparency related to IT value delivery and IT risk management.

The remainder of the paper is organized as follows. First, I provide the literature background. Building on agency theory, I develop a series of arguments to illustrate how corporate governance mechanisms can influence IT governance transparency. Drawing on these arguments, I develop four hypotheses. I then present my research methodology, data, empirical models, findings, additional analyses, sensitivity analyses, and robustness tests. Finally, I conclude with a summary, contributions, and limitations of the study.

\subsection{Background and Hypotheses}

Following the major accountings scandals of the last decade (e.g., Enron), the Sarbanes Oxley Act (SOX) was introduced in 2002 to strengthen firms' corporate governance practices. Evidently, the act became instrumental in implementing internal control over financial reporting practices and requiring managers to explicitly state the effectiveness of these internal controls in their corporate disclosure (Li, Peters, Richardson, \& Weidenmier Watson, 2012). As a consequence, the overall quality of mandatory financial reporting has increased considerably in the last decade. In addition to the effect on mandatory financial reporting practices, extant literature offers some interesting empirical evidence the significant influence corporate governance has on voluntary information dissemination in corporate disclosure in this time period (Eng \& Mak, 2003; Gul \& Leung, 2004). The focus of these studies is mainly on voluntary financial and non-financial disclosure in public documents. Moreover, a notable amount of studies has also shown that corporate governance is associated with the level of voluntary disclosure on some special topics, for example, intellectual capital 
disclosure and corporate social responsibility disclosure (e.g., Cerbioni \& Parbonetti, 2007; Haniffa \& Cooke, 2005; Hidalgo, et al., 2011). From the perspective of economic theory, prior literature suggests that firms' voluntary disclosure beyond the standard mandatory requirements helps reduce information asymmetry problems and may lead to capital market benefits. Such benefits include reduced cost of capital (Barry \& Brown, 1984, 1985; Barry \& Brown, 1986; Easley \& O’Hara, 2004; Vanstraelen, et al., 2003), improvement in liquidity (Diamond \& Verrecchia, 1991; Kim \& Verrecchia, 1994), and better information intermediation (Bhushan, 1989; Lang \& Lundholm, 1996).

While collectively these studies show the importance of and incentives for voluntary disclosure, transparency on IT governance in corporate disclosure to this date has remained limited. This paucity of IT governance transparency research can be attributed to several factors. First, the demand for IT related information is assumed to be relevant only in IT intensive environments (Dehning, et al., 2003; Zmud, et al., 2010). Second, for the facilitation of IT governance disclosure firms need attention, discussion, and IT experts in corporate boards (Huff, et al., 2006; ITGI, 2003). Third, assuming the significant value implications of IT information in public documents, corporate disclosure on IT information is particularly sensitive to competitive costs (Zmud, et al., 2010). Finally, it is essential to note that there is no tradition of IT information reporting in corporate disclosure beyond specific IT announcements, for example, such as IT investment decisions, the announcement of CIO appointment, and undertaking of major IT projects such as ERP implementation (Anderson, et al., 2003; Chatterjee, et al., 2001; Mauldin \& Richtermeyer, 2004).

To alleviate this dearth of research and provide further empirical insights on the topic, I focus on corporate governance factors, which might be associated with the choice of firms to voluntarily disclose information on IT governance. Prior literature considers efficient corporate governance an important incentive for firms in disseminating information voluntarily (Hidalgo, et al., 2011). In this sense, my interest is focused on two rigorously examined and theoretically well rooted mechanisms of corporate governance that extant literature assumes to be drivers of voluntary disclosure: (1) ownership structure; and (2) board structure. First, I examine the impact of board size and board independence to assess the influence of board structure on IT governance disclosure. Second, I focus on managerial ownership and blockholder ownership, which represent significant outside ownership in the firm, to investigate the role of ownership structure in IT governance disclosure.

Corporate governance studies show that board attributes and ownership concentration are influential in corporate decisions including disclosure choices 
(Fama, 1980; Shleifer \& Vishny, 1997). In this view, agency theory (Jensen \& Meckling, 1976) offers a comprehensive framework to assess the relationship between these corporate governance mechanisms and IT governance transparency. Agency theory deals with the contractual relationship among shareholders, board of directors, managers, and employees in an organization and other stakeholders. Generally, shareholders are treated as principals, and board of directors and managers as agents. Depending on the level of analysis, the role in this relationship can change. For instance, in a contractual relationship between the board of directors and managers, the board of directors is treated as principal and managers are treated as agents. Specifically, the origin of agency theory is the separation of control and ownership in large organizations (Karake, 1992). Moreover, the theory assumes that both principals and agents are rational, economic individuals who act in their own self-interest that in turn leads to various agency problems, such as conflict of interest, different risk sharing attitudes and the existence of asymmetric information (Eisenhardt, 1989; Jensen \& Meckling, 1976; Karake, 1992, 1995). Agency theory suggests that the commitment to and focus on good corporate governance practices should mitigate the agency problems between the principals and agents (Jensen \& Meckling, 1976). In this view, the corporate governance literature investigates how firms' transparency helps to reduce agency costs by improving external monitoring and thereby corporate governance (Bushman, Piotroski, \& Smith, 2004; Ho \& Wong, 2001).

Specifically, extant literature suggests that ownership structure and board structure as mechanisms of corporate governance influence the level of voluntary disclosure (Eng \& Mak, 2003; Felo, 2009; Gul \& Leung, 2004; Kelton \& Yang, 2008; Patelli \& Prencipe, 2007; Xiao, Yang, \& Chow, 2004). These two mechanisms either act as complementary or substitutive monitoring mechanisms with regard to the level of voluntary disclosure (Ho \& Wong, 2001; Kelton \& Yang, 2008): a complementary mechanism when they stimulate the level of disclosure as a result of strong internal control practices; or a substitutive one when the mechanisms reduce information asymmetry and behavior of managers to withhold information for self-interest (Kelton \& Yang, 2008).

\subsubsection{Board Structure}

From a corporate governance view, the two most important duties of the board of directors are to monitor the management of the firm on behalf of shareholders and to provide resources in form of expertise (Hillman \& Dalziel, 2003). To this end, the literature suggests that the presence of an independent board of directors enhances the supervision of firm resources and indicates better protec- 
tion of shareholder interest in corporate decisions (Fama, 1980). Board independence enhances the monitoring of managerial opportunism and reduces management's prospects of withholding information (Ajinkya, et al., 2005; Kelton \& Yang, 2008; Patelli \& Prencipe, 2007; Reeb \& Zhao, 2010). A notable amount of studies in information systems literature has also examined the role the board of directors in IT governance (e.g., Andriole, 2009; Huff, et al., 2006; Jewer \& McKay, 2012; Nolan \& McFarlan, 2005). These studies report that several board attributes including board independence and board size influence board involvement in IT governance.

The current corporate governance literature reports a varying role of board size in voluntary disclosure practices of firms (e.g., Cheng \& Courtenay, 2006; Hidalgo, et al., 2011; Xiao \& Yuan, 2007). Samaha, Dahawy, El-Megid, $\&$ Abdallah (2012) suggest that a large board improves the monitoring of managerial opportunism and reduces management's chance of withholding information. Following Goodstein, Gautam, \& Boeker (1994), Haynes \& Hillman (2010), and Reeb \& Zhao (2010), I suggest that a larger board will result in an increased pool of expertise for the organization. This might also imply that there will be higher IT knowledge capabilities at the board level and more attention to IT related topics. I assume that IT representation in boards will enhance the quality of the discussion and debate on IT related topics. While the board itself acts as information and monitoring system in the interest of shareholders, this might also result in improved monitoring and dissemination of IT governance disclosure.

H1: There is a positive association between board size and the level of governance disclosure.

In a recent study on IT investments $\mathrm{Ho}, \mathrm{Wu}, \& \mathrm{Xu}$ (2011) show mixed evidence on how the proportion of independent directors moderates the association between IT spending and firm performance. Concerning IT governance practices at the board level, Jewer \& McKay (2012) suggest that the non-independent (inside) directors have relevant knowledge of IT and business activities in comparison to independent directors. However, independent directors are associated with encouraging higher transparency and accountability on corporate decisions pertaining to firm resources (Baysinger \& Butler, 1985; Leftwich, Watts, \& Zimmerman, 1981; Rosenstein \& Wyatt, 1990). As a result, this might lead to an agency conflict where inside directors can withhold IT information for their own interest. Given that the interests of independent directors are aligned with shareholders of the firm, I predict that board independence will work as a com- 
plementary monitoring mechanism in providing higher IT governance transparency. That is, higher board independence will lead to an increase in voluntary disclosure on IT governance.

$\mathrm{H} 2$ : There is a positive association between the proportion of independent directors and the level of IT governance disclosure.

\subsubsection{Ownership Structure}

Corporate ownership structure is an increasingly influential form of corporate governance (Pacheco-de-Almeida \& Zemsky, 2012). The proportion of ownership is a determinant of who controls and monitors firm resources. That is, the level of ownership may influence important firm attributes including firm performance, strategy, or decision structure of a firm. Prior information systems literature suggests that ownership structure, particularly managerial ownership, is positively associated with creating some specific IT governance mechanisms at the top level of management (Karake, 1992). These mechanisms include the creation of a Chief Information Officer (CIO) position and IT investment decision rights (Karake, 1992, 1995). However, managerial ownership only represents the influence of inside ownership of the firm. Our understanding of the role of external ownership in relation to IT governance mechanisms is still underdeveloped.

I posit that the efficient monitoring and control of IT requires richer IT governance disclosure from managers to shareholders to reduce information asymmetry and subsequent agency costs. In this view, managerial ownership helps in aligning the interests of shareholders and managers, so that it reduces shareholders' demand for monitoring (Baek, et al., 2009; Jensen \& Meckling, 1976). Thus, I predict the impact of managerial ownership on the level of IT governance disclosure to be substitutive, such that the need for more IT governance disclosure is decreased by a greater percentage of managerial ownership. In other words, higher ownership of managers will reduce the demand for external reporting on IT as such information can be retrieved privately. A counter argument to this assumption could be that firms' voluntary disclosure seeks to benefit in capital markets from improved liquidity and reduce cost of capital. As a result, managers might have an incentive to disclose more IT related information in higher managerial ownership setting to reduce the cost of capital. However, previous studies indicate that in a higher managerial ownership setting mangers have incentives to distort the information disseminated in public documents (Donnelly \& Mulcahy, 2008). That is, managers are likely to refrain 
from the disclosure of negative firm outcomes and tend to reveal information, which is beneficial to their self-interest to extend their tenure (Eisenhardt 1989; Shleifer and Vishny 1997). In this study, I do not distinguish the IT governance information disclosed as positive or negative as far as managerial ownership influence is concerned, rather assume that greater managerial ownership can monitor and control IT assets by retrieving IT asset information privately. Moreover, considering the strategic value relevance of IT information (Davis, et al., 2003), it is likely that managers of firm in high managerial ownership situation are reluctant to disseminate competitively sensitive information including IT governance information in external reporting. I express my hypothesis as follows:

H3: There is a negative association between firm's managerial ownership and the level of IT governance disclosure.

Blockholder ownership refers to entities holding more than 5\% of a firm's outstanding shares (Pacheco-de-Almeida and Zemsky 2012) and represents a group of shareholders with a relatively large stake of shares. Given the value relevance of IT information in corporate disclosure (e.g., Gordon, Loeb et al. 2010), I assume that the level of blockholder ownership may have a positive influence on IT governance disclosure. A higher blockholder ownership concentration will represent a dominant ownership structure (Pacheco-de-Almeida and Zemsky 2012). In a dominant blockholding environment, blockholders have better information and control over the key assets of the firm including IT. I therefore posit a positive impact of blockholding on the level of IT governance disclosure. In sum, the following hypothesis is developed to test the impact of block-holder ownership structure:

H4: There is a positive association between blockholder ownership and the level of IT governance disclosure.

In this study, I also examine the impact of ownership and board structure at the level of four different categories of IT governance disclosure, namely IT strategic alignment, IT value delivery, IT risk management, and IT performance measurement. These four categories for disclosure are developed in the existing IT governance literature (Buckby, et al., 2008; ITGI, 2003) . I assume that the analysis at the category level will shed some more light on the association between these corporate governance mechanisms and transparency on specific IT governance topics. However, I am not aware of any theory or empirical evi- 
dence which indicates that the relationship between corporate governance and the level of IT governance disclosure will vary depending on the specific category of this IT governance disclosure framework. Therefore, I do not present separate hypotheses for the four categories that are examined in this additional analysis. Also, the predicted signs for the hypotheses in these categories are similar to those of the overall IT governance disclosure hypotheses.

\subsection{Research Methodology}

\subsubsection{Data and Dependent Variable}

This chapter uses the same sample data as described in Chapter Two. The final sample includes 180 firms out of the initial sample of 200 firms. I drop 20 firms because of missing data on either independent variables or control variables included in this study. The overall sample of 180 firms is consisting of 61 banks across 15 European countries and 119 banks from the US. In addition, the construction of the dependent variable (IT governance disclosure index) is also similar to the description provided in Chapter Two.

\subsubsection{Measurement of Independent and Control Variables}

The independent variables in the study include board structure and ownership structure. I measure board structure by including board size (BSIZE) and board independence $(B I N D)$ as the variables of interest. Board size $(B S I Z E)$ is measured by the total number of board of directors, whereas board independence $(B I N D)$ is the proportion of the independent directors to the total number of board directors. Ownership structure is measured by the proportion of ordinary shares held by blockholders (BLOCKOWN, shareholding of 5\% or more) and managers $(M A N O W N)$. The data on ownership structure and board structure is obtained from the annual report and SEC filings for the year 2008 (such as the $10-\mathrm{K}$ report and the DEF 14A filing). In addition to ownership structure and board structure variables, previous literature on corporate governance and voluntary disclosure suggests that the size of the firm, profitability (ROE), growth opportunities (BTM), leverage ratio (LEV), and audit quality (BIG4) affects a firm's degree of transparency (Bushman, et al., 2004; Eng \& Mak, 2003; Hsiang-Tsai \& Li-Jen, 2010; Kim \& Lim, 2010; Zmud, et al., 2010). Prior studies have included the total number of employees or market capitalization to control for the firm size. In a recent study on strategic signaling on IT, Zmud et al.(2010) measured firm size by formulating a metric variable called communi- 
cation intensity (CI). Following their method, I calculate communication intensity (CI) by summing the standardized value of the natural logarithms of market capitalization (LnMCAP), the natural logarithms of total number of employees (LnEMP), and channel utilization index (CHI). The CHI is calculated as the number of channels utilized by a firm for the disclosure to the total number of available channels ${ }^{7}$. The description of these variables along with the dependent variables and independent variables is presented in Table 3.1. The data on control variables included in the study is obtained from the annual report, the SEC filings, COMPUSTAT Global, and DataStream.

\footnotetext{
${ }^{7}$ See Chapter 2 for the number of channels used to record the data using IT governance disclosure framework.
} 
Table 3.1: Variable Definitions

\begin{tabular}{|c|c|}
\hline Variable & Variable Description \\
\hline \multicolumn{2}{|c|}{ Dependent variables } \\
\hline ITGDI & Average score for all items of IT governance disclosure framework \\
\hline ITSA & Average score for IT strategic alignment category items \\
\hline ITVD & Average score for IT value delivery category items \\
\hline ITRM & Average score for IT risk management category items \\
\hline ITPM & Average score for IT performance management category items \\
\hline \multicolumn{2}{|c|}{ Independent variables } \\
\hline BSIZE & Total number of directors on the board \\
\hline BIND & The percentage of independent directors on the board \\
\hline MANOWN & $\begin{array}{l}\text { Proportion of ordinary shares owned by top managers (including directors and } \\
\text { supervisors) }\end{array}$ \\
\hline BLOCKOWN & $\begin{array}{l}\text { Proportion of ordinary shares owned by substantial shareholders (with equity of } \\
5 \% \text { or more) }\end{array}$ \\
\hline \multicolumn{2}{|c|}{ Control variables } \\
\hline LnEMP & The natural logarithm of total number of employees \\
\hline LnMCAP & The natural logarithm of market capitalization \\
\hline $\mathrm{CHI}$ & $\begin{array}{l}\text { The number of channels utilized for the disclosure to the total number of availa- } \\
\text { ble channels. }\end{array}$ \\
\hline $\mathrm{CI}$ & $\begin{array}{l}\text { Communication intensity is calculated by summing the standardized value of } \\
\text { LnMCAP, LnEMP, and CHI }\end{array}$ \\
\hline ROE & $\begin{array}{l}\text { Return on shareholders' equity calculated as the ratio of pretax income to the } \\
\text { common equity }\end{array}$ \\
\hline LEV & Ratio of total liabilities to total assets \\
\hline BTM & Ratio of book value of equity to market capitalization \\
\hline BIG4 & 1 if auditor is big four firm, 0 otherwise \\
\hline US & 1 if the firm is located in US; 0 otherwise. \\
\hline
\end{tabular}

\subsubsection{Research Model}

Ordinary Least Squares (OLS) multiple regression analysis is used to examine the association between the dependent variable (the level of IT governance disclosure) and the independent variables (ownership structure and board structure). The approach for the statistical analysis is specified in the following model:

$$
\begin{aligned}
\text { ITGDI }= & \beta_{0}+\beta_{1} \mathrm{BSIZE}+\beta_{2} \mathrm{BIND}+\beta_{3} \mathrm{MANOWN}+\beta_{4} \mathrm{BLOCKOWN}+\beta_{5} \mathrm{ROE}+\beta_{6} \mathrm{LEV}+\beta_{7} \mathrm{BTM} \\
& +\beta_{8} \mathrm{BIG} 4+\beta_{9} \mathrm{SIZE}+\varepsilon
\end{aligned}
$$




\subsubsection{Descriptive Statistics and Correlation Analysis}

Table 3.2 provides descriptive statistics for the variables employed in the study. The mean for the overall IT governance disclosure index $(\mathrm{N}=180)$ is 0.24 , representing that on average a firm reports on 9 out of 39 items of the IT governance disclosure framework. However, the range of the overall IT governance disclosure index is broad. Based on a theoretical maximum score of 1, the maximum score is 0.69 and the minimum is 0.03 .

\section{Table 3.2: Descriptive Statistics}

\begin{tabular}{|c|c|c|c|c|c|}
\hline Variable & Obs & Mean & Std. Dev. & Min & Max \\
\hline \multicolumn{6}{|c|}{ Dependent Variable } \\
\hline ITGDI & 180 & 0.24 & 0.14 & 0.03 & 0.69 \\
\hline ITSA & 180 & 0.15 & 0.10 & 0 & 0.45 \\
\hline ITVD & 180 & 0.29 & 0.22 & 0 & 0.92 \\
\hline ITRM & 180 & 0.35 & 0.25 & 0 & 1.00 \\
\hline ITPM & 180 & 0.19 & 0.17 & 0 & 0.75 \\
\hline \multicolumn{6}{|c|}{ Independent Variable } \\
\hline MANOWN & 180 & 0.09 & 0.12 & 0.00 & 0.57 \\
\hline BLOCKOWN & 180 & 0.19 & 0.19 & 0.00 & 0.99 \\
\hline BSIZE & 180 & 14.42 & 5.59 & 7.00 & 36.00 \\
\hline BIND & 180 & 0.71 & 0.15 & 0.19 & 0.93 \\
\hline COUNTRY & 180 & 0.67 & 0.47 & 0 & 1 \\
\hline \multicolumn{6}{|c|}{ Control Variable } \\
\hline LnEMP & 180 & 8.08 & 1.71 & 4.93 & 12.66 \\
\hline LnMcap & 180 & 7.70 & 1.81 & 3.72 & 12.19 \\
\hline $\mathrm{CHI}$ & 180 & 0.54 & 0.19 & 0.14 & 1 \\
\hline $\mathrm{CI}$ & 180 & 1.81 & 0.39 & 1.01 & 2.89 \\
\hline ROE & 180 & 0.16 & 0.08 & -0.15 & 0.38 \\
\hline LEV & 180 & 0.92 & 0.03 & 0.74 & 0.99 \\
\hline BTM & 180 & 0.77 & 0.64 & 0.00 & 7.61 \\
\hline BIG4 & 180 & 0.79 & 0.41 & 0 & 1 \\
\hline US & 180 & 0.66 & 0.47 & 0 & 1 \\
\hline
\end{tabular}

See Table 3.1 for the variable definitions. 
This indicates that the firm scoring highest on the IT governance disclosure framework reports on 27 items, and the firm with the lowest score reports on a single disclosure item. On average, $71 \%$ of the sample firms' boards is made up of independent directors. The average board size of the sample firms' is around 14 directors. On average, managerial ownership is around $9 \%$, whereas the average percentage of blockholding is around $19 \%$.

Table 3.3 presents the correlation analysis between dependent, independent, and control variables. When analyzing the correlation between the independent variables and the dependent variable, all correlations are significant. The independent variable $B L O C K O W N$ has the highest association with ITGDI ( $\rho=$ 0.33 ). This shows that blockownership is positively associated with the level of IT governance disclosure. As predicted in hypothesis H1, I find a significant correlation between BSIZE and ITGDI. As expected in H3, I find that the managerial ownership $(M A N O W N)$ is negatively correlated with the ITGDI. Contrary to my assumption, I find that board independence (BIND) is negatively associated with the ITGDI. Regarding the correlation between the control variables and the dependent variable, large firms are positively associated with a higher level of IT governance disclosure and also with the independent variables (for example, correlation between $C I$ and $M A N O W N ; C I$ and BSIZE). I have tested the variables for multicollinearity by looking at the values of the variance inflation factor (VIF). All the VIF values are well below the cut-off value (less than 10), suggesting that multicollinearity is not a problem for the regression analysis.

\subsubsection{Regression Results}

Table 3.4 presents the multivariate results of the OLS regression analysis for the model specified earlier in equation (1). The F-statistics show that the model is significant. The regression coefficients and t-statistics for the model in the table are reported after adjusting for standard errors for heteroskedasticity. The result shows $\mathrm{H} 1$ is not supported. A plausible explanation for the lack of support to the board size hypothesis is the high positive correlation between CI and BSIZE $(\rho=0.50)$. While it is not surprising that large firms are associated with larger board size, the lack of a significant coefficient may suggest a stronger influence of size variable which has overshadowed the association of BSIZE with ITGDI. Hypothesis $\mathrm{H} 2$ predicts that board independence will be positively associated with the level of IT governance disclosure. Contrary to my assumption, I find that increased percentage of independent directors is associated with reduced disclosure on IT governance. Therefore, H2 is not supported. This finding sug- 
gests that board independence is a substitutive mechanism for IT governance disclosure. This means that higher board independence might lead to better monitoring of IT governance practices at the board level, but might not encourage the communication in public disclosure. In addition, independent directors might have lesser information exposure on IT topics compared to inside directors (Jewer, 2009). This might result into an attention deficit issue that can impede the level of IT governance disclosure (Andriole, 2009).

Hypothesis $\mathrm{H} 3$ predicts that the level of IT governance disclosure is negatively associated with a firm's managerial ownership. As shown in the model 1, the coefficient of $M A N O W N$ is statistically insignificant and negative, therefore $\mathrm{H} 3$ is not supported. One possible explanation may be that the extent of IT governance disclosure may be less significant compared to its strategic influence. That is, it is might be plausible that for the managerial ownership hypothesis the type of IT governance disclosure may be more relevant than its extensiveness. A Hypothesis H4 predicts that blockownership will be associated with IT governance disclosure. I find the coefficient of BLOCKOWN statistically significant, hence H4 is supported. Results suggests that the effect of blockholding on the level of IT governance disclosure is complementary, such that higher blockholding will improve the disclosure environment by demanding more transparency on IT governance related topics. The findings also show that firms with a high leverage ratio $(L E V)$ and high growth opportunities $(B T M)$ are positively associated with the level of IT governance disclosure. I also find a positive association between firm size $(C I)$ and the level of IT governance disclosure ${ }^{8}$.

\footnotetext{
${ }^{8}$ I also run the regression model using LnEMP and LnMcap as a size variable. For both firm size variables, I find support for only hypothesis 4 only, which suggests a positive association between $B L O C K O W N$ and $I T G D I$. However, the coefficient on BIND turns insignificant. This suggests that $\mathrm{H} 2$ is sensitive across different size measures and should be interpreted with much caution.
} 


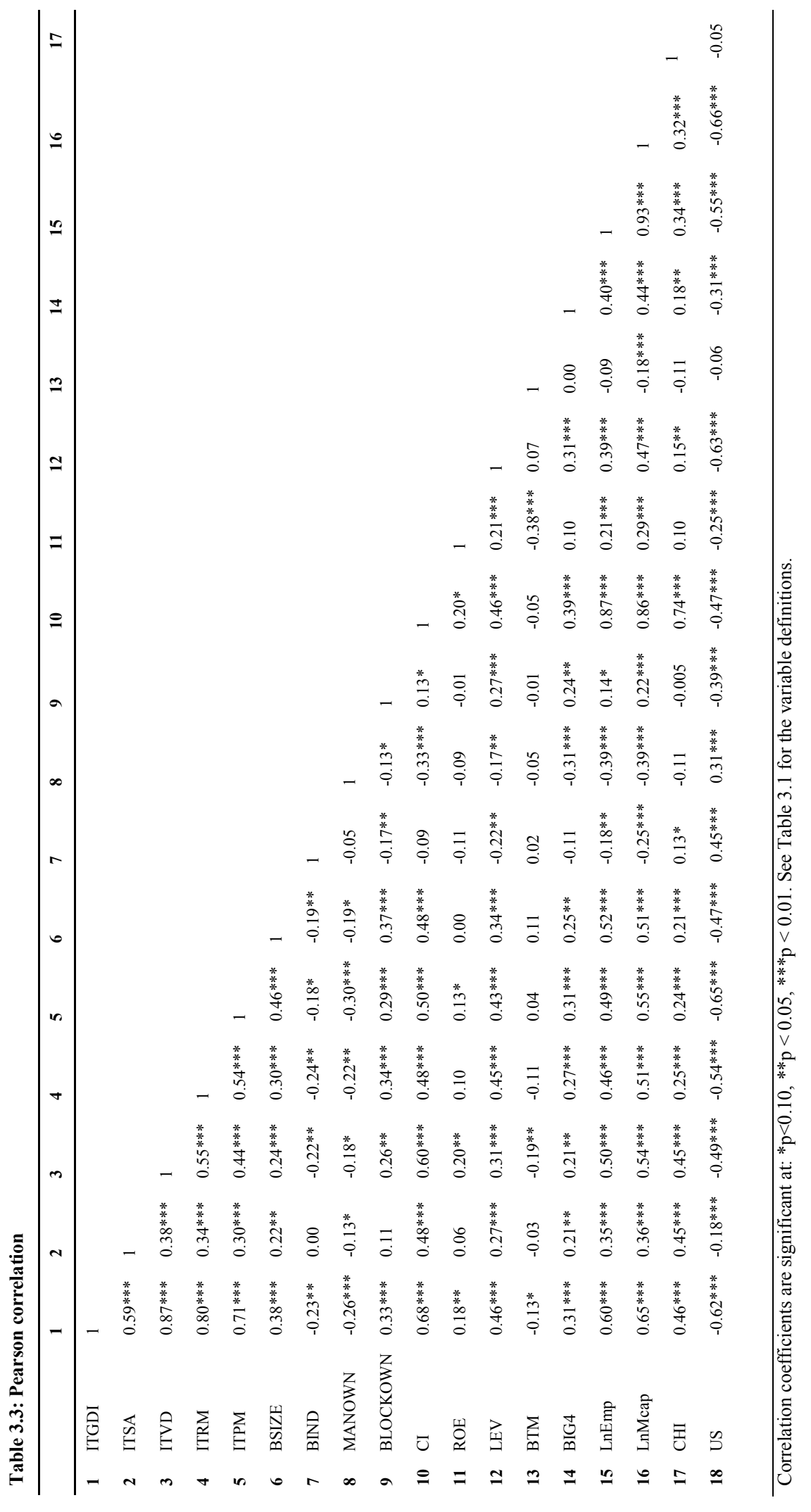


Table 3.4: OLS Model for the Main Effect on IT Governance Disclosure

\begin{tabular}{|c|c|c|}
\hline Variable & Expected sign & ITGDI \\
\hline & & Coefficient \\
\hline \multirow[t]{2}{*}{ BSIZE } & + & -0.002 \\
\hline & & $(-0.979)$ \\
\hline \multirow[t]{2}{*}{ BIND } & + & $-0.114 * *$ \\
\hline & & $(-1.893)$ \\
\hline \multirow[t]{2}{*}{ MANOWN } & - & -0.052 \\
\hline & & $(-0.801)$ \\
\hline \multirow[t]{2}{*}{ BLOCKOWN } & + & $0.161^{* * *}$ \\
\hline & & (3.197) \\
\hline \multirow[t]{2}{*}{ ROE } & + & -0.058 \\
\hline & & $(-0.619)$ \\
\hline \multirow[t]{2}{*}{ LEV } & + & $0.703 * * *$ \\
\hline & & $(3.222)$ \\
\hline \multirow[t]{2}{*}{ BTM } & $+/-$ & $-0.012^{*}$ \\
\hline & & $(-1.478)$ \\
\hline \multirow[t]{2}{*}{ BIG4 } & + & -0.013 \\
\hline & & $(-0.756)$ \\
\hline \multirow[t]{2}{*}{ CI } & $+/-$ & $0.224 * * *$ \\
\hline & & (7.948) \\
\hline \multirow[t]{2}{*}{ INTERCEPT } & & $-0.702 * * *$ \\
\hline & & $(-3.440)$ \\
\hline $\mathrm{N}$ & & 180 \\
\hline Adjusted R2 & & 0.546 \\
\hline $\mathrm{F}$ & & $19.9^{* * *}$ \\
\hline
\end{tabular}

Statistical significance: ${ }^{*} \mathrm{p}<0.10,{ }^{* *} \mathrm{p}<0.05,{ }^{* * *} \mathrm{p}<0.01$ (One tailed); a t-statics is reported in parentheses. See Table 1 for variable definitions.

\subsubsection{Additional Analysis}

To gain further insight into IT governance transparency and its association with corporate governance mechanisms, I examine the impact of ownership structure and board structure on each category of the IT governance disclosure framework. These categories are IT strategic alignment (ITSA), IT value delivery (ITVD), IT risk management (ITRM), and IT performance measurement (ITPM). The results for this additional analysis are presented in Table 3.5. 
Table 3.5: OLS Model for the Categories of the IT Governance Disclosure Framework

\begin{tabular}{|c|c|c|c|c|}
\hline & (1) & (2) & (3) & (4) \\
\hline & ITSA & ITVD & ITRM & ITPM \\
\hline Variable & Coefficient & Coefficient & Coefficient & Coefficient \\
\hline \multirow[t]{2}{*}{ BSIZE } & -0.001 & $-0.006^{* *}$ & -0.003 & $0.006^{* *}$ \\
\hline & $(-0.571)$ & $(-2.181)$ & $(-0.682)$ & $(2.374)$ \\
\hline \multirow[t]{2}{*}{ BIND } & 0.044 & $-0.215^{* *}$ & $-0.236^{*}$ & -0.071 \\
\hline & (1.002) & $(-2.122)$ & $(-1.775)$ & $(-0.812)$ \\
\hline \multirow[t]{2}{*}{ MANOWN } & 0.043 & -0.009 & -0.135 & $-0.183^{*}$ \\
\hline & $(0.760)$ & $(-0.083)$ & $(-0.668)$ & $(-1.845)$ \\
\hline \multirow[t]{2}{*}{ BLOCKOWN } & 0.024 & $0.249 * * *$ & $0.290 * * *$ & 0.102 \\
\hline & $(0.527)$ & $(2.887)$ & $(2.736)$ & $(1.315)$ \\
\hline \multirow[t]{2}{*}{ ROE } & -0.081 & 0.007 & -0.277 & 0.069 \\
\hline & $(-0.896)$ & $(0.041)$ & $(-1.388)$ & $(0.465)$ \\
\hline \multirow[t]{2}{*}{ LEV } & 0.334 & 0.177 & $1.953 * * *$ & $0.927 * * *$ \\
\hline & (1.437) & $(0.420)$ & $(4.151)$ & (2.699) \\
\hline \multirow[t]{2}{*}{ BTM } & 0.003 & $-0.028^{*}$ & -0.038 & 0.016 \\
\hline & $(0.310)$ & $(-1.910)$ & $(-1.565)$ & (1.096) \\
\hline \multirow[t]{2}{*}{ BIG4 } & 0.004 & -0.046 & -0.008 & 0.012 \\
\hline & $(0.193)$ & $(-1.512)$ & $(-0.198)$ & $(0.490)$ \\
\hline \multirow[t]{2}{*}{ CI } & $0.132 * * *$ & $0.360 * * *$ & $0.231 * * *$ & $0.122 * * *$ \\
\hline & (5.054) & $(8.717)$ & $(3.790)$ & (3.128) \\
\hline \multirow[t]{2}{*}{ ITERCEPT } & $-0.415 * *$ & -0.276 & $-1.613 * * *$ & $-0.946^{* * *}$ \\
\hline & $(-2.014)$ & $(-0.732)$ & $(-3.672)$ & $(-3.082)$ \\
\hline $\mathrm{N}$ & 180 & 180 & 180 & 180 \\
\hline Adjusted $\mathrm{R}^{2}$ & 0.213 & 0.418 & 0.349 & 0.357 \\
\hline $\mathrm{F}$ & $5.456 * * *$ & $17.43 * * *$ & $9.551 * * *$ & $11.37 * * *$ \\
\hline
\end{tabular}

Statistical significance: ${ }^{*} \mathrm{p}<0.10,{ }^{*} \mathrm{p}<<0.05,{ }^{* * *} \mathrm{p}<0.01$ (One tailed).T-statics is reported in parentheses. See Table 1 for variable definitions.

This additional explanatory analysis suggests that blockownership $(B L O C K O W N)$ is significantly and positively associated with IT governance topics concerning IT value delivery (ITVD) and IT risk management (ITRM). Pertaining to the disclosure on IT performance matters (ITPM), I find a negative and significant association with managerial ownership $(M A N O W N)$. The regression analysis reveals that the size of board (BSIZE) is significantly associated with the disclosure regarding IT performance measurement topics (ITPM). The results also show that firms with a high leverage ratio $(L E V)$ disclose more on IT risk management efforts as well as on IT performance measurement matters to gain (regain) shareholder confidence. High growth firms $(B T M)$ in the sample 
are significantly and positively associated with communication on IT value matters. The findings are consistent with previous literature on IT related disclosures (Kim \& Lim, 2010). Firm size appears to be the most significant driving variable behind all the categories of the framework. As noted earlier, large firms dedicate more resources to communicate on IT governance disclosure (Zmud, et al., 2010).

\subsubsection{Sensitivity Analysis and Robustness Checks}

In the sensitivity analysis, I examine the impact of those items from the IT governance disclosure framework that have high mean values by constructing a disclosure index for items that have reported high mean values. The index is computed as the average score of high mean value items. The results and description for these high mean items are reported in the model lof Table 3.6. This sensitivity analysis helps to validate the consistency of the main results, and to further detail the impact of independent variables on specific items, where firms have shown higher propensity for disclosure. Consistent with the main analysis, the results in table 3.6 (See Model 1) indicate that blockholder ownership is an influential variable to explain the level of IT governance disclosure. Interestingly, the findings indicate a negative association between the board size variable and high mean value items index. More specifically, I find that larger boards are negatively correlated with the disclosure items that include: the presence of CIO or equivalent position in the firm, specifying the role of IT in achieving specific objectives, IT as an operational risk, and an appropriate IT security policy. In addition to the above sensitivity analysis, I also conduct a split sample analysis. I divide the sample at the median value of the firm size variable $(C I)$ into two groups: Small and Big Firms. Table 3.6 reports the results of OLS regressions for the two subsamples (See Model 2 and 3). The results show that blockholder ownership in small firm size group is positively associated with the level of IT governance disclosure. Based on prior literature (Zmud, et al., 2010), a possible explanation for this result may be that smaller firm's disclosure of IT governance activities might represent or considered to be important information disclosure from external shareholder's point of view when compared to big firms. Big firms have more resources and scope for larger IT activities, and may maintain a certain level of IT governance disclosure.

As noted in Chapter Two, I argue that the level of IT governance disclosure is associated to external corporate governance environment represented by the difference between the US and EUR firms. To re-examine this claim in a multivariate setting, I include a dummy variable US to the main analysis (See Model 
4 in table 3.6). Consistent with my findings in Chapter Two, the result shows that US firms are associated with less disclosure when compared with the EUR group firms. I further split the overall sample into two groups: US and EUR firms to carry additional sensitivity analysis. The results are reported in Table 3.6 (See Model 5 and 6). For US firms, I find that the level of IT governance disclosure is negatively associated with the board size. This may suggest that bigger boards might impede discussion on IT governance disclosure in public documents. I report a positive association between the level of IT governance disclosure and board independence for the US firms. This sensitivity analysis also reveals that managerial ownership for US firms is positively associated with ITGDI. For the EUR group (see Model 6 in Table 3.6), I find that the level of IT governance disclosure is positively associated with blockownership. These different sets of findings for two groups suggest that IT governance transparency might be sensitive to external corporate governance environment, which normally shapes different firm characteristics including board and ownership structure. 
Table 3.6: OLS Model for Sensitivity Analysis

\begin{tabular}{|c|c|c|c|c|c|c|c|}
\hline Variable & $\begin{array}{c}\text { Predicted } \\
\text { Sign }\end{array}$ & Model 1 & Model 2 & Model 3 & Model 4 & Model 5 & Model 6 \\
\hline & & & Small Firms & Big Firms & Overall & US Firms & EUR Firms \\
\hline & & IT_Index & ITGDI & ITGDI & ITGDI & ITGDI & ITGDI \\
\hline \multirow[t]{2}{*}{$\overline{\mathrm{BSIZE}}$} & + & $-0.006 * *$ & 0.001 & 0.002 & $-0.003 *$ & $-0.002 *$ & -0.004 \\
\hline & & $(-1.994)$ & $(0.526)$ & $(0.604)$ & $(-1.772)$ & $(-1.291)$ & $(-1.641)$ \\
\hline \multirow[t]{2}{*}{ BIND } & + & 0.74 & 0.048 & -0.152 & -0.000 & $0.059 *$ & -0.105 \\
\hline & & $(0.607)$ & $(0.646)$ & $(-1.582)$ & $(-0.003)$ & (1.312) & $(-0.906)$ \\
\hline \multirow[t]{2}{*}{ MANOWN } & - & 0.141 & -0.016 & -0.036 & 0.028 & $0.093 * *$ & -0.037 \\
\hline & & $(0.981)$ & $(-0.217)$ & $(-0.226)$ & $(0.448)$ & $(2.123)$ & $(-0.218)$ \\
\hline \multirow[t]{2}{*}{ BLOCKOWN } & + & $0.252 * * *$ & $0.231 * *$ & 0.067 & $0.110 * *$ & 0.058 & $0.178 * *$ \\
\hline & & $(2.960)$ & $(2.256)$ & $(0.948)$ & $(2.192)$ & $(0.998)$ & $(2.670)$ \\
\hline \multirow[t]{2}{*}{ ROE } & + & $-0.484 * *$ & -0.09 & 0.043 & $-0.158 *$ & -0.080 & -0.187 \\
\hline & & $(-1.568)$ & $(-0.571)$ & $(0.276)$ & $(-1.809)$ & $(-0.964)$ & $(-0.618)$ \\
\hline \multirow[t]{2}{*}{ LEV } & + & -0.812 & $0.941 * * *$ & $1.284 * *$ & 0.022 & 0.172 & -0.380 \\
\hline & & $(-1.675)$ & $(3.167)$ & $(2.246)$ & $(0.094)$ & $(0.724)$ & $(-0.567)$ \\
\hline \multirow[t]{2}{*}{ BTM } & $+/-$ & $-0.046 * *$ & $-0.019 * *$ & -0.013 & $-0.020 * *$ & -0.004 & -0.014 \\
\hline & & $(-2.407)$ & $(-2.221)$ & $(-0.604)$ & $(-2.504)$ & $(-0.143)$ & $(-1.127)$ \\
\hline \multirow[t]{2}{*}{ BIG4 } & + & -0.017 & -0.009 & 0.006 & -0.009 & 0.002 & $-0.155^{*}$ \\
\hline & & $(-0.340)$ & $(-0.429)$ & $(0.130)$ & $(-0.660)$ & $(0.158)$ & $(-1.838)$ \\
\hline \multirow[t]{2}{*}{ CI } & $+/-$ & $0.425 * * *$ & - & - & $0.203 * * *$ & $0.209 * * *$ & $0.231 * * *$ \\
\hline & & $(7.808)$ & & & $(7.519)$ & (11.058) & $(4.196)$ \\
\hline \multirow[t]{2}{*}{ US } & & & & & $-0.121 * * *$ & - & - \\
\hline & & & & & $(-4.465)$ & & \\
\hline \multirow[t]{2}{*}{ INTERCEPT } & & $0.767^{*}$ & $-0.747 * *$ & -0.805 & 0.001 & $-0.353^{*}$ & 0.533 \\
\hline & & $(1.783)$ & $(-2.568)$ & $(-1.551)$ & $(0.004)$ & $(-1.664)$ & $(0.868)$ \\
\hline $\mathrm{N}$ & & 180 & 91 & 89 & 180 & 119 & 61 \\
\hline Adjusted $\mathrm{R}^{2}$ & & 0.295 & 0.144 & 0.159 & 0.603 & 0.525 & 0.218 \\
\hline $\mathrm{F}$ & & $12.45^{* * *}$ & $1.873^{*}$ & $4.123 * * *$ & $22.37 * * *$ & $20.36^{* * *}$ & $6.005^{* * *}$ \\
\hline
\end{tabular}

Statistical significance: $* \mathrm{p}<0.10, * * \mathrm{p}<0.05, * * * \mathrm{p}<0.01$ (Two tailed).T-statics is reported in parentheses. See Table 3.1 for the variable definition. The dependent variable (IT_Index) for the model is computed by taking the average of high mean value items, which are: ITSA3, ITVD6, ITVD9, ITRM1, and ITRM5. See appendix A for a detail description of these items. For model 2 and 3, small and big sample groups are formed on the basis of median split.

To provide additional robustness checks to the main OLS model, I specify two types of regression models by using the negative binomial count model and generalized linear model. I specify a count regression model as I can also construct the dependent variable as a count variable. A count dependent variable 
Table 3.7: Negative Binomial Count Model and Generalized Linear Model for Robustness Checks

\begin{tabular}{|c|c|c|c|}
\hline & Predicted Sign & & \\
\hline Variables & & $\begin{array}{c}\text { ITGD } \\
\text { ( Negative binomial) }\end{array}$ & $\begin{array}{l}\text { ITGDI } \\
(\text { GLM) }\end{array}$ \\
\hline$\overline{B S I Z E}$ & + & $\begin{array}{l}-0.003 \\
(0.007)\end{array}$ & $\begin{array}{l}-0.007 \\
(0.010)\end{array}$ \\
\hline BIND & + & $\begin{array}{l}-0.129 \\
(0.236)\end{array}$ & $\begin{array}{l}-0.194 \\
(0.350)\end{array}$ \\
\hline MANOWN & - & $\begin{array}{l}-0.075 \\
(0.300)\end{array}$ & $\begin{array}{l}-0.104 \\
(0.406)\end{array}$ \\
\hline BLOCKOWN & + & $\begin{array}{c}0.448 * * * \\
(0.180)\end{array}$ & $\begin{array}{c}0.651^{* *} \\
(0.268)\end{array}$ \\
\hline ROE & + & $\begin{array}{c}-0.29 \\
(0.416)\end{array}$ & $\begin{array}{l}-0.38 \\
(0.571)\end{array}$ \\
\hline LEV & + & $\begin{array}{c}3.143 * * * \\
(1.086)\end{array}$ & $\begin{array}{c}4.184 * * * \\
(1.488)\end{array}$ \\
\hline BTM & $+/-$ & $\begin{array}{l}-0.05 \\
(0.050)\end{array}$ & $\begin{array}{l}-0.06 \\
(0.063)\end{array}$ \\
\hline BIG4 & + & $\begin{array}{c}0.021 \\
(0.107)\end{array}$ & $\begin{array}{c}0.007 \\
(0.132)\end{array}$ \\
\hline LnMCAP & + & $\begin{array}{c}0.163 * * * \\
(0.025)\end{array}$ & $\begin{array}{c}0.229 * * * \\
(0.036)\end{array}$ \\
\hline INTERCEPT & & $\begin{array}{l}-1.849^{*} \\
(0.968)\end{array}$ & $\begin{array}{c}-6.605 * * * \\
(1.350)\end{array}$ \\
\hline $\mathrm{N}$ & & 180 & 180 \\
\hline Log pseudo-likelihood & & -483.838 & -66.046 \\
\hline Wald $\chi^{2}$ & & $190.8 * * *$ & $162.1 * * *$ \\
\hline
\end{tabular}

Statistical significance: ${ }^{*} \mathrm{p}<0.10,{ }^{* *} \mathrm{p}<0.05,{ }^{* * *} \mathrm{p}<0.01$ (One tailed). Robust standard errors are in parentheses. GLM: Generalized linear model (utilizing a Bernoulli variance function and a logit link function).See Table 3.1 for variable defintions. Dependent variable: For Negative Binomial count model: ITGD=Sum of the number of items reported by the firm of the IT governance disclosure framework. For Generalized Linear Model: ITGDI=Ratio of the sum of number of items reported to the total number of IT governance disclosure framework items.

ITGD is computed as the sum of the number of IT governance items disclosed by a firm. I then use the negative binomial count model as the count dependent variable $I T G D$ is over-dispersed (Zmud, et al., 2010). The results of this statistical approach are consistent in terms of sign and significance with the main OLS model (See Table 3.7).The dependent variable ITDGI is fractional variable ranging between zero to one. For such type of variable, Papke and Wooldridge (1996) have specified a special generalized linear model. This model provides a fractional logit solution, which overcomes any possible arbitrary limit imposition problems by independent variables in an OLS model. Consistent with the main analysis, the results of this model also suggest similar statistical significance and direction for all the independent variables. I also run the above two 
models using $C I$ as a firm size variable. The analysis yields similar results in terms of significance and direction reported in main analysis.

\subsection{Summary, Contribution, and Limitations}

This paper explores the relationship between corporate governance and IT governance transparency. Given the theoretical premise that corporate governance fosters the mechanisms of IT governance, this study provides empirical evidence to verify this claim. The result of the study shows that board structure and ownership structure influence the level of IT governance disclosure. In specific, the findings suggest blockholder ownership is associated to a higher level of IT governance transparency. On the other hand, board independence is found to be substitutive mechanisms, indicating that it reduces the demand for IT governance transparency in public disclosure.

The results of the study indicate that higher blockholder ownership might be associated with more pressure to be informative; as a result there will be more disclosure on IT in public documents to reduce agency problems. With regard to higher board independence, I argue that independent directors might have lesser information exposure on IT topics compared to inside directors (Jewer, 2009). As a consequence, it might impede the level of IT governance disclosure practices. Additional exploratory analysis suggests that firm size is a powerful variable to explain the IT governance disclosure behavior of firms. Specifically, this indicates that large banking firms might devote more resources and efforts to communicating IT governance practices. While examining the disclosure at the category level of the disclosure framework, I find that blockholder ownership specifically stimulates the disclosure concerning IT value delivery and IT risk management.

This research offers several contributions to the existing literature in the IT governance area. First, I extend the work of Zmud, Shaft, Zheng, \& Croes (2010) on the disclosure behavior of firms in relation to IT. In doing so, I contribute to the IT governance literature and extend it further on the importance of IT governance transparency. While prior research has affirmed the role of corporate governance in developing overall IT governance mechanisms, empirical examination to reinforce this claim remains rather limited. This study, therefore, specifically contributes to the body of literature that investigates the link between corporate governance and IT governance. Second, this study provides new theoretical insights into board IT governance research. While the IT governance concept acknowledges that the board of directors has a fiduciary duty of 
care in IT governance (Jewer \& McKay, 2012), I extend this view on how the board of directors helps to enhance information transparency on IT governance.

This study has some limitations that should be considered when interpreting the results. First, the focus of the study is on technology intensive organizations. Within this sector, I have included only banking firms; this may limit the external validity of the results. Second, it is important to note that the disclosure on IT governance is voluntary. This may lead to the potential limitation that for items in the IT governance framework, which are applicable to a particular firm, the firm may choose not to disclose this information item. Consequently, it is hard to distinguish between firms that deliberately do not disclose particular IT governance issues even though they are applicable (i.e., are not transparent with respect to such items) and firms for which such items are not applicable. As a result, my measure of transparency might be an underestimation of the actual level of transparency.

Nevertheless, future research should include different industry types to examine variance in the level of IT governance disclosure and its association with corporate governance. The current study's focus is on a cross-sectional setting to examine IT governance activities in corporate disclosure. However, an eventbased longitudinal setting might provide a better variance and explanatory power to explain the association between the variables of interest in this study. 


\title{
4.
}

\section{IT GOVERNANCE MATURITY, INDUSTRY IT STRATEGIC ROLE, AND IT GOVERNANCE DISCLOSURE ${ }^{9}$}

\begin{abstract}
This chapter provides evidence on the association between IT governance maturity, the strategic role of IT in the industry, and IT governance disclosure of firms. Adding to current information systems literature, which shows that organizational performance is strongly influence by IT governance, I investigate the relation between the maturity of IT governance processes on the IT governance disclosure of firms. I find that higher maturity of IT governance is positively associated with higher disclosure on IT governance in firms' annual report. In addition, I find that the strategic role of IT at the industry level is directly associated with the level of information dissemination on IT governance topics. Consistent with my hypothesis, I also find that firms in industries where IT serves a transformative strategic role to fundamentally redefine business and industry processes are inclined toward more IT governance related disclosure. The study suggests that the maturity of IT governance not only improves the IT-

\footnotetext{
${ }^{9}$ I gratefully acknowledge the IT Alignment \& Governance (ITAG) Research Institute of University of Antwerp for providing the Control Objectives for Information and Related Technologies (COBIT) survey database. My special thanks to Steven De Haes and Wim Van Grembergen for their valuable comments.
} 
related information environment within the firm, but can be used to improve strategic non-financial disclosure practices to retain and enhance stakeholder confidence.

\subsection{Introduction}

Senior management is increasingly engaged in implementation of IT governance frameworks to provide structure, processes, and relational mechanisms for efficient IT decision making and monitoring of IT assets (Van Grembergen \& De Haes, 2009). In fact, a recent IT governance global status report (ITGI, 2011) found a considerable increase in the adoption and maturity of best practice based IT governance frameworks to improve IT performance at the firm level. Consistent with this, some recent academic studies have shown that the level of IT governance maturity has a significant positive impact on IT performance as well as firm performance (e.g., Liang, Chiu, Wu, \& Straub, 2011; Simonsson, Johnson, \& Ekstedt, 2010) ${ }^{10}$.

Although these studies have certainly contributed to our understanding of the complex association between maturity of IT governance practices and firm performance, what remains unclear is how IT governance maturity in firms influences firms' overall IT information environment, and more importantly external reporting on IT governance. Given that IT capabilities are dominant in achieving strategic business goals (Martin-Oliver \& Salas-Fumas, 2012), ITrelated information becomes crucial for external stakeholders (e.g., customers and investors) to assess firms IT related capabilities (Zmud, et al., 2010). In this regard, few prior studies have explored the impact of corporate governance (See Chapter Two) and industry characteristics (Dehning, et al., 2003; Zmud, et al., 2010) on IT governance transparency and the IT signaling behavior of firms. However, the association between maturity of IT governance practices and IT governance disclosure remain unexplored in extant literature ${ }^{11}$. To address this research gap, one of the main research objectives of this study is to examine how the level of IT governance maturity influences firms' external reporting on IT governance practices. In addition, I also argue that the strategic role of IT at the industry level can influence the disclosure on IT governance topics. Prior research on the strategic role of IT at the industry level has focused on the im-

\footnotetext{
${ }^{10}$ According to Simonsson, Johnson, \& Ekstedt (2010, p.11) the term IT governance maturity implies how well an efficient organization is aligned with best practice based IT governance frameworks.

${ }^{11}$ In this chapter, I use the term IT governance transparency interchangeably with IT governance disclosure and define it as "the extent to which firms provide adequate and relevant IT governance information in a timely and effective manner to their stakeholders" (See Chapter Two).
} 
pact IT signaling (for example, disclosure on IT investment) has on firm performance (e.g., Anderson, et al., 2003; Chatterjee, Pacini, \& Sambamurthy, 2002; Dehning, et al., 2003; Zmud, et al., 2010). This research stream has clearly noted that, depending on the strategic role of IT at industry level, systematic variation exists regarding firms' specific IT information disclosure. Given that IT disclosure is widely used to understand firms' IT related behavior (Zmud, et al., 2010), it is surprising that there is a lack of research examining how the strategic role of IT at the industry level impacts firms' overall IT governance disclosure. To fill this research gap, the second research objective of this study is to examine whether the strategic role of IT in an industry induces systematic variation in IT governance disclosure.

This study uses cross-sectional data from 124 firms to examine how IT governance maturity and the strategic role of IT at the industry level relate to the level of IT governance disclosure. I measure firms' IT governance disclosure by using a framework developed in Chapter Two. I use annual reports as the primary source of data since previous literature has indicated it to be the most reliable source of information in examing voluntary information disclosure behviour of firms (Zmud, et al., 2010). Following the IT governance literature (Simonsson, et al., 2010; Van Grembergen \& De Haes, 2009), I assess firms' IT governance maturity by employing the Control Objectives for Information and Related Technologies (COBIT) framework ${ }^{12}$. Specifically, the findings of an international field survey conducted across different industry sectors to assess the level of maturity on COBIT processes, is used to proxy IT governance maturity in this study setting. Following literature on the strategic role of IT (Anderson, et al., 2003; Chatterjee, et al., 2001; Dehning, et al., 2003; Zmud, et al., 2010; Zuboff, 1988), I classify a firm's industry IT strategic role to three categories: automate, informate, and transform. In automate industries IT replaces human labor. Informate industries are classified by the use of IT for creating efficient and effective information flows for decision making across upper and lower level of the firm. In transform industries, IT is deployed to "fundamentally redefine business and industry processes and relationships" (Dehning, et al., 2003, p. 639). My analysis suggests that the level of IT governance maturity is positively associated with the level of IT governance disclosure. This study also finds that transform and informate industry IT strategic roles are associated with a higher level of IT governance disclosure when compared with

${ }^{12}$ Control Objectives for Information and Related Technologies (COBIT) is a well-known industry IT governance framework for implementing a set of best practices for management, control, and assurance of IT. The next sections in the study will discuss the framework in more detail. 
automate industries. These findings corroborate the findings of previous literature on IT signaling behavior of firms (e.g., Zmud, et al., 2010). I also hypothesize and analyze the moderating effect of industry IT strategic role on the association between IT governance maturity and IT governance disclosure. The analysis does not provide evidence for moderating effect. However, I find that that the level of IT governance maturity is the single most influential variable to explain firms' IT governance disclosure level.

The study continues as follows. First, I provide background and research hypotheses. Next, I describe the source of data and the operationalization of variables. Further, I present the results of our empirical analysis. Last, I discuss the conclusion, contribution, limitations, and implications of the study.

\subsection{Background and Hypotheses}

\subsubsection{COBIT as IT governance framework}

IT governance provides firms with effective mechanisms, such as the allocation of IT decision rights, and management of IT risks, to achieve firms' business goals (Van Grembergen \& De Haes, 2009). It also ensures that the role and responsibility of IT within organizations is not only limited to acquiring internal IT efficiency through establishing better IT processes or by addressing regulatory compliance issues. The ultimate objective of IT governance is to create synergy between business and IT to obtain business value through IT investments (Weill \& Ross, 2004). To uphold this view, Van Grembergen \& De Haes (2009, p. 3) describe the enterprise governance of IT as "an integral part of corporate governance and addresses the definition and implementation of processes, structures, and relational mechanisms in the organization that enable both business and IT people to execute their responsibility in support of business/IT alignment and the creation of business value from IT-enabled business investments". Several IT governance frameworks exist that incorporate all elements of the aforementioned definition and assist organizations in deploying effective IT governance. The basic premise of these frameworks is to offer firms a set of best practices to effectively design structures, processes, and relational mechanisms to govern their IT assets.

Control Objectives for Information and Related Technologies (COBIT) is a well-known industry IT governance framework to implement a set of best practices for management, control, and assurance of IT. COBIT is widely accepted as an unifying framework that incorporates other IT standards, including ISO 17799, ISO/IEC 38500, Information Technology Infrastructure Library (ITIL), 
and Capability Maturity Model Integration (CMMi) ${ }^{13}$. COBIT is developed and distributed freely by Information Systems Audit and Control Association (ISA$\mathrm{CA})^{14}$. Initially developed as a framework to conduct IT audit assignments, COBIT has now emerged as one of the major de facto frameworks to implement and assess the maturity of IT governance practices in organizations. In its most updated version, COBIT 4.1 (ITGI, 2007) represents a comprehensive IT control and management framework with inclusion of metrics and maturity models for IT processes ${ }^{15}$. The framework consists of 34 generic IT processes organized in four domains (See Appendix A). For each of the 34 processes the framework describes control objectives, management guidelines and a maturity model. Each process of the framework has one high level control objective followed by several detailed objectives. More specifically, COBIT 4.1 describes 34 high level control objectives and 210 detailed control objectives across four domains: Plan and Organize (PO), Acquire and Implement (AI), Deliver and Support (DS), and Monitor and Evaluate (ME).

Plan and Organize (PO) domain includes ten IT processes that deals with recognizing a suitable way to contribute to the achievement of business objectives. In this view, the PO domain processes involve strategy and tactics for the information and technology architecture, strategic IT planning, assessment and management of IT risks, a well-structured IT organization, IT human resource management, communication of management's aims and direction, and management of IT investments and projects. The Acquire and Implement (AI) domain is mainly concerned with the identification of suitable IT solutions to realize the IT strategy of the organization, the acquisition and maintenance of application software and technical infrastructure, creating documentation and user training for users of information systems. Additionally, this domain also manages application changes and maintenance requirements to continue and fulfill business objectives. Following the AI domain, the focus of the Delivery and

\footnotetext{
${ }^{13}$ The focus of this study is on COBIT as an IT governance framework. For brevity, a discussion of other IT standards/guidance is not provided. A detailed comparison of COBIT to most of the above mentioned IT standards can be found in Van Grembergen \& De Haes (2009).

${ }^{14}$ Founded in 1967, ISACA is engaged in providing guidance, tools, and benchmarking practices to firms that employ information systems. According to ISACA's website, the organization has more than 100,000 members and 180 branches across 75 countries. ISACA has developed several IT governance frameworks including COBIT, VALIT and Risk IT governance frameworks. Further research and publication on these frameworks is conducted at the IT governance institute (ITGI), which works under the flagship of the ISACA. Next to these activities, ISACA also provides several information systems related certification programs. More details on its activities and initiatives can be found at: www.isaca.org.

${ }^{15}$ The focus of this study is on COBIT 4.1 as an IT governance framework. While completing this research study, ISACA has launched its new version, COBIT 5.0, which is outside the scope of this study.
} 
Support (DS) domain is on the delivery of required services that cover defining and managing service level agreements, ensuring business continuity, configuration management, data management, problem management, performance and capacity management of hardware, providing education and training to users, management of information systems operations, and physical environment. The fourth and last domain, Monitor and Evaluate (ME), provides a set of IT processes to assess the quality and compliance with the control requirements for all IT processes prescribed under the other three domains. The domain specifically includes performance management, monitoring of internal control, regulatory compliance, and establishing IT governance ${ }^{16}$.

Although initially seen as a practitioner based IT governance framework, in the last decade COBIT has also undergone rigorous academic investigation similar to theory driven conceptual models (Ridley, Young, \& Carroll, 2008; Tuttle \& Vandervelde, 2007). Building on COBIT as an IT governance framework, a considerable amount of academic studies have examined a wide range of IT governance topics that include the impact on IT governance performance, IT-business alignment, business performance, trust in electronic commerce, and audit setting (Bowen, Cheung, \& Rohde, 2007; De Haes \& Van Grembergen, 2009, 2010; Huang, Shen, Yen, \& Chou, 2011; Simonsson, et al., 2010; Tuttle $\&$ Vandervelde, 2007). Collectively, these studies have indicated that a higher level of IT governance maturity is positively associated with higher IT-business alignment, IT governance performance, customer trust, and business performance. While these studies have certainly contributed to our understanding of the complex association between best IT practices and business outcomes, what remains unclear is how IT governance maturity in organizations influences their overall IT information environment, and specifically their external reporting on IT governance. In a wider context, existing literature has already noted value relevance of IT information in external reporting practices (e.g., Dehning, et al., 2003; Gordon, et al., 2010). Given that IT assets are fundamental to achieving strategic business objectives and competitive advantage (Martin-Oliver \& SalasFumas, 2012; Mata, et al., 1995), I expect that IT-related information is crucial for external stakeholders (e.g., customers and investors) to assess firms' ITrelated capabilities and firm value ${ }^{17}$. Therefore, I posit that implementation of an

\footnotetext{
${ }^{16}$ The above discussion of COBIT domains and its high level processes is based on the description provided in Van Grembergen \& De Haes (2009, p.137-163). Additional discussion on control objectives, management guidelines, and maturity models can be found in the official version of COBIT 4.1 of the ITGI (2007).

${ }^{17}$ In this study, I use the term internal and external stakeholders to describe the type of stakeholders involved in IT governance. Internal stakeholders, for example includes IT leadership, IT and business managers, and
} 
IT governance framework like COBIT can influence firms' IT information environment. Specifically, I anticipate that the level of IT governance maturity will potentially improve and increase the information dissemination opportunities of firms in relation to IT governance disclosure. Nonetheless, I observe a paucity of research to examine this association.

\subsubsection{The association between IT governance maturity and IT governance disclosure}

According to Simonsson et al. (2010, p. 11), "a maturely governed IT organization is an organization that is efficient and aligned with-state-of-the-practiceframeworks (such as COBIT)". It is argued that IT governance maturity exhibits the internal IT organization efficiency measured on an IT process based framework like COBIT. The term IT organization essentially relates to IT-related decision making and includes participants from both the IT and business sides of the organization. In this study, I adhere to the above definition to conceptualize and simplify our understanding of IT governance maturity ${ }^{18}$. The current strategic information systems and accounting information systems literature provides a variety of studies to understand two important contributions of IT governance using COBIT. First, as stated earlier, firms that exhibit higher IT governance maturity will show a positive impact on IT-business alignment, IT related performance, and overall organizational performance (e.g., De Haes \& Van Grembergen, 2009; Simonsson, et al., 2010; Van Grembergen \& De Haes, 2009). This stream of literature specifically emphasizes the influence of IT governance in improving IT-related performance to achieve business objectives. This describes the role of IT governance in creating IT capabilities to increase firm value and gain competitive advantage.

A second important contribution of IT governance, specifically using COBIT, is noted in establishing efficient and effective internal control systems in organizations. Since the introduction of the Sarbanes-Oxley Act of 2002 (SOX), executive management of firms under the section 404 of this act, is required to report on the quality of firms' internal controls over financial reporting ${ }^{19}$. This

different IT users of management information systems. External stakeholders include customers, investors, and regulatory authority.

${ }^{18}$ The concept of maturity within COBIT 4.1 is described as IT governance maturity model. This maturity model concept is based on the Software Engineering Institute's maturity model for software development capability to assess the maturity on 34 COBIT processes.

19 The Sarbanes-Oxley Act (SOX) was passed by the US congress in 2002 in response to a number of corporate governance scandals, for example, Enron and WorldCom. The act is focused on improving corporate 
act also explicitly demands disclosure on material weaknesses including IT material weaknesses ${ }^{20}$. Given that IT-enabled systems in firms are pervasive in supporting management to formulate earnings forecasts, financial statements, and to make critical business decisions, it has become essential for firms to establish efficient and effective IT control to ensure reliable financial reporting (Li, et al., 2012). In this view, COBIT provides a valuable and most suitable IT process control framework. It explains IT processes in detail, outlines their control objectives and essential quality indicators, and also provides a guideline to self-assess firms' maturity level in implementing each IT process (Hardy, 2006; McFarlane, 2005). In the last decade, there is a substantial amount of literature that has explored the topic of IT internal control and IT auditing employing the COBIT framework and has established its importance in developing IT governance practices in firms (e.g., Lainhart, 2000; Merhout \& Havelka, 2008; Ridley, et al., 2008; Tuttle \& Vandervelde, 2007).

Collectively, the aforementioned contributions can be attributed or "mapped" to the five focus areas of IT governance namely, IT strategic alignment, IT value delivery, IT resource management, IT risk management, and IT performance measurement (Buckby, et al., 2008; ITGI, 2007) ${ }^{21}$. While the first type of literature contribution provides a significant documentation of the topic of IT strategic alignment, IT value delivery, and IT performance measurement; notable research studies on IT internal control have helped to develop our understanding of IT resource management and IT risk management topics. In this chapter, I argue that the influence of effective IT governance practices and their impact on the above mentioned five focus areas is not only relevant or limited to the firm and its internal stakeholders. In fact, there is a broader ramification of these practices on external stakeholders. As effective and mature IT governance in firms can ensure IT leadership and other internal stakeholders about firmwide performance of IT assets, it also has the potential to directly influence a variety of issues relevant to external stakeholders. For example, Gordon, Loeb, Lucyshyn, \& Sohail (2006) showed that voluntary disclosure of information security activities has dramatically increased (over 100\%) since the introduction

governance practices, providing reliable and high quality financial reporting, and improving the quality of audit effectiveness.

${ }^{20}$ According to the Public Company Auditing Oversight Board (PCAOB), "A material weakness is a deficiency, or a combination of deficiencies, in internal control over financial reporting, such that there is a reasonable possibility that a material misstatement of the company's annual or interim financial statements will not be prevented or detected on a timely basis". For more details see: (PCAOB, 2007)

${ }^{21}$ A detailed discussion of the IT governance and its focus areas can be found in ITGI's board briefing on IT governance (ITGI, 2003). Also, a comprehensive literature summary is provided in Buckby, Best, \& Stewart (2008). 
of SOX. They have also noted that such type of voluntary disclosure of firms not only improve transparency on non-financial topics, but also have resulted in enhancing their market value (Gordon, et al., 2010).

Drawing on voluntary disclosure theory and the notion of information asymmetry, research in IT governance has clearly advocated the importance of IT governance communications to external stakeholders of the firm (Gordon, et al., 2006; Raghupathi, 2007). The theoretical underpinning, rooted in voluntary disclosure theory and agency theory predicts that firms can improve their liquidity and firm valuation through better information intermediation, enhance market reputation, reduce litigation costs, and the cost of capital (Diamond \& Verrecchia, 1991; Healy \& Palepu, 2001; Jensen \& Meckling, 1976; Narayanan, et al., 2000). Building on this theoretical premise of an association between potential economic benefits and voluntary disclosure, I posit that a higher maturity of IT governance activities enables firms to create a better IT information environment and dissemination capability ${ }^{22}$. Such improved environment and capability can be exploited by increasing disclosure on IT activities. In this study, I predict that a higher level of IT governance maturity, which leads firms to an enriched IT information dissemination capability on key focus areas of IT governance, will be associated with more disclosure in their external reporting practices. This prediction is hypothesized as follows:

H1a: The level of IT governance maturity is positively associated with the level of IT governance disclosure.

To examine this hypothesis, I use 1) all the 34 IT processes across the four COBIT domains to assess the IT governance maturity, and 2) the IT governance disclosure framework developed in Chapter Two to measure the level of disclosure on key focus areas of IT governance. As reported earlier, the five focus areas of IT governance could be well mapped on to the four COBIT domains. In this regard, I note a potential association between the Plan and Organize (PO) domain of the COBIT with the strategic alignment focus area of IT governance. Prior literature suggests that firms that have organized different IT governance structures to align business and IT engage in disclosing these activities to increase firm value. For example, Chatterjee, Richardson, \& Zmud (2001) show that the announcement of the creation of a Chief Information Officer (CIO)

\footnotetext{
${ }^{22}$ As disclosure on IT activities is voluntary, the literature on voluntary disclosure and agency theory provides a suitable theoretical framework. See Chapter 2, and Gordon, Loeb, \& Sohail (2010).
} 
position has a significant positive impact on the stock price of the firm ${ }^{23}$. Likewise, I also note a relationship between the Monitor and Evaluate (ME) domain and IT performance measurement focus area. For instance, Im, Dow, and Grover (2001) show a positive market performance of firms that provide information about their IT spending. The empirical evidence certainly warrants further examination of a domain level association of COBIT maturity with the disclosure behavior of firms. To this end, I specifically identify and focus on the PO and ME domains that are primarily concerned with those IT processes that potentially affect IT-business alignment and performance measurement (Van Grembergen \& De Haes, 2009). Therefore, I predict that the maturity of the PO and ME domains will show a positive and significant association with the disclosure of IT strategic alignment and IT performance measurement focus area of IT governance, respectively. The following two hypotheses are formulated to examine these relationships:

$\mathrm{H} 1 \mathrm{~b}$ : The level of maturity of the Plan and Organize domain within COBIT is positively associated with the level of disclosure on IT strategic alignment.

H1c: The level of maturity of the Monitor and Evaluate domain within COBIT is positively associated with the level of disclosure on IT performance measurement.

\subsubsection{Industry IT strategic role and IT governance disclosure}

The extant information systems research has extensively examined the dominant role that IT deployment plays for competing firms in an industry (Chiasson \& Davidson, 2005; Crowston \& Myers, 2004). There is a basic premise that the strategic role of IT across industries varies because of the difference in the nature of competitive opportunities and pressures, business processes, and the need to develop certain IT infrastructure capabilities to meet the requirements of information processing (Kobelsky, et al., 2008). Nonetheless, variation in the requirements at the firm level results in a considerable similarity in the nature of IT deployment within industries (Dehning, et al., 2003). The information systems research classifies these similarities of IT strategic role at the industry

\footnotetext{
${ }^{23}$ From the Plan and Organize domain perspective creating a CIO position is part of establishing and implementing IT roles and responsibilities, nevertheless, it is also seen as a mechanism to create synergy between IT and business.
} 
level into three distinct categories: automate, informate, and transform (Schein, 1992; Zuboff, 1988) ${ }^{24}$. Automate industries signify a primary role of IT is to substitute human labor by automating business processes. In automate IT strategic role, IT deployments help firms to reduce the cost of operating business processes in order to pursue a cost leadership strategy (Anderson, et al., 2003). According to Zmud et al (2010, p. 154) firms in automate industry category are perceived to be more stable, and "digitization of business processes, products or services for such firms are either difficult or for whom digitization is difficult to justify". As a result, automate industry IT strategic role is associated with less frequent IT deployments, such that developing and structuring of IT capabilities occur in an incremental manner (Kobelsky, et al., 2008). Contrary to this, transform IT strategic role portends a less stable business environment where business processes, products or services are dynamic and highly digitizable. In such business environment, because of greater competitive opportunities and pressures firms are engaged in frequent IT deployments, which are emerging and innovative in nature (Sambamurthy, Bharadwaj, \& Grover, 2003). In transform industry IT strategic role, IT deployments assist firms to regularly reinvent their IT capabilities to advance in new product market niches or to bring radical changes to existing IT-enabled business processes (Dehning, et al., 2003). In between these two extreme scenarios, informate industry IT strategic role includes those firms that operate in 'moderately' dynamic business environment, but exhibit greater opportunities for digitization of their business processes, products or services (Zmud, et al., 2010). Informate industry IT strategic role is primarily focused on the use of IT to create flexible business processes that in turn would help firms to archive, analyze and distribute digitized data and information for efficient decision making (Zmud, et al., 2010). Collectively, the dissemination of information and data flow about business activities to senior management (informate-up) and to employees (informate-down) using IT creates "decision-making and decision-taking structure at, respectively, higher and lower firm levels" (Dehning, et al., 2003, p. 640).

The current information systems research has extensively employed the IT strategic role construct to examine the business value of IT both at the industry (Anderson, et al., 2003; Chatterjee, et al., 2002; Chatterjee, et al., 2001) and the firm level (Armstrong \& Sambamurthy, 1999). In this study, I employ the construct at the industry level using the typology suggested in Chatterjee et al. (2001). A notable amount of studies have also empirically observed that the

\footnotetext{
${ }^{24}$ Following Zmud et al., (2010) and Dehning et al., (2003), I define and use the term industry IT strategic role interchangeably with IT strategic role at the industry level.
} 
industry strategic IT role is associated with the information disclosure behavior of firms. Specifically, these studies are based on the notion that "IT deployments and its external communications practices are largely determined by institutional actors that include regulatory agencies, markets analysts, industry consortiums, and embedded business practices conditioned by dominant industry participants" (Zmud, et al., 2010, p. 154). In their study on the value relevance of announcement of IT investments, Dehning et al. (2003) observed that investors react positively to IT investment disclosure in transform industries in comparison to informate and automate industries. Drawing on signaling theory, Zmud et al. (2010) have noted systematic differences in IT information signaling across industry IT strategic roles, such that transform industries are engaged in higher IT signaling when compared to informate and automate industries. Collectively, the empirical evidence clearly suggests that firms operating in a more dynamic and less stable environment, and for whom IT deployments posit a dominant role in (re)designing business processes, products or services, are more likely to engage in greater IT signaling than firms in a stable business environment. In other words, transform industries are likely to show higher IT information dissemination when compared to informate and automate industries. In addition, the results show that external stakeholders certainly acknowledge value implications of IT-enablement in relation to the strategic role of IT. While the above empirical studies are limited to IT investment signaling (Dehning, et al., 2003) and the specific nature of the IT signal i.e., transform, informate, and automate (Zmud, et al., 2010), I am not aware of any prior research investigating the industry level IT strategic role and how it influences overall IT governance disclosure practices. Building on the aforementioned literature as the theoretical framework, I would expect that IT governance disclosure of firms is likely to be influenced by the industry IT strategic role. More specifically, I expect that the propensity of IT governance disclosure for IT deployments of firms in dynamic and less stable environments (i.e., transform industries) as well as moderately dynamic environments (i.e., informate industries) will be greater than firms that operate in a relatively stable business environment (i.e., automate industries). Also, from a value implication perspective (Davis, et al., 2003; Dehning, et al., 2003), I assume that investors would expect higher IT governance disclosure from firms who face more competitive pressure and opportunities through IT deployments (i.e., transform and informate industries). This discussion leads to the following hypothesis:

H2: The level of IT governance disclosure differs across industries, depending on the strategic role of IT in the respective industry. 


\subsubsection{Moderating effect of Industry IT strategic role}

As noted earlier, Zmud et al. (2010) and Dehning et al. (2003) empirically observed that firms in transformative industries signal more about their IT-related activities compared to firms in informate and automate industries. Both these studies attribute this finding to the strategic role of IT in transformative industries and its subsequent value implications. On the other hand, from an IT governance perspective, the IT Governance Global Status Report (ITGI, 2008) indicates that firms that could be categorized as transformative are adopting and implementing IT governance practices more proactively compared to automate industry firms. The descriptive statistics in the ITGI report also reveal that the firms that use IT to create sustainable competitive advantage (i.e., transformative industries) have shown a greater level of IT governance maturity by implementing a variety of IT governance frameworks when compared to conservative firms - which could be characterized as automate industries in this study's setting. In addition, there are other notable research studies that have focused on industry characteristics in relation to IT governance, and have acknowledged the prominence of IT governance practices in transformative industries (e.g., Armstrong \& Sambamurthy, 1999; Sohal \& Fitzpatrick, 2002). Drawing on this discussion, I therefore expect that firms with higher IT governance maturity in transformative industries will have an enriched IT governance information environment. As a result, firms will not only have the opportunities to distribute such information, but also the potential to benefit from it due to its value implications in the competitive arena. Additionally, I also expect a similar relationship for firms in the informate industry group for whom higher IT governance maturity will induce efficient and effective IT processes monitoring. This will potentially result in an improved information environment not only for better decision making and taking environment at different levels of the firm, but also for external communication practices. Based on these arguments, I state following research hypothesis:

H3: The relationship between IT governance maturity and IT governance disclosure is moderated by the industry IT strategic role. 


\section{3. $\quad$ Research Method}

\subsubsection{Sample, data, and variable measurement}

This research study draws on two data sources: 1) survey data on the selfassessment of IT governance maturity by executives and managers of firms and 2) annual reports in a cross-sectional setting for the year 2008. I acquired the survey data from a study conducted by De Haes \& Van Grembergen (2010) in 2008 to assess the implementation level of 34 COBIT processes (See Appendix $\mathrm{D}{ }^{25}$. This survey included 538 responses from $\mathrm{CxO}$ level officers, who at the time of the survey were registered members of the Information Systems Audit and Control Association (ISACA). From this survey data, I considered only those $\mathrm{CxO}$ responses where I could identify their firm affiliation and obtain the firm annual report to measure the level of IT governance disclosure. This important condition resulted in a final sample of 124 observations where I was able to retrieve their firm's annual report. Respondents provided their assessment of the implementation status of 34 COBIT processes on a fivepoint Likert scale $(1=$ not implemented, $5=$ fully implemented $)$. Each process was briefly explained by some of its key activities and a 'Don't know' option was provided to enhance the quality of the assessments. Next, the industry IT strategic role coding was applied on the sample firms using Chatterjee et al. (2001) typology. According to this typology, I assign each sample firm into one of three categories, namely: transform, informate, and automate. The industry segment indicated by the respondent in the survey and the firm's annual report was used as an additional source to perform this classification. The description of this analysis is presented in Table 4.1. Out of 124 firms, financial and banking firms represent $32 \%$ of the total sample, followed by governmental organizations at $18 \%$. The manufacturing industry represents $8 \%$ of the total sample.

\footnotetext{
${ }^{25}$ In addition to COBIT processes, this survey also includes data on IT goals, business goals, and the VALIT framework. As this study exclusively focuses on COBIT, I exclude all other data of this survey. See De Haes \& Van Grembergen (2010) for a detailed discussion and descriptive analysis on the survey data.
} 
Table 4.1: Strategic Role of IT at the Industry Level ${ }^{26}$

\begin{tabular}{lccc}
\hline Industry & $\begin{array}{c}\text { Number of observa- } \\
\text { tions }\end{array}$ & $\begin{array}{c}\text { Percentage of the total } \\
\text { sample }\end{array}$ & $\begin{array}{c}\text { Industry IT strategic } \\
\text { role }\end{array}$ \\
\hline Financial/Banking & 40 & $32 \%$ & Transform \\
Government/Military- & 22 & $18 \%$ & Informate \\
National/State/Local & 14 & $11 \%$ & Transform \\
Insurance & 10 & $8 \%$ & Automate \\
Manufacturing/Engineering & 7 & $6 \%$ & Informate \\
Retail/Wholesale/Distribution & 6 & $5 \%$ & Informate \\
Education/Student & 6 & $5 \%$ & Automate \\
Mining/Construction/Petroleum/ & 5 & $4 \%$ & Informate \\
Health Care/Medical & 3 & $2 \%$ & Automate \\
Utilities & 3 & $2 \%$ & Informate \\
Pharmaceutical & 2 & $2 \%$ & Automate \\
Transportation & 2 & $2 \%$ & Transform \\
Telecommunica- & 1 & $1 \%$ & Transform \\
tions/Communications & 1 & $1 \%$ & Transform \\
Public Accounting & 1 & $1 \%$ & Informate \\
Aerospace & 1 & $1 \%$ & Transform \\
Legal/Law/Real Estate & $\mathbf{1 2 4}$ & $\mathbf{1 0 0 \%}$ & \\
Advertising/Marketing/Media & & & \\
Total & & & \\
\hline
\end{tabular}

Data on IT governance disclosure is collected from the annual reports of the 124 sample firms. I recognize that beside the annual report, firms' voluntary IT governance disclosure is made through various disclosure channels, for example, corporate governance report, press releases, website, newsletters, firms' presentations to investors, and corporate social responsibility report. The choice of the annual report as a preferred medium for data gathering was based on two main reasons. First, the annual report is easily accessible through firms' websites. It is also noted that firms treat the annual report as a most preferred medium when voluntarily disclosing on IT activities (See Chapter Two). Second, in many countries annual reports are audited; therefore, voluntary disclosed information on IT in the annual report is more credible compared to other mediums

\footnotetext{
${ }^{26}$ The classification of the strategic role IT across industries is based on the typology suggested by Chatterjee et al. (2001). However, their classification does not include the following industries: Aerospace, Government/Military, Legal/Law/Real estate, and Education. I assigned the industry strategic role of IT to these industries in agreement with other two strategic information system researchers.
} 
of reporting which are mostly non-audited. To codify data on IT governance from the annual report, I used the IT governance disclosure framework developed in Chapter Two.This framework is developed on the four key focus areas of the COBIT framework that include IT strategic alignment (ITSA), IT value delivery (ITVD), IT risk management (ITRM), and IT performance measurement (ITPM). Each of this focus area is represented as a disclosure category in the IT governance disclosure framework with a list of key disclosure items relevant to each of the categories (See Appendix A). The disclosure items of this framework are originally developed through an extensive literature review and a pilot study.

\subsubsection{Dependent, independent and control variables}

Using content analysis (Weber, 1985), I examined whether or not each item on the IT governance disclosure framework is reported $(1=$ reported, $0=$ not reported). Next, I estimated the disclosure index score for each category of the IT governance disclosure framework as well as an overall IT governance disclosure index (ITGDI), which is simply an average score on all the items disclosed by a firm. ITGDI is the dependent variable to test H1a and H2. For testing H1a and H1b, I computed category level index score ITSA and ITPM as dependent variables. The interest of this paper lies in investigating the association of IT governance maturity and industry IT strategic role to the level of IT governance disclosure. To capture IT governance maturity (ITG_MATURITY) as an independent variable, the COBIT framework is used to assess the firm's maturity on IT governance related processes. ITG_MATURITY score for a firm is computed as the average score on all the 34 COBIT processes from the survey data (Cronbach's alpha $=0.97$ ).

Next, average maturity scores for all COBIT domains, PO, AI, DS, and $\mathrm{ME}$, are also estimated. The variable PO and ME maturity scores are used as independent variables to test hypotheses $\mathrm{H} 1 \mathrm{a}$ and $\mathrm{H} 1 \mathrm{~b}$, respectively. Besides ITG_MATURITY, the other independent variable of the study is industry IT strategic role. Consistent with prior literature (e.g., Chatterjee, et al., 2001; Dehning, et al., 2003), I classify sample firms in one of the three categories and create three indicator variables, namely, TRANSFORM, INFORMATE, and AUTOMATE to represent a distinct industry IT strategic role. Further, I include firm size as a control variable. Previous literature has documented mixed evidence of firm size on firm's information disclosure propensity (Zmud, et al., 2010). The firm size measure in this study is based on firms' employee number information indicated by participants from 8 different firm employee size cate- 
gories. Using this information, I created three indicator variables - SMALL, MEDIUM, and LARGE to capture the firm size effect. As the sample is drawn form an international survey, I employed a dummy variable (US) to control for potential country differences noted in Chapter Two. I further include an indicator variable - GOV to control for the difference between public and private firms. In addition, I used LIST as a control variable to account for the difference between public listed and non-listed firms. Table 4.2 provides a description of the dependent, independent, and control variables used in this study. 
Table 4.2: Variable definitions

\begin{tabular}{|c|c|c|}
\hline Variable & Variable Code & Description \\
\hline \multicolumn{3}{|l|}{ Dependent Variable } \\
\hline $\begin{array}{l}\text { IT governance dis- } \\
\text { closure index }\end{array}$ & ITGDI & $\begin{array}{l}\text { Average score for all items of IT governance disclosure } \\
\text { framework. }\end{array}$ \\
\hline $\begin{array}{l}\text { IT strategic align- } \\
\text { ment disclosure index }\end{array}$ & ITSA & Average score for IT strategic alignment category items. \\
\hline $\begin{array}{l}\text { IT value delivery } \\
\text { disclosure index }\end{array}$ & ITVD & Average score for IT value delivery category items. \\
\hline $\begin{array}{l}\text { IT risk management } \\
\text { disclosure index }\end{array}$ & ITRM & Average score for IT risk management category items. \\
\hline $\begin{array}{l}\text { IT performance } \\
\text { measurement disclo- } \\
\text { sure index }\end{array}$ & ITPM & $\begin{array}{l}\text { Average score for IT performance measurement category } \\
\text { items. }\end{array}$ \\
\hline \multicolumn{3}{|l|}{ Independent Variable } \\
\hline $\begin{array}{l}\text { IT governance ma- } \\
\text { turity }\end{array}$ & ITG_MATURITY & Average maturity score on all the $34 \mathrm{COBIT}$ processes. \\
\hline Plan and Organize & $\mathrm{PO}$ & $\begin{array}{l}\text { Average maturity score on the Plan and Organize domain } \\
\text { processes. }\end{array}$ \\
\hline $\begin{array}{l}\text { Acquire and Imple- } \\
\text { ment }\end{array}$ & AI & $\begin{array}{l}\text { Average maturity score on the Acquire and Implement domain } \\
\text { processes. }\end{array}$ \\
\hline Decision and Support & DS & $\begin{array}{l}\text { Average maturity score on the Decision and Support domain } \\
\text { processes. }\end{array}$ \\
\hline Monitor and Evaluate & ME & $\begin{array}{l}\text { Average maturity score on the Monitor and Evaluate domain } \\
\text { processes }\end{array}$ \\
\hline Automate & AUTOMATE & $\begin{array}{l}1 \text { if the firm has membership in an industry characterized as } \\
\text { having an automate IT strategic role; } 0 \text { otherwise. }\end{array}$ \\
\hline Informate & INFORMATE & $\begin{array}{l}1 \text { if the firm has membership in an industry characterized as } \\
\text { having an informate IT strategic role; } 0 \text { otherwise. }\end{array}$ \\
\hline Transform & TRANSFORM & $\begin{array}{l}1 \text { if the firm has membership in an industry characterized as } \\
\text { having a transform strategic role; } 0 \text { otherwise. }\end{array}$ \\
\hline \multicolumn{3}{|l|}{ Control Variable } \\
\hline Small firm group & SMALL & $\begin{array}{l}\text { Indicator variable taking value } 1 \text { if the total number of em- } \\
\text { ployees is equal or less than } 49 ; 0 \text { otherwise. }\end{array}$ \\
\hline Medium firm group & MEDIUM & $\begin{array}{l}\text { Indicator variable taking value } 1 \text { if the total number of em- } \\
\text { ployees is greater than } 1,500 \text { and less than } 9,999,0 \text { otherwise. }\end{array}$ \\
\hline Large firm group & LARGE & $\begin{array}{l}\text { Indicator variable taking value } 1 \text { if the total number of em- } \\
\text { ployees is greater than } 10,000,0 \text { otherwise. }\end{array}$ \\
\hline US & US & 1 if the firm is located in US; 0 otherwise. \\
\hline Gov & GOV & $\begin{array}{l}1 \text { if the firm is operating in Government/Military- } \\
\text { National/State/Local/Education/Legal/Law industry; } 0 \text { other- } \\
\text { wise. }\end{array}$ \\
\hline Listed & LIST & 1 if the firm is public listed; 0 otherwise. \\
\hline
\end{tabular}




\subsubsection{Regression models}

OLS multiple regression analysis is used to test the proposed hypotheses. Several OLS models were specified to test the main effects and the interaction effect of IT governance maturity and industry IT Strategic role on the level of IT governance disclosure. The following functional model indicates the approach for the empirical analysis:

$$
\text { ITGDI }=f(\text { IT governance maturity, Industry IT strategic role, control variables })
$$

Specifically, I estimate the coefficients of the following regression analysis:

$$
\begin{aligned}
\text { ITGDI }= & \beta_{0}+\beta_{1} * \text { ITG_MATURITY }+\beta_{2} * \text { TRANSFORM }+\beta_{3} \text { INFORMATE } *+\beta_{4} * \text { AUTOMATE }+\beta_{5} * \\
& \text { MEDIUM }+\beta_{6} * \text { LARGE }+\beta_{7} * \text { SMALL }+\beta_{8} * \text { US }+\beta_{9} * \text { GOV }+\beta_{10} * \text { LIST }+\varepsilon
\end{aligned}
$$

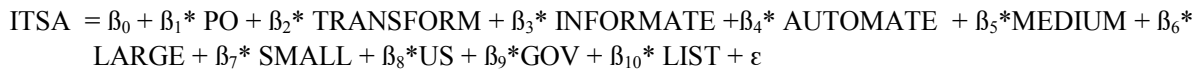

ITPM $=\beta_{0}+\beta_{1} *$ ME $+\beta_{2} *$ TRANSFORM $+\beta_{3} *$ INFORMATE $+\beta_{4} *$ AUTOMATE $+\beta_{5} *$ MEDIUM + $\beta_{6} *$ LARGE $+\beta_{7} *$ SMALL $+\beta_{8} *$ US $+\beta_{9} *$ GOV $+\beta_{10} *$ LIST $+\varepsilon$

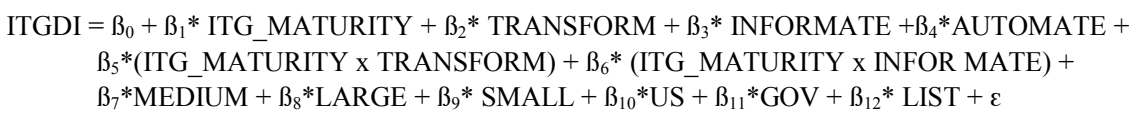

The aforementioned functional and regression models represent the specification to test the main effect, interaction effect, and accounts for testing all the hypotheses. Model 2 is specified to test $\mathrm{H} 1 \mathrm{a}$ and $\mathrm{H} 2$. I estimate the coefficients of model 3 and 4 to test the impact of PO and ME domains of the COBIT (H1b and H1c). To examine hypothesis H3, I estimate the coefficients of model 5.

\subsection{Results}

\subsubsection{Descriptive statistics}

Table 4.3 shows the descriptive statistics. Panel A shows that on average $16 \%$ of items of the IT governance disclosure framework are publicly disclosed by 
the sample firms in their annual report. Based on a theoretical maximum score of 1 , the maximum score is 0.56 , which indicates that the firm scoring highest on the IT governance disclosure framework has reported on 22 items out of 39 disclosure items. At the category level of disclosure scores vary significantly. The disclosure on IT value delivery is found to be the highest compared to other categories. Table 4.3 also indicates that the average IT governance maturity score (ITG_MATURITY) is 0.67 . This implies that on average firms have scored 114 points out of a theoretical maximum of 170 points. From the point of view of COBIT implementation, results shows that on average 23 of 34 COBIT processes are fully implemented by the sample firms. In panel B the frequencies of the dichotomous variables employed in the study are tabulated.

Table 4.3: Descriptive Statistics

\begin{tabular}{|c|c|c|c|c|c|}
\hline \multicolumn{6}{|c|}{ Panel A: Descriptive Statistics } \\
\hline Variable & $\mathrm{N}$ & Mean & $\begin{array}{l}\text { Standard } \\
\text { Deviation }\end{array}$ & Minimum & Maximum \\
\hline \multicolumn{6}{|l|}{ Dependent Variables } \\
\hline ITGDI & 124 & 0.1606 & 0.1126 & 0 & 0.56 \\
\hline ITSA & 124 & 0.0980 & 0.0960 & 0 & 0.45 \\
\hline ITVD & 124 & 0.2002 & 0.1928 & 0 & 0.77 \\
\hline ITRM & 124 & 0.1760 & 0.2090 & 0 & 1 \\
\hline ITPM & 124 & 0.1676 & 0.1449 & 0 & 0.63 \\
\hline \multicolumn{6}{|c|}{ Independent Variables } \\
\hline ITG_MATURITY & 124 & 0.6794 & 0.1542 & 0.23 & 1 \\
\hline $\mathrm{PO}$ & 124 & 0.6605 & 0.1615 & 0.18 & 1 \\
\hline AI & 124 & 0.7011 & 0.1745 & 0 & 1 \\
\hline DS & 124 & 0.6874 & 0.1581 & 0.18 & 1 \\
\hline ME & 124 & 0.6629 & 0.1727 & 0.15 & 1 \\
\hline \multicolumn{6}{|c|}{ Panel B: Frequency tabulation for binary variables } \\
\hline Variable & $\mathrm{N}$ & $\begin{array}{l}\text { Frequency } \\
(\text { if value }=1)\end{array}$ & $(\%)$ & $\begin{array}{l}\text { Frequency } \\
(\text { if value }=0)\end{array}$ & $(\%)$ \\
\hline \multicolumn{6}{|l|}{ Independent variable } \\
\hline AUTOMATE & 124 & 21 & 16.94 & 103 & 83.06 \\
\hline INFORMATE & 124 & 44 & 35.48 & 80 & 64.52 \\
\hline TRANSFORM & 124 & 59 & 47.58 & 65 & 52.42 \\
\hline \multicolumn{6}{|l|}{ Control Variables } \\
\hline SMALL & 124 & 40 & 32.26 & 84 & 67.74 \\
\hline MEDIUM & 124 & 42 & 33.87 & 82 & 66.13 \\
\hline LARGE & 124 & 42 & 33.87 & 82 & 66.13 \\
\hline US & 124 & 48 & 38.71 & 76 & 61.29 \\
\hline GOV & 124 & 29 & 23.39 & 95 & 76.61 \\
\hline LIST & 124 & 73 & 58.87 & 51 & 41.13 \\
\hline
\end{tabular}




\subsubsection{Univariate analysis}

Table 4.4 offers correlations between dependent, independent, and control variables included in the study. This analysis indicates that the level of IT governance disclosure (ITGDI) is positively and significantly correlated with the level of IT governance maturity (ITG_MATURITY). This is in line with the expectations from H1a. The correlation between the level of IT strategic alignment (ITSA) and the Plan and Organize (PO) sub-domain of the maturity framework also indicates a positive and significant association, which is in line with $\mathrm{H} 1 \mathrm{~b}$. This signifies that firms with higher process maturity on the PO domain of COBIT have more extensive disclosure related to IT strategic alignment. Consistent with my prediction for $\mathrm{H} 1 \mathrm{c}$, I find a positive and significant correlation between the level of IT performance measurement disclosure (ITPM) and Monitor and Evaluate (ME) maturity level. This implies that firms that have achieved high maturity on monitoring and evaluating their IT processes show greater propensity in signaling IT performance issues in their annual report. Next, the association between TRANSFORM industry and ITGDI is found to be positive and significant, conforming to my expectation for H2a. In sum, the correlation analysis is in line with expectations.

I conduct several T-tests and one-way ANOVA to facilitate comparison between the independent variables and the level of both IT governance disclosure and its sub- categories. Table 4.5 reports the T-test results for industry IT strategic role, firm size, and IT maturity groups. Panel A of the table indicates a significant difference on overall level of IT governance disclosure (ITGDI), IT value delivery (ITVD), and IT risk management (ITRM) between the TRANSFORM and AUTOMATE industry groups. This is in line with my prediction for $\mathrm{H} 2 \mathrm{a}$. In panel B, I find that large firms have shown a significantly higher propensity in disclosing IT value delivery issues compared to small firms. In addition, I investigated the influence of IT governance maturity on the level of IT governance disclosure.

As there is no standard on the cutoff point or specifications of IT governance maturity, I divided firms into three equal groups on the basis of their IT governance maturity scores (Low ITG_MATURITY $<0.63$; $0.63<$ MEDIUM ITG_MATURITY $<0.75$; High ITG_MATURITY $>0.75$ ). In the T-test, I compared High ITG_MATURITY with Low ITG_MATURITY, skipping Medium ITG_MATURITY group. Panel C indicates that firms with higher IT governance maturity show higher propensity in disclosing IT governance information on an overall level. The results also imply that higher maturity leads to better 


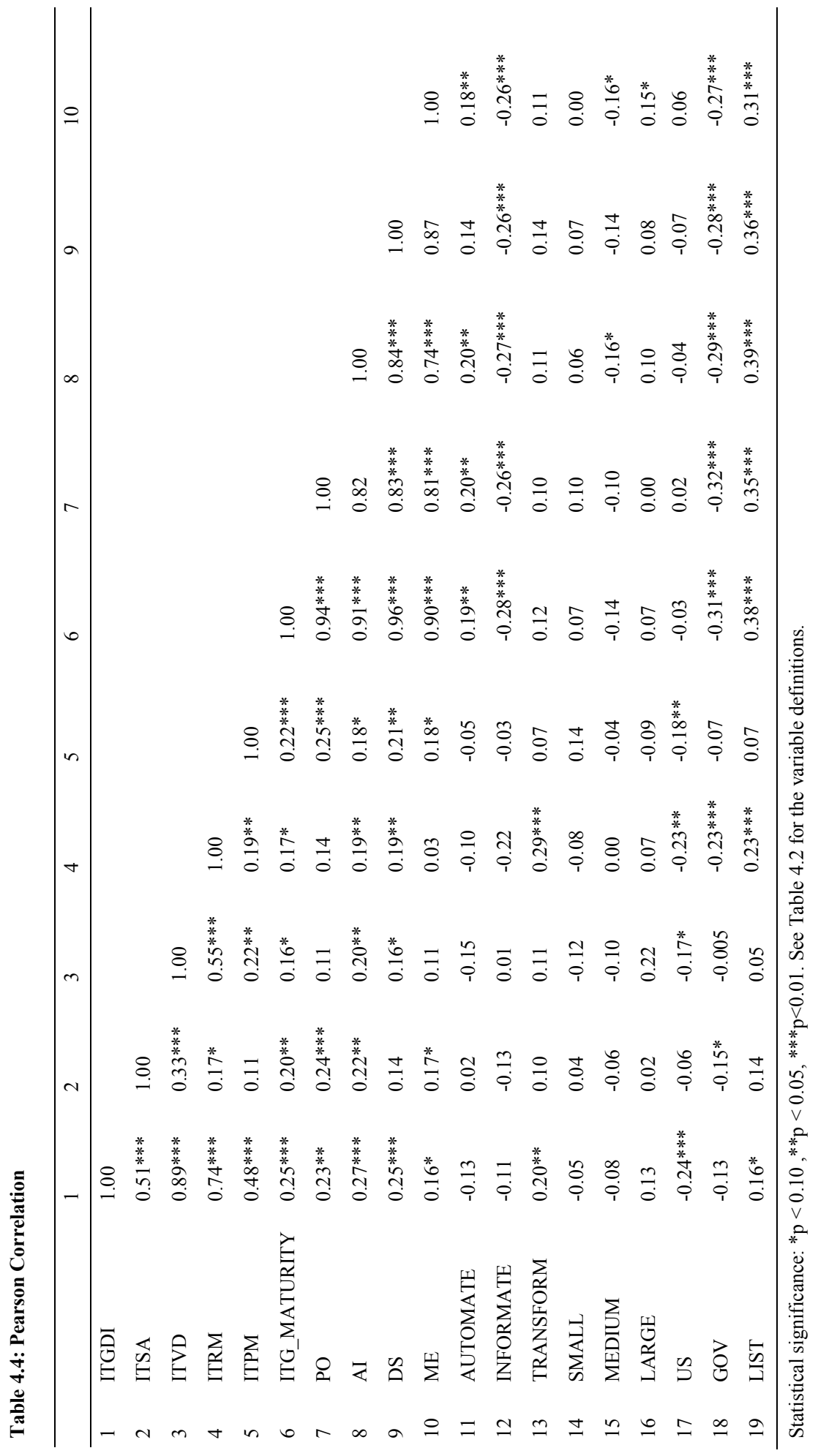




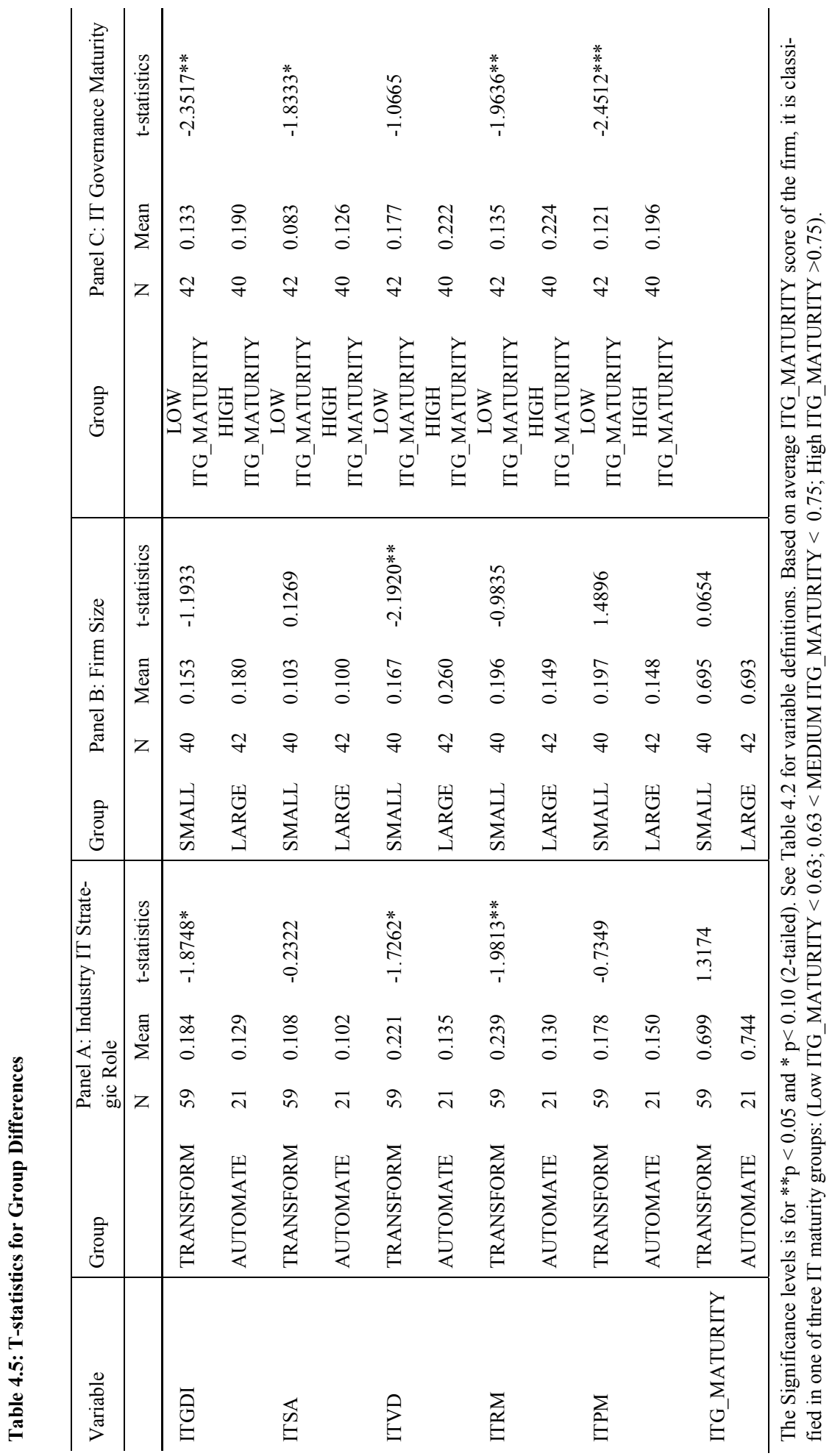




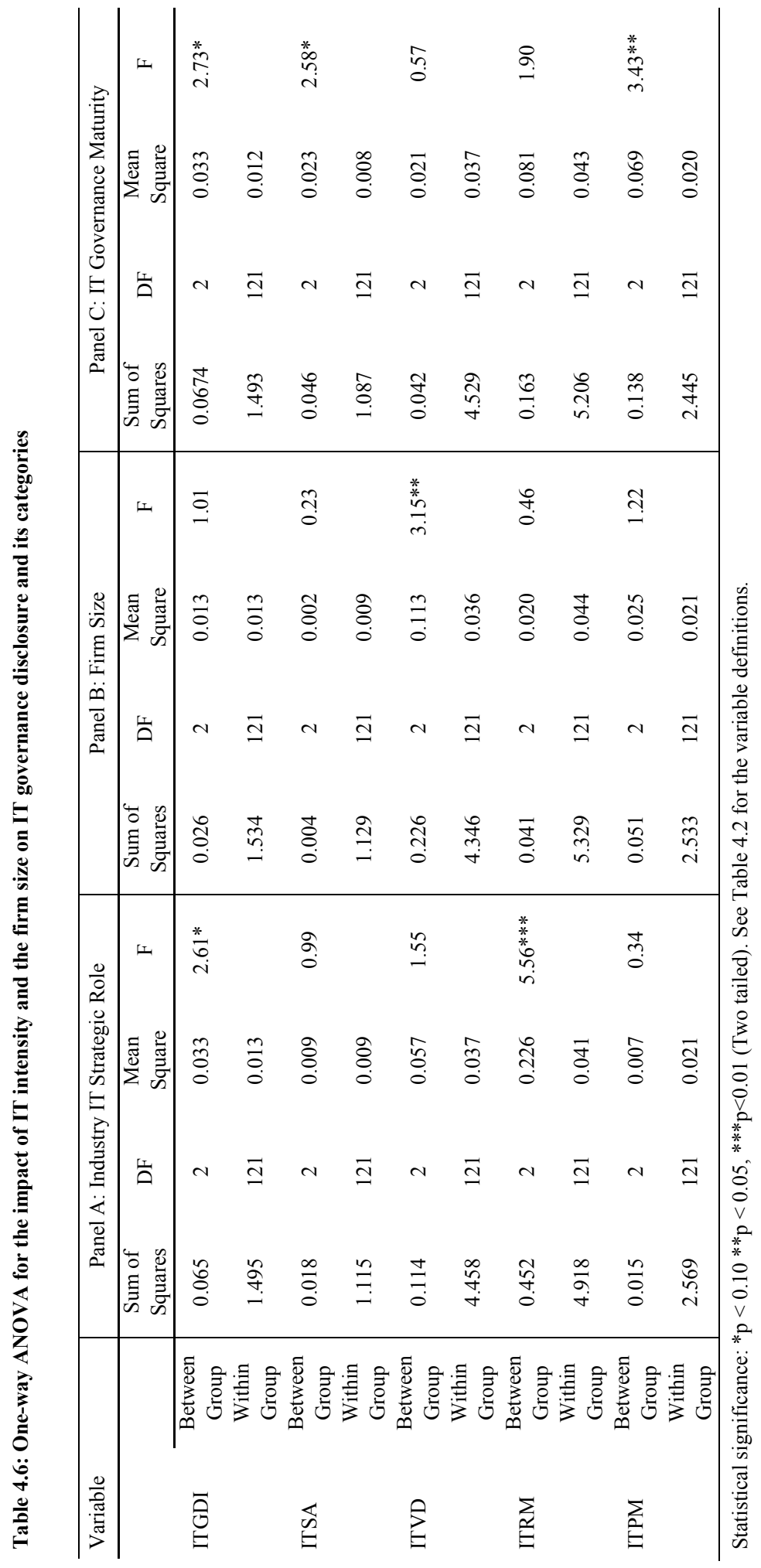


information disclosure on IT strategic alignment, IT risk management, and IT performance measurement.

In line with most of the hypotheses, I find consistent results for the one-way ANOVA. Table 4.6 shows the one-way ANOVA results across industry IT strategic role (Panel A), Firm size (Panel B), and IT governance maturity (Panel C). Panel A shows a significant variation within and between firms on overall IT governance and IT risk management disclosure such that the between-group mean square is significantly larger than that of the within-group. This suggests that the disclosure propensity varies more across than within industry IT strategic role groups. The findings also suggest that the level of IT value delivery (ITVD) disclosure is significantly different across firm size groups compared to within-group variation (Panel B). The results in Panel C indicate that there is a significant variation on the level of overall IT governance disclosure, IT strategic alignment, and IT performance measurement across proposed IT maturity groups.

\subsubsection{Multivariate analysis}

Table 4.7 presents the multivariate regression results of the four different OLS models employed for hypotheses testing. For all the regression models in the analysis, I controlled for the multicollinearity among all the independent variables. The variance inflation factor (VIF) statics was well below the threshold value $(\mathrm{VIF}=10)$, which confirms that the analysis does not suffer from a multicollinearity problem. Next, the regression coefficients and t-statistics for all models in the table are reported after adjusting for standard errors for heteroskedasticity. Model 1 and 4 use the IT governance disclosure index (ITGDI) as dependent variable. IT strategic alignment (ITSA) is used as dependent variable in Model 2. For Model 3, IT performance measurement (ITPM) is employed as dependent variable.

Model 1 (Column 1 in Table 4.7) shows the test of hypothesis H1a and H2. ITG_MATURITY indicates a significant positive coefficient of $0.165(\mathrm{p}<0.01)$. As expected, the level of overall IT governance disclosure is positively associated with IT governance maturity, hence H1a is supported. I also find significant and positive regression coefficients for INFORMATE $(0.045, \mathrm{p}<0.10)$ and TRANSFORM $(0.064, \mathrm{p}<0.01)$. Consistent with my expectation, I find that the industry IT strategic role is associated with the disclosure propensity on IT governance. Both the INFORMATE and TRANSFORM category firms provide higher disclosure compared to AUTOMATE industry firms. The findings clearly indicate that information dissemination on IT topics is industry sensitive. 
Firms that are highly IT-enabled in conducting and achieving their business and governance objectives are likely to engage in greater IT governance reporting. Considering the magnitude of the regression coefficients, the result shows that this behavior is likely to be observed more predominately in TRANSFORM industries (0.064) when compared to INFORMATE (0.045) industries. Thus, hypotheses $\mathrm{H} 2$ is supported. The results also indicate that larger firms are more inclined to disclose on IT topics as the coefficient of LARGE is positive and significant $(0.043, \mathrm{p}<0.05)$. Model 1 explains approximately $12 \%$ of the overall IT governance disclosure.

Model 2 (Column 2 in Table 4.7) shows that maturity on the Plan and Organize domain (PO) which is primarily focuses on establishing tactics and strategy on IT topics through appropriate IT-business alignment have positive and significant association $(0.133, \mathrm{p}<0.01)$ with the level of IT strategic alignment category. This estimate is consistent with hypothesis $\mathrm{H} 1 \mathrm{~b}$.

The results in Model 3 (Column 3 in Table 4.7) indicate a positive and significant coefficient on $\mathrm{ME}(0.181, \mathrm{p}<0.05)$. Consistent with hypothesis $\mathrm{H} 1 \mathrm{c}$, this suggests that firms with higher process maturity score on the Monitoring and Evaluate domain are associated with a higher level of disclosure on IT performance measurement. This result is in line with the recommendations of COBIT, which encourages higher communication transparency to stakeholders under this specific domain. The results in Model 2 and 3 also show that the industry IT strategic role do not exert any specific influence on the level of disclosure of ITSA and ITPM as both the INFORMATE and TRANSFORM variables yields equal but insignificant coefficients.

Next, the finding in Model 3 shows that smaller firms, when they achieve a higher level of maturity on the ME domain, increase their disclosure on IT performance measurement compared to large firms. I test hypothesis H3 in Model 4 (Column 4 in Table 4.7). The results indicate that both interaction term coefficients are insignificant. Thus, I do not observe any moderating effect of the industry IT strategic role on the association between IT governance maturity and the level of disclosure. Therefore, $\mathrm{H} 3$ is not supported. However, the coefficient on ITG_MATURITY is positive and significant $(0.297, \mathrm{p}<0.10)$. This implies that the level of IT governance maturity is the single best predictor of the disclosure level in the model. The model explains approximately $11 \%$ of overall IT governance disclosure. It is essential to note that the strategic role of IT operates at both firm and industry levels (Dehning, et al., 2003). 
Table 4.7: Impact of IT Maturity on IT governance disclosure (Number of observations =124)

\begin{tabular}{|c|c|c|c|c|}
\hline & Model 1 & Model 2 & Model 3 & Model 4 \\
\hline & ITGDI & ITSA & ITPM & ITGDI \\
\hline \multirow[t]{2}{*}{ INTERCEPT } & 0.009 & 0.016 & 0.064 & -0.091 \\
\hline & $(0.172)$ & $(0.417)$ & $(0.866)$ & $(-0.721)$ \\
\hline \multirow[t]{2}{*}{ ITG_MATURITY } & $0.165^{* * *}$ & & & $0.297 *$ \\
\hline & $(2.860)$ & & & $(1.881)$ \\
\hline \multirow[t]{2}{*}{$\mathrm{PO}$} & & $0.133 * * *$ & & \\
\hline & & $(2.871)$ & & \\
\hline \multirow[t]{2}{*}{ ME } & & & $0.181 * * *$ & \\
\hline & & & $(2.400)$ & \\
\hline \multirow[t]{2}{*}{ TRANSFORM } & $0.064 * * *$ & 0.010 & 0.032 & 0.182 \\
\hline & $(2.623)$ & $(0.455)$ & $(0.871)$ & $(1.236)$ \\
\hline \multirow[t]{2}{*}{ INFORMATE } & $0.045^{*}$ & 0.004 & 0.048 & 0.140 \\
\hline & $(1.508)$ & $(0.139)$ & $(1.183)$ & $(1.031)$ \\
\hline AUTOMATE & Baseline & Baseline & Baseline & Baseline \\
\hline \multirow[t]{2}{*}{ ITG_MATURITY x INFORMATE } & & & & -0.125 \\
\hline & & & & $(-0.711)$ \\
\hline \multirow[t]{2}{*}{ ITG_MATURITY x TRANSFORM } & & & & -0.160 \\
\hline & & & & $(-0.832)$ \\
\hline \multirow[t]{2}{*}{ MEDIUM } & 0.014 & -0.007 & -0.027 & 0.014 \\
\hline & $(0.555)$ & $(-0.327)$ & $(-0.823)$ & $(0.559)$ \\
\hline \multirow[t]{2}{*}{ LARGE } & $0.043^{* *}$ & 0.003 & -0.047 & $0.044^{*}$ \\
\hline & $(1.764)$ & $(0.145)$ & $(-1.396)$ & (1.717) \\
\hline SMALL & Baseline & Baseline & Baseline & Baseline \\
\hline \multirow[t]{2}{*}{ US } & $-0.060 * * *$ & -0.013 & $-0.053^{* *}$ & $-0.060 * * *$ \\
\hline & $(-3.268)$ & $(-0.762)$ & $(-2.010)$ & $(-3.245)$ \\
\hline \multirow[t]{2}{*}{ GOV } & -0.012 & -0.012 & -0.003 & -0.012 \\
\hline & $(-0.351)$ & $(-0.399)$ & $(-0.079)$ & $(-0.340)$ \\
\hline \multirow[t]{2}{*}{ LIST } & 0.001 & 0.004 & 0.021 & 0.003 \\
\hline & $(0.048)$ & $(0.204)$ & $(0.590)$ & $(0.099)$ \\
\hline Adj.R2 & 0.124 & 0.005 & 0.03 & 0.111 \\
\hline $\mathrm{F}$ & $4.194 * * *$ & $1.712 *$ & 1.679 & $3.309^{* * *}$ \\
\hline
\end{tabular}

Statistical significance: ${ }^{*} \mathrm{p}<0.10,{ }^{* *} \mathrm{p}<0.05,{ }^{* * *} \mathrm{p}<0.01$ (One tailed).T-statistics is in parentheses. See Table 4.2 for variable definitions.

In this study, I am only focusing on IT strategic role at the industry level and the firm level IT strategic role is not examined. While noticing a significant and positive coefficient on the level of IT governance maturity in the interaction term model 4, it could be argued that a higher level of IT governance maturity might also imply a dominant IT strategic role at the firm level. In other words, it might be plausible that the level of IT governance maturity together with unob- 
served firm level IT strategic role have overshadowed the findings for the interaction term model.

\subsubsection{Additional analysis}

As mentioned in the univariate analysis section there is no standard cut-off point for the specification of IT governance maturity. Thus, I include some additional analysis to test the sensitivity of the association between IT governance maturity and the disclosure on IT governance. To perform this additional analysis and develop further insights into the association between IT governance maturity and the disclosure on IT governance, I split the sample at the median value of ITG_MATURITY into two groups: High and Low IT governance maturity. Table 4.8 reports the results of OLS regressions for the two subsamples. The coefficient of ITG_MATURITY in the high IT governance maturity group (Column 1 in Table $4 . \overline{8})$ is significant and positive $(0.289, \mathrm{p}<0.05)$. In the low IT governance maturity group (Column 2 in Table 4.8), the result shows a significant and positive coefficient estimate for ITG_MATURITY $(0.369, \mathrm{p}<0.01)$. When comparing the magnitude of the ITG_MATURITY coefficients in the two regression models, I find that the firms below median value of IT governance maturity achieve a larger impact on the level of disclosure. The low IT maturity group also shows positive and significant coefficients for the INFORMATE $(0.105, \mathrm{p}<0.01)$ and TRANSFORM $(0.150, \mathrm{p}<0.01)$ industry groups. This suggests that firms in the below median level of IT governance maturity group from these two industry groups present a higher propensity for disclosure compared to the AUTOMATE group. 
Table 4.8: Split Sample Analysis

High IT Governance Maturity

Low IT Governance Maturity

\begin{tabular}{|c|c|c|}
\hline & ITGDI & ITGDI \\
\hline INTERCEPT & $\begin{array}{c}-0.070 \\
(-0.537)\end{array}$ & $\begin{array}{l}-0.166^{*} \\
(-1.750)\end{array}$ \\
\hline ITG_MATURITY & $\begin{array}{c}0.289 * * \\
(1.784)\end{array}$ & $\begin{array}{c}0.369^{* * *} \\
(3.016)\end{array}$ \\
\hline TRANSFORM & $\begin{array}{c}0.024 \\
(0.818)\end{array}$ & $\begin{array}{c}0.150 * * * \\
(3.202)\end{array}$ \\
\hline INFORMATE & $\begin{array}{c}0.022 \\
(0.604)\end{array}$ & $\begin{array}{l}0.105^{* *} \\
(2.155)\end{array}$ \\
\hline AUTOMATE & Baseline & Baseline \\
\hline MEDIUM & $\begin{array}{c}0.015 \\
(0.417)\end{array}$ & $\begin{array}{c}0.037 \\
(0.894)\end{array}$ \\
\hline LARGE & $\begin{array}{l}0.049^{*} \\
(1.523)\end{array}$ & $\begin{array}{c}0.048 \\
(1.070)\end{array}$ \\
\hline SMALL & Baseline & Baseline \\
\hline US & $\begin{array}{c}-0.075 * * * \\
(-3.207)\end{array}$ & $\begin{array}{c}-0.046 \\
(-1.541)\end{array}$ \\
\hline GOV & $\begin{array}{c}-0.038 \\
(-0.764)\end{array}$ & $\begin{array}{c}-0.005 \\
(-0.104)\end{array}$ \\
\hline LIST & $\begin{array}{c}0.006 \\
(0.173)\end{array}$ & $\begin{array}{c}-0.031 \\
(-0.760)\end{array}$ \\
\hline Number of Observations (N) & 62 & 62 \\
\hline Adj. $R^{2}$ & 0.123 & 0.110 \\
\hline $\mathrm{F}$ & $2.47 * *$ & $2.58^{* * *}$ \\
\hline
\end{tabular}

Statistical significance: ${ }^{*} \mathrm{p}<0.10 * * \mathrm{p}<0.05,{ }^{* * *} \mathrm{p}<0.01$ (One tailed). T-statistics is in parentheses. See Table 2 for variable definitions. High and low IT Governance Maturity sample groups are formed on the basis of median split.

\subsubsection{Robustness test}

I specify three additional types of regression models: the negative binomial count model, generalized linear model, and Tobit regression model to provide addition robustness to the OLS regressions. A count regression model is specified as the dependent variable can be computed as a count variable. For this, a count dependent variable ITGD is computed as the sum of the number of IT governance items disclosed by a firm. Using this method, I also compute ITSA_SUM and ITPM_SUM as two dependent variables to verify hypothesis $\mathrm{H} 1 \mathrm{~b}$ and $\mathrm{H} 1 \mathrm{c}$. To estimate regression coefficients, I then use the negative binomial count model as the count dependent variable ITGD is over-dispersed (Zmud, et al., 2010). The results are presented in columns for Model A, C, and $\mathrm{E}$ of Table 4.9. The findings from this statistical approach are consistent with the main OLS results in terms of sign and significance. 
The dependent variables ITDGI, ITSA, and ITPM are fractional variables ranging between zero and one. For such type of variable, Papke and Wooldridge (2008) have specified a special generalized linear model. This model provides a fractional logit solution, which overcomes any possible arbitrary limit imposition problems by independent variables in an OLS model (Hadden, Hermanson, $\&$ DeZoort, 2003). Consistent with the main analysis, the results of this model also suggest similar statistical significance and direction for all the independent variables.

Table 9: Robustness Test (Number of observations=124)

\begin{tabular}{|c|c|c|c|c|c|c|}
\hline & Model A & Model B & Model C & Model D & Model E & Model F \\
\hline & ITGD & ITGDI & ITSA_SUM & ITSA & ITPM_SUM & ITPM \\
\hline \multirow[t]{2}{*}{ Intercept } & $0.693 * *$ & $-2.894 * * *$ & $-0.823^{*}$ & $-3.226^{* * *}$ & -0.374 & $-2.394 * * *$ \\
\hline & $(1.836)$ & $(-6.894)$ & $(-1.949)$ & $(-6.906)$ & $(-0.851)$ & $(-4.530)$ \\
\hline \multirow[t]{2}{*}{ ITG_MATURITY } & $1.239 * * *$ & $1.355^{* * *}$ & & & & \\
\hline & $(2.886)$ & $(2.948)$ & & & & \\
\hline \multirow[t]{2}{*}{$\mathrm{PO}$} & & & $1.364 * * *$ & $1.512 * * *$ & & \\
\hline & & & $(2.614)$ & $(2.621)$ & & \\
\hline \multirow[t]{2}{*}{ ME } & & & & & $1.012 * *$ & $1.224 * *$ \\
\hline & & & & & $(2.207)$ & (2.196) \\
\hline \multirow[t]{2}{*}{ INFORMATE } & $0.331 * *$ & $0.365^{*}$ & 0.034 & 0.039 & 0.264 & 0.328 \\
\hline & $(1.602)$ & $(1.569)$ & $(0.117)$ & $(0.121)$ & $(1.072)$ & $(1.122)$ \\
\hline \multirow[t]{2}{*}{ TRANSFORM } & $0.421 * * *$ & $0.468^{* *}$ & 0.093 & 0.105 & 0.17 & 0.211 \\
\hline & $(2.577)$ & $(2.440)$ & $(0.447)$ & $(0.454)$ & $(0.751)$ & $(0.783)$ \\
\hline AUTOMATE & Baseline & Baseline & Baseline & Baseline & Baseline & Baseline \\
\hline \multirow[t]{2}{*}{ MEDIUM } & 0.033 & 0.09 & -0.059 & -0.067 & -0.155 & -0.199 \\
\hline & $(0.207)$ & $(0.480)$ & $(-0.283)$ & $(-0.287)$ & $(-0.864)$ & $(-0.913)$ \\
\hline \multirow[t]{2}{*}{ LARGE } & $0.253 * *$ & $0.310^{* *}$ & 0.034 & 0.038 & -0.276 & -0.332 \\
\hline & $(1.737)$ & (1.849) & $(0.157)$ & $(0.156)$ & $(-1.422)$ & $(-1.424)$ \\
\hline SMALL & Baseline & Baseline & Baseline & Baseline & Baseline & Baseline \\
\hline \multirow[t]{2}{*}{ US } & $-0.348 * * *$ & $-0.444 * * *$ & -0.137 & -0.153 & $-0.315^{*}$ & $-0.376^{*}$ \\
\hline & $(-2.903)$ & $(-3.242)$ & $(-0.798)$ & $(-0.798)$ & $(-1.930)$ & $(-1.946)$ \\
\hline \multirow[t]{2}{*}{ GOV } & -0.085 & -0.125 & -0.18 & -0.193 & -0.048 & -0.052 \\
\hline & $(-0.341)$ & $(-0.446)$ & $(-0.527)$ & $(-0.517)$ & $(-0.190)$ & $(-0.172)$ \\
\hline \multirow[t]{2}{*}{ LIST } & -0.014 & -0.017 & 0.03 & 0.035 & 0.09 & 0.114 \\
\hline & $(-0.072)$ & $(-0.080)$ & $(0.139)$ & $(0.145)$ & $(0.440)$ & $(0.467)$ \\
\hline Log pseudo-likelihood & -333.657 & -38.767 & -162.180 & -29.638 & -183.841 & -40.850 \\
\hline Wald $\chi^{2}$ & $32.66 * * *$ & $35.70^{* * *}$ & 11.95 & 11.96 & $14.60 *$ & $14.11 *$ \\
\hline
\end{tabular}

Statistical significance: ${ }^{*} \mathrm{p}<0.10^{* *} \mathrm{p}<0.05,{ }^{* *} \mathrm{p}<0.01$ (One tailed). Z-statistics is in parentheses. Model A, C, and E is a negative binomial count model. Generalized linear model is employed in Model B,D, and F Note: ITGD = Total disclosure count for overall disclosure, ITSA_SUM = Total disclosure count for ITSA category, ITPM_SUM = Total disclosure count for ITPM category.

The results are presented in columns for Model B, D, and F of Table 4.9. I also run Tobit regressions for all the three dependent variables to account for any 
potential bias in the OLS regression estimates due to potential truncation at zero of the dependent variable; the results were similar in sign and significance. For brevity, results are not reported.

\subsection{Summary and Conclusion}

The primary objective of this study is to examine if IT governance maturity and industry IT strategic role are systematically related to the variation in the level of IT governance disclosure. This study aims to better understand the role of IT governance framework, like COBIT, in improving the public disclosure of IT related information. The study shows that IT governance maturity at the firm level is positively associated with information dissemination of IT in the annual report. That is, the level of implementation of IT governance processes enhances the information environment on IT governance topics. This improved IT related information environment is utilized by firms to improve the level of transparency in their external reporting practices. This shows a broader and overreaching role of IT governance framework like COBIT in stimulating accountability and transparency via external reporting. A fundamental premise of COBIT is to provide a robust and efficient governance framework to control and monitor IT processes and IT resources that in turn, contribute to the achievement of firms' business goals. Interestingly, this study exhibits that firms that have attained superior control over their IT resources and IT processes engage in more IT information disclosure. In doing so, it is plausible that firms might be using IT information signaling as a strategic instrument to exhibit their intended IT actions to external stakeholders to improve firm value. This study provides clear empirical evidence that the adoption of an IT governance framework is associated to external communication practices on IT governance. Next, the study also reveals the impact of various domains of COBIT on IT governance disclosure. Specifically, I show that the level of disclosure on IT strategic alignment matters and IT performance measurement is systematically correlated with the maturity of sub-domains of the COBIT framework. Firms with better IT process maturity on the planning and organization sub-domain have shown a positive inclination in signaling IT strategic alignment topics in their annual report. A higher disclosure propensity is noted on IT performance matters for those firms that have established and achieved a greater degree of IT monitoring and evaluation maturity on the ME domain of COBIT. The overall findings in the study present the first empirical support to link IT governance disclosure with the adoption of an IT governance framework. 
The study also shows that the strategic role of IT in the industry plays a crucial role in IT information disclosure. The transformative industry type firms, which are heavily leveraged on IT-enabled products and services, show higher inclination toward information disclosure compared to the automate industry types. The study finding also indicates that firms in informative industries, which heavily rely on IT enabled processes to cater their services, report more IT relevant information compared to firms in the automate industry. Further, I find that the level of IT governance maturity is the most influential explanatory variable to explain the level of disclosure when analyzed together with the strategic role of IT across industries. The rejection of moderating effects suggested in hypothesis H3 indicates the importance of IT at the firm level rather than the industry level. That is, the strategic role of IT can also vary at the firm level, which is unobserved in the analysis of this study.

This study offers several contributions to the information systems literature. First, it contributes to the current body of IT information disclosure literature by examining the role of the IT governance framework in influencing the external information environment of firms. In this way, the study extends our understanding of the role of IT governance frameworks beyond that of improving IT enabled business processes and thereby business value of IT. More specifically, our understanding of IT governance frameworks like COBIT is limited to its contribution to improve IT processes; however, little is known about how it might improve the overall information environment with regard to IT. With this study, I suggest that firms with superior IT governance maturity are associated with external communication practices on IT topics. Second, the study provides a significant contribution by showing how IT strategic role at the industry level describes the propensity towards information dissemination on IT governance related topics. The results of this study corroborate and contribute to the extant academic literature that examines the association between IT information disclosure and the strategic role of IT in different industries. While it is challenging to examine IT related phenomena due to limitations in the availability of archival data (Zmud, et al., 2010), my research design contributes to alleviating this issue by providing a disclosure framework that is well grounded in existing qualitative and empirical IS literature. Researchers can employ this framework to capture and tabulate publicly available IT governance information more comprehensively and study IT related phenomenon in cross-sectional as well as in event based settings. In sum, the results of this study help to serve and stimulate future theoretical development in the area of IT governance and related frameworks. 
From a practical implication aspect, managers might leverage their IT governance practices to improve their formal communication on IT through public disclosure. Such external reporting can aware stakeholders on: firms' various IT initiatives to improve customer products or services; on-going IT related planning and project(s) updates that might add significant value to the existing business model; overall IT governance achievement by signaling information on operational efficiency and functional effectiveness.

I recognize that this study has some limitations. I use the COBIT implementation status as a proxy to measure IT governance maturity. Although this proxy variable is widely employed in IT governance literature, it should be interpreted with some caution. In my research design, I assume the implementation status of the process as a maturity status of COBIT processes. This assumption is different than the proposed general maturity model concept within the COBIT framework $^{27}$. Next, the data on IT governance evaluation is collected through self-assessment survey of IT governance. Thus, I do not rule out the possibility of a common method variance with respect to the explanatory variables employed in the study. The dependent variable ITGDI is an index variable based on the coding of items of the IT governance disclosure framework. Although I validated the reliability of items through measuring inter-coder agreement on a limited sample of data, it is important to note that the process of coding data from public disclosure is inevitably subjective. Although industry IT strategic role classification is widely used in prior literature, it, however, does not account for IT strategic role at the firm level. For instance, it is plausible that a strategic role of IT within automate industry might be transformative or informate. Therefore, the findings of the study might impose some limitations.

The study results suggest several topics for future research. First, this study looks at the cross sectional impact of IT governance maturity, which provides a status of the adoption level. Nevertheless, IT governance in a firm is not stationary in terms of its process implementation and maturity status. In other words, the sample firms in the study have different timelines for the adoption of COBIT. In this view, it would be worthwhile to conduct a study in a longitudinal setting to better understand the relationship between the level of IT governance maturity and the level of disclosure over time. Second, future research might look into consequences of higher IT governance maturity on firm value.

\footnotetext{
${ }^{27}$ In the COBIT framework, maturity modeling of IT related processes is based on a 0-5 scale. A process can be evaluated from a level of non-existent (0) to optimized (5). This maturity model concept is based on the Software Engineering Institute's maturity model for software development capability. For further explanation and details refer to COBIT 4.1.
} 
For example, the impact of IT governance maturity on stock returns of a firm. Further studies can also include other available frameworks such as VALIT or the newly released COBIT 5.0 as a more sophisticated research design to measure IT governance maturity and its subsequent impact on disclosure, as well as business value of IT. 


\section{5.}

\section{SUMMARY AND CONCLUSION}

\subsection{Introduction}

This dissertation brings together three distinct but related studies on the transparency of IT governance. Chapter Two provides an IT governance disclosure framework to assess how firms disclose information about their IT governance activities. In this chapter, I also explore the influence of the internal and external corporate governance environment on IT governance disclosure. In Chapter Three, I study whether board structure and ownership structure impact the level of IT governance disclosure. In Chapter Four, I examine the impact of the maturity of IT governance and the strategic role of IT on the disclosure of IT governance. This final chapter first reviews the empirical results of Chapters Two, Three and Four in Section 5.2. Next, implications are provided in Section 5.3. Finally, limitations of this dissertation and recommendations for future research are discussed in Section 5.4.

\subsection{Summary of results}

The purpose of the first study was to assess the transparency of the IT governance of firms. To achieve this, I first developed a descriptive framework of IT governance disclosure to examine the transparency of IT governance. To develop this framework, I focused on five key focal areas of IT governance, namely, the strategic alignment of IT, value delivery of IT, IT risk management, measurement of IT performance, and IT resource management to identify essential 
indicators of IT governance. Using content analysis on a variety of public documents, and using the developed IT governance disclosure framework, I assessed how firms communicate about their IT governance initiatives. Assuming that IT information dissemination is important for IT-intensive firms, the first two studies of the dissertation included only commercial banks as the study sample. The analysis suggests that firms provide IT governance information using various public documents instead of a single reliable disclosure source. Among the various disclosure media I examined, the annual report appears to be the most preferred medium to communicate information on IT governance topics. Drawing on voluntary disclosure and corporate governance literature, I further explore the impact of internal and external corporate governance environments on the transparency of IT governance. First, I characterize the US and European corporate governance environments as two distinct external governance settings to examine the impact of external corporate governance on the disclosure of IT governance. Assuming that the US corporate governance environment is more shareholder driven, I hypothesize that US firms are characterized by higher disclosure of IT governance in comparison with European firms. Contrary to my assumption, I find that the level of IT governance disclosure is higher for European firms than for US firms. A possible explanation for this finding is that US firms - in comparison with European firms - are largely driven by standardized reporting frameworks. As a consequence, it is plausible that US firms might have limited the disclosure of information to those topics which are regulated extensively under standardized reporting frameworks, and paid less attention to voluntary disclosure topics such as IT governance, to keep reporting costs at an optimum level. Second, I investigate the impact of internal corporate governance on the transparency of IT governance to assess how firm level corporate governance practices affect the communication on IT governance topics in public documents. I hypothesized that superior quality of corporate governance at firm level is related to higher disclosure of IT governance. The findings suggest that although overall IT governance disclosure is not significantly associated with the quality of internal corporate governance, firms with higher corporate governance performance do provide more information on IT performance issues.

In Chapter Three I study the influence of board structure and ownership structure on the transparency of IT governance. Drawing on agency theory, I investigate how boards of directors act as a monitoring mechanism to improve the dissemination of information on strategic assets like IT for addressing agency problems, which occur because of information asymmetry between stakeholders and management. I examined two hypotheses to study the impact of 
board structure on the level of disclosure on IT governance. First, consistent with previous literature on corporate governance, I suggest that higher board independence is positively related to the level of disclosure on IT governance. Second, I assume that a larger board size results in a larger pool of expertise about strategic firm assets, including IT. This, in turn, is likely to improve the potential for disseminating information about IT-related topics via corporate disclosure. Next, I argue that the ownership structure of firms is related to the transparency of IT governance. Drawing on literature on agency theory, I hypothesize that higher managerial ownership in firms is associated with lower transparency on IT governance. I argue that higher managerial ownership in firms creates a substitution effect, where managers are exposed to relatively less coercive demand from the capital market to provide voluntary information on strategic assets like IT in public documents. On the other hand, I assume that higher blockholder ownership in firms is positively associated with the level of disclosure of IT governance. I assume that large blockholding in firms acts as a dominant monitoring mechanism and generates a complementary effect, where management faces pressure to provide more information on IT governance to alleviate agency conflicts.

Consistent with prior findings, the empirical analysis reveals that firm size is the most powerful variable in explaining the propensity of IT governance disclosure. I also find that blockholder ownership is positively associated with the level disclosure of IT governance. Contrary to the prediction of the board independence hypothesis, the result indicates that higher board independence is associated with lower disclosure of IT governance. I argue that higher board independence might lead to better monitoring of IT governance practices at the board level, but might not encourage the communication in public disclosure. Also, consistent with prior literature, I assume that independent directors might have less exposure to information on IT topics in comparison with inside directors, which possibly leads to an attention deficit that can implicitly limit the level of disclosure on IT governance. In an additional analysis, I find that blockholder ownership is associated with IT governance topics, specifically concerning the value delivery of IT and IT risk management.

After assessing the association of the corporate governance environment, board structure and ownership structure with the transparency of IT governance in Chapters Two and Three, respectively, Chapter Four studies the association of the maturity of IT governance and the strategic role of IT at the industry level. In Chapter Four I argue that the adoption of a framework based on best practices not only supports firms' achievement of efficiency and effectiveness in their IT-related processes, but the level of adoption influences firms' overall IT 
information environment. This in turn is likely to affect the potential of firms to improve the transparency of their IT governance via corporate disclosure. Consistent with voluntary disclosure and economic theory, I hypothesize that the level of maturity of IT governance attained by firms through the implementation of an IT governance framework is positively associated with the level of transparency of IT governance. To assess the maturity of the IT governance of firms, I use a database on the adoption level of IT processes compiled according to the the Control Objectives for Information and Related Technologies (COBIT) framework. Next, I also hypothesize a positive association between the level of maturity of two specific domains of COBIT, namely, Plan and Organize (PO) and Monitor and Evaluate (ME), with two subcategories of the IT governance disclosure framework: the strategic alignment of IT, and IT performance measurement, respectively. Further, I examine the relationship between the strategic role of IT at the industry level and the disclosure of IT governance. Previous research has extensively documented that the strategic role of IT can be classified into three groups: automate, informate, and transform. Drawing on this characterization and prior literature, I hypothesize that transform and informate industries, which are classified as IT-intensive in relation to automate industries, are associated with a higher level of IT governance disclosure. In Chapter Four I also hypothesize that the relationship between the maturity of IT governance and the disclosure of IT governance is moderated by the strategic role of IT in a given industry.

The results show that the level of maturity of IT governance is positively associated with the level of disclosure of IT governance. This confirms the prediction that firms that have adopted an IT framework leverage their enriched IT information environment to strengthen their external communication on IT governance. I also find that the Plan and Organize (PO) domain maturity is positively associated with the level of disclosure on the IT strategic alignment category.

Moreover, the empirical result confirms that the level of maturity on the Monitor and Evaluate (ME) domain is significantly associated with higher disclosure in the category of IT performance measurement. The results regarding the influence of the strategic role of IT in an industry on the disclosure of IT governance confirm both predicted expectations. I find that both transform and informate industries are associated with higher levels of transparency of IT governance in comparison with automated industry firms. Further, the results provide no convincing empirical evidence for the moderating effect of the strategic role of IT in an industry on the relationship between the maturity of IT governance and the disclosure of IT governance, although overall chapter results indicate that the 
maturity of IT governance and the strategic role of IT at industry level influence the disclosure of IT governance.

In conclusion, this dissertation examines the extent of IT governance disclosure in public documents, which has remained an unexplored topic in existing information systems literature. Recognizing the importance of IT topics in corporate disclosure, this research work has developed a comprehensive framework for examining and understanding disclosure on IT governance. This research draws on economic theory to develop the disclosure framework and investigates the determinants that can explain the extent of disclosure on IT governance. Specifically, the dissertation shows that corporate governance mechanisms and the implementation of IT governance processes at firm level are associated with the extent of IT governance disclosure. This research work suggests that the transparency of IT governance can easily be embedded within the concept of IT governance, which is seen as an integral part of corporate governance.

\subsection{Implications}

This dissertation offers implications for academic literature concerning strategic information systems and IT governance, as well as for investors and business practitioners in organizations. The framework for disclosure of IT governance developed in the dissertation can be employed by practitioners to enhance the dissemination of IT information. While recognizing that the identification of relevant topics for reporting on intangible assets like IT is difficult, the proposed framework for disclosing IT governance can guide firms in developing their competence in financial and non-financial sections of corporate disclosure. Also, I assume that policy makers or managers can utilize such a framework to make benchmarks on IT-related practices. From an academic perspective, such a framework can be employed, revised, and extended to examine IT-related phenomena, as extant research notes the lack of a framework for documenting IT information. Combining the conclusions of Chapters Two and Three, the dissertation also provides important practical and theoretical implications on IT governance at board level. Specifically, these chapters show that the board of directors and shareholders of firms are associated with the transparency of firms' IT governance in external reporting. While existing strategic information systems literature examines the role of the board of directors in the governance of IT assets, this dissertation provides evidence on the role of corporate boards in the transparency of IT governance. This dissertation exhibits the theoretical implication of the framework on IT governance, beyond designing effective and 
efficient IT processes, by underscoring the significance of the COBIT in improving communication on IT governance practices. Finally, the dissertation underlines the importance of IT's strategic role at the industry level in which firms operate and its association with the transparency of IT governance. Given the greater intensity of IT deployments in transformative industries to (re)design business processes, products, and services, the results imply that transform firms are more engaged in disseminating IT governance information.

\subsection{Limitations and recommendations for future research}

This dissertation has several limitations. First, all the empirical studies in this dissertation could be affected by the problem of omitted variables, which influence the dependent variable of interest (i.e., the disclosure of IT governance) and one or more independent variables. The choice of IT governance disclosure in public documents could be attributed to many organizational, financial, and accounting factors. To include all of the variables in an empirical analysis to circumvent endogeneity is challenging and extremely difficult. Nonetheless, I attempted to include all the possible control variables and employ robustness checks to ensure the empirical validity of results. Second, IT governance disclosure is voluntary. As a consequence, the measure of transparency might be an underestimation of the actual level of transparency. That is, it is difficult to differentiate between firms that intentionally do not disclose IT governance topics even though the topics are applicable and firms for which such topics are not relevant or applicable. Third, the coding of IT governance disclosure items is based upon qualitative and factual information (descriptive or financial data) provided in corporate disclosure. Although I attempted to be as systematic as possible with the coding procedure, the process is prone to errors. Lastly, I employ COBIT as a proxy to measure the maturity of IT governance in Chapter Four. I assume the implementation status of the process as a maturity status of COBIT processes, which is different from the proposed general maturity model concept within the COBIT framework. This might impose some minor limitation on the validity of the results.

This dissertation suggests a number of topics for future research. First, future studies may examine the economic consequences of the disclosure of IT governance using the proposed framework for the disclosure of IT governance. While the existing literature has focused on the impact of specific IT signals, such as the impact of IT spending on the market value of firms, a comprehensive IT information disclosure scenario can help to extend this stream of research to the next level. Second, all three empirical studies in this dissertation 
employ a cross-sectional setting to examine IT governance activities in corporate disclosure. I propose that an event-based setting might provide a better variance and explanatory power for explaining the association between the variables of interest in this study. Also, some specific event, for example the introduction of SOX or the occurrence of the financial crisis in 2007, may provide an interesting setting for examining the behavior of firms in communicating IT governance topics in external reporting. Third, I suggest that board level IT governance may provide some interesting avenues for exploring the transparency of IT governance. This dissertation focused on examining the influence of board structure (measured by board size and board independence) on the disclosure of IT governance. However, examination of some specific board characteristics, for example, board heterogeneity, board level IT committees, the CIO reporting structure, can yield interesting theoretical insights. Finally, I recommend the inclusion and examination of rapidly emerging IT governance frameworks like VALIT and COBIT 5.0 in the analysis of IT communicating practices. 



\section{REFERENCES}

Aguilera, \& Jackson (2003). The Cross-National Diversity of Corporate Governance: Dimensions and Determinants. The Academy of Management Review, 28(3), 447-465.

Ajinkya, Bhojraj, \& Sengupta (2005). The Association between Outside Directors, Institutional Investors and the Properties of Management Earnings Forecasts. Journal of Accounting Research, 43(3), 343376.

Ali, \& Green (2009). Effective information technology (IT) governance mechanisms: An IT outsourcing perspective. Information Systems Frontiers.

Anderson, Banker, \& Hu (2003). The Impact of Information Technology Spending on Future Performance Paper presented at the Proceedings of the International Conference on Information Systems, Seattle, USA December 2003. Association for Information Systems.

Andriole (2009). Boards of Directors and Technology Governance: The Surprising State of the Practice. Communications of AIS, 24(Article 22), 373-394.

Armstrong, \& Sambamurthy (1999). Information Technology Assimilation in Firms: The Influence of Senior Leadership and IT Infrastructures. Information Systems Research, 10(4), 304-327.

Baek, Johnson, \& Kim (2009). Managerial Ownership, Corporate Governance, and Voluntary Disclosure. Journal of Business \& Economic Studies, 15(2), 44-61.

Banker, Chen, Liu, \& Ou (2009). Business Value of IT in Commercial Banks. Paper presented at the the International Conference on Information Systems, Phoenix,Arizona, USA December 2009. Association for Information Systems.

Barry, \& Brown (1984). Differential Information and the Small Firm Effect. Journal of Financial Economics, 13(2), 283-295.

Barry, \& Brown (1985). Differential Information and Security Market Equilibrium. Journal of Financial and Quantitative Analysis, 20(4), 407-422.

Barry, \& Brown (1986). Limited Information as a Source of Risk. Journal of Portfolio Management, 12(2), 66-72.

Baysinger, \& Butler (1985). Corporate Governance and the Board of Directors: Performance Effects of Changes in Board Composition. Journal of Law, Economics, \& Organization, 1(1), 101-124.

Becht, \& Rodl (1999). Blockholding in Europe: An international comparison. European Economic Review, 43, 1049-1056.

Benko, \& McFarlan (2003). Connecting the Dots: Boston (MA): Harvard Business School Press.

Berger (2003). The Economic Effects of Technological Progress: Evidence from the Banking Industry. Journal of Money, Credit, and Banking, 35(2), 141-175.

Berglof (1991). Corporate control and capital structure: Essays on property rights and financial contracts. Stockholm:IIB Institute of International Business.

Bharadwaj (2000). A Resource-Based Perspective on Information Technology Capability and Firm Performance: An Empirical Investigation. MIS Quarterly, 24(1), 169-196.

Bharadwaj, Keil, \& Mähring (2009). Effects of information technology failures on the market value of firms. The Journal of Strategic Information Systems, 18(2), 66-79.

Bhattacherjee (1998). Managerial Influences on Intraorganizational Information Technology Use: A PrincipalAgent Model. Decision Sciences, 29(1), 139-162.

Bhushan (1989). Collection of Information about Publicly Traded Firms: Theory and Evidence. Journal of Accounting and Economics, 11(2-3), 183-206.

Bollen, Hassink, \& Bozic (2006). Measuring and Explaining the Quality of Investor relations activities: a multinational empirical analysis. International Journal of Accounting Information Systems., 7(4), 273-298.

Boritz, \& Lim (2008). IT Control Weaknesses, IT Governance and Firm Performance. Paper presented at the American Accounting Association's Annual Meeting, Anaheim, California, USA August 2008. American Accounting Association.

Botosan (1997). Disclosure Level and the Cost of Equity Capital. Accounting Review, 72(3), 323-349. 
Bowen, Cheung, \& Rohde (2007). Enhancing IT governance practices: A model and case study of an organization's efforts. International Journal of Accounting Information Systems, 8, 191-221.

Brown (1997). Examining the Emergence of Hybrid IS Governance Solutions: Evidence From a Single Case Site. Information Systems Research, 8(1), 69-94.

Brown, \& Grant (2005). Framing the frameworks: A review of IT governance Research. [journal articale]. Communications of AIS, 15, 696-712.

Brynjolfsson, \& Hitt (1996). Paradox lost? Firm-level evidence on the returns to information systems spending. Management Science 42(4), 541-560.

Buckby, Best, \& Stewart (Eds.). (2008). IT Governance and Service Management: Frameworks and Adaptations: Hershey, PA: Idea Group Publishing.

Bushman, Piotroski, \& Smith (2004). What determines corporate transparency? . Journal of Accounting Research, 42 (2), 207-252.

Byrd (2001). Information technology, Core Competencies and Sustained Competitive Advantage. Information Resources Management Journal, 14(2), 27-36.

Cerbioni, \& Parbonetti (2007). Exploring the Effects of Corporate Governance on Intellectual Capital Disclosure: An Analysis of European Biotechnology Companies. European Accounting Review, Forthcoming.

Chatterjee, Pacini, \& Sambamurthy (2002). The shareholder-wealth and trading-volume effects of information-technology infrastructure investments. Journal of Management Information Systems, 19(2), 7-42.

Chatterjee, Richardson, \& Zmud (2001). Examining the Shareholder Wealth Effects of Announcements of Newly Created CIO Positions. MIS Quarterly, 25(1), 43-70.

Chau, \& Gray (2002). Ownership structure and corporate voluntary disclosure in Hong Kong and Singapore. The International Journal of Accounting, 37(2), 247-265.

Cheng, \& Courtenay (2006). Board composition, regulatory regime and voluntary disclosure. The International Journal of Accounting, 41(3), 262-289.

Chiasson, \& Davidson (2005). Taking Industry Seriously in Information Systems Research. MIS Quarterly, 29(4), 591-605.

Chowdhury (2003). Information technology and productivity payoff in the banking industry: Evidence from the emerging markets. Journal of International Development, 15(6), 693-708.

Clarkson, Li, \& Richardson (2004). The market valuation of environmental expenditures by pulp and paper companies. Accounting Review, 79(2), 329-353.

Clarkson, Li, Richardson, \& Vasvari (2008). Revisiting the relation between environmental performance and environmental disclosure: An empirical analysis. Accounting, Organizations and Society, 33(4-5), 303-327.

Crowston, \& Myers (2004). Information technology and the transformation of industries: three research perspectives. The Journal of Strategic Information Systems, 13(1), 5-28.

Damianides (2005). Sarbanes-Oxley And IT Governance: New Guidance on IT Control and Compliance. Information Systems Management., 77-85.

Darrough (1993). Disclosure Policy and Competition: Cournot vs. Bertrand. Accounting Review, 8(3), 534561.

Darrough, \& Stoughton (1990). Financial disclosure policy in an entry game. Journal of Accounting and Economics, 12(1-3), 219-243.

Davies (1999). A Strategic Approach to Corporate Governance: Aldershot: Gower.

Davis, Dehning, \& Stratopoulos (2003). Does the market recognize IT-enabled competitive advantage? Information \& Management, 40(7), 705-716.

De Haes, \& Van Grembergen (2008). An Exploratory Study into the Design of an IT Governance Minimum Baseline through Delphi Research. Communications of AIS, 22(Article 24), 443-458.

De Haes, \& Van Grembergen (2009). An Exploratory Study into IT Governance Implementations and its Impact on Business/IT Alignment. Information Systems Management, 26(2), 123-137.

De Haes, \& Van Grembergen (2010). Analysing the Impact of Enterprise Governance of IT Practices on Business Performance. International Journal on IT/Business Alignment and Governance, 1(1), 1438.

Dehning, Richardson, \& Zmud (2003). The value relevance of announcements of transformational information technology investments. MIS Quarterly 27(4), 637-656.

Diamond, \& Verrecchia (1991). Disclosure, Liquidity and the Cost of Capital. Journal of Finance, 66, 13251355 .

Diamond, \& Verrecchia (1991). Disclosure, Liquidity, and the Cost of Capital. The Journal of Finance, 46(4), 1325-1359. 
Donnelly, \& Mulcahy (2008). Board Structure, Ownership, and Voluntary Disclosure in Ireland. Corporate Governance: An International Review, 16(5), 416-429.

Dos Santos, Peffers, \& Mauer (1993). The Impact of Information Technology Investment Announcements on the Market Value of the Firm. Information Systems Research 4(1), 1-23.

Easley, \& O'Hara (2004). Information and the cost of capital. The Journal of Finance, LIX(4), 1553-1582.

Eccles, Herz, Keegan, \& Phillips (2001). The ValueReporting Revolution: Moving Beyond the Earnings Game. New York: John Wiley \& Sons.

Eisenhardt (1989). Agency Theory: An Assessment and Review. The Academy of Management Review, 14(1), $57-74$.

Eldomiaty, \& Choi (2006). Corporate governance and strategic transparency: East Asia in the international business systems. Corporate Governance, 6(3), 281-295.

Eng, \& Mak (2003). Corporate governance and voluntary disclosure. Journal of Accounting and Public Policy, 22(4), 325-345.

Fama (1980). Agency Problems and the Theory of the Firm. The Journal of Political Economy, 88(2), 288307.

Felo (2009). Voluntary Disclosure Transparency, Board Independence and Expertise, and CEO Duality. SSRN eLibrary.

Forker (1992). Corporate governance and disclosure quality. Accounting and Business Research 22(86), 111124.

Fu $\beta$, Gmeiner, Schiereck, \& Strahringer (2007). ERP Usage in Banking: An Exploratory Survey of the World's Largest Banks. Information Systems Management, 24(2), 155 - 171.

Gartner (2012). Gartner Says Worldwide Enterprise IT Spending is Forecast to Grow 2.5 Percent in 2013. from http://www.gartner.com/it/page.jsp?id=2238915.

Gillan (2006). Recent Developments in Corporate Governance:An Overview. Journal of Corporate Finance 12(3), 381-402.

Goodstein, Gautam, \& Boeker (1994). The effects of board size and diversity on strategic change. Strategic Management Journal, 15(3), 241-250.

Gordon, Loeb, \& Lucyshyn (2003). Sharing information on computer systems: An economic analysis. Journal of Accounting and Public Policy 22(6), 461-485.

Gordon, Loeb, Lucyshyn, \& Sohail (2006). The impact of the Sarbanes-Oxley Act on the corporate disclosures of information security activities. Journal of Accounting and Public Policy 25, 503530.

Gordon, Loeb, \& Sohail (2010). Market Value of Voluntary Disclosures Concerning Information Security. MIS Quarterly, 34(3), 567-A562.

Grant, Miller, \& Alali (2008). The effect of IT controls on financial reporting. Managerial Auditing Journal, 23(8), $803-823$.

Gray (2004). Is there a relationship between IT governance and corporate governance?: What improvements (if any) would IT governance bring to the LSC?. Retrieved September 27, 2009 from http://www.netcentrum.nl/auditweb/3.pdf.

Gu, Xue, \& Ray (2008). IT Governance and IT Investment Performance: An Empirical Analysis. Paper presented at the International Conference on Information Systems, Paris, France December 2008. Association of Information Systems.

Gul, \& Leung (2004). Board leadership, outside directors expertise and voluntary corporate disclosures. Journal of Accounting and Public Policy 23 (2004) 351-379, 23, 351-379.

Hadden, \& Hermanson (2003). Is Your Audit Committee Watching IT Risks? The Journal of Corporate Accounting \& Finance(July/August), 35-39.

Hadden, Hermanson, \& DeZoort (2003). Audit Committees' Oversight of Information Technology Risk. Review Of Business Information Systems, 7(4), 1-12.

Hall, \& Soskice (2001). Varieties of capitalism: The institutional foundations of comparative advantage Oxford University Press.

Haniffa, \& Cooke (2005). The impact of culture and governance on corporate social reporting. Journal of Accounting and Public Policy, 24(5), 391-430.

Hardy (2006). Using IT governance and COBIT to deliver value with IT and respond to legal, regulatory and compliance challenges. Information Security Technical Report, 11(1), 55-61.

Haynes, \& Hillman (2010). The effect of board capital and CEO power on strategic change. Strategic Management Journal, 31(11), 1145-1163.

Healy, \& Palepu (2001). Information Asymmetry, Corporate Disclosure, and the Capital Markets:Areview of the Empirical Disclosure Literature. Journal of Accounting and Economics 31, 405-440. 
Heart, Maoz, \& Pliskin (2010). From Governance to Adaptability: The Mediating Effect of IT Executives' Managerial Capabilities. Information Systems Management, 27(1), 42-60.

Henderson, \& Venkatraman (1993). Strategic Alignment: Leveraging Information Technology for Transforming Organizations. IBM Systems Journal, 32(1).

Hermalin, \& Weisbach (2007). Transparency and Corporate Governance. Retrieved 15 April 2010 from http://ssrn.com/abstract=958628.

Heroux (2010). Exploring IT Governance and Strategic Control of Web Site Content: A Case Study. Paper presented at the 33rd Annual Congress of European Accounting Association, Istanbul, Turkey May 2010. European Accounting Association.

Hidalgo, García-Meca, \& Martínez (2011). Corporate Governance and Intellectual Capital Disclosure. Journal of Business Ethics, 100(3), 483-495.

Hillman, \& Dalziel (2003). Boards of Directors and Firm Performance: Integrating Agency and Resource Dependence Perspectives. The Academy of Management Review, 28(3), 383-396.

Ho, \& Wong (2001). A study of the relationship between corpoarte governance structures and the extent of voluntry disclosure. Journal of International Accounting ,Auditing \& Taxation, 10, 139-156.

$\mathrm{Ho}, \mathrm{Wu}, \& \mathrm{Xu}$ (2011). Corporate Governance and returns on information technology investment: evidence from an emerging market. Strategic Management Journal, 32(6), 595-623.

Hsiang-Tsai, \& Li-Jen (2010). Board Supervision Capability and Information Transparency. Corporate Governance: An International Review, 18(1), 18-31.

Huang, Shen, Yen, \& Chou (2011). IT governance: Objectives and assurances in internet banking. Advances in Accounting, 27(2), 406-414.

Huang, Zmud, \& Price (2010). Influencing the effectiveness of IT governance practices through steering committees and communication policies. European Journal of Information Systems, 19(3), 288302.

Huff, Maher, \& Munro (2006). "Information Technology and the Board of Directors:Is There an IT Attention Deficit?”. MIS Quarterly Executive, 5(2), 55-68.

Im, Dow, \& Grover (2001). A Reexamination of IT Investment and the Market Value of the Firm-An Event Study Methodology. Information Systems Research 12(1), 103-117.

ISO/IEC (2008). Corporate governance of information technology, Geneva : International Standards Organisation.

ITGI (2003). Board Briefing on IT Governance. IT Governance Institute, 2nd Edition, www.itgi.org, consulted on 1/11/2007.

ITGI (2005). IT governance domain practices and competencies: Governance of outsourcing. IT Governance Institute.

ITGI (2007). "Control objectives, management guidelines, maturity models in CobiT 4.1",Rolling Meadows,IL: IT Governance Institute.

ITGI (2008). IT Governance Global Status Report. (ISBN 978-1-60420-064-5).

ITGI (2011). Global Status Report on the Governance of IT (CGEIT) - 2011. Rolling Meadows, IL 60008 USA.

Jarvenpaa, \& Ives (1991). Executive Involvement and Participation in the Management of Information Technology. MIS Quarterly, 15 (2), 205-227.

Jensen, \& Meckling (1976). Theory of the firm: managerial behaviour, agency cost and ownership structure. Journal of Financial Economics, 3, 305-360.

Jewer (2009). Towards an Understanding of Board IT Governance: Antecedents and Consequences. University of Waterloo

Jewer, \& McKay (2012). Antecedents and Consequences of Board IT Governance: Institutional and Strategic Choice Perspectives. Journal of the Association for Information Systems Vol. 13, Issue 7, pp. 581 617, July 2012, 13(7), 581-617.

Jiang, Raghupathi, \& Raghupathi (2009). Content and Design of Corporate Governance Web Sites. Information Systems Management, 26(1), 13-27.

Jordan, \& Musson (2004). Corporate Governance and IT Governance: exploring the board's perspective. Retrieved , May 2009, from the World Wide Web:http://ssrn.com/abstract=787346.

Jordan, \& Silcock (2005). Beating IT Risks: John Wiley \& Sons Inc.

Kambil, \& Lucas (2002). The Board of Directors and the Management of Information Technology. Communications of AIS, 8(Article 26).

Karahanna, \& Watson (2006). Information systems leadership. Engineering Management, IEEE Transactions on, 53(2), 171-176.

Karake (1992). Information Technology and Management Control: An Agency Theory Perspective.: Praeger, Westport, CT. 
Karake (1995). The management of information technology, governance, and managerial characteristics. Information Systems Journal, 5(4), 271-284.

Karimi, Bhattacherjee, Gupta, \& Somers (2000). The Effects of MIS Steering Committees on Information Technology Management Sophistication. Journal of Management Information Systems, 17(2), 207230.

Kelton, \& Yang (2008). The impact of corporate governance on Internet financial reporting. Journal of Accounting and Public Policy, 27(1), 62-87.

Kim, \& Lim (2010). IT Investments Disclosure, Information Quality, and Factors Influencing Managers'Choices. Paper presented at the Annual Meeting of the American Accounting Association, San Francisco, California.

Kim, \& Verrecchia (1994). Market liquidity and volume around earnings announcements. Journal of Accounting and Economics, 17(1-2), 41-67.

Kobelsky, Richardson, Smith, \& Zmud (2008). Determinants and Consequences of Firm Information Technology Budgets. Accounting Review, 83(4), 957-995.

Korac-Kakabadse, \& Kakabadse (2001). IS/IT governance: need for an integrated model. Corporate Governance, 1(4), 9-11.

Lainhart (2000). COBIT ${ }^{\mathrm{M}}$ : A Methodology for Managing and Controlling Information and Information Technology Risks and Vulnerabilities. Journal of Information Systems, 14, 21-25.

Lang, \& Lundholm (1996). Corporate Disclosure Policy and Analyst Behavior. Accounting Review, 71, 467 492.

Larcker, Richardson, \& Tuna (2007). Corporate Governance, Accounting Outcomes, and Organizational Performance. The Accounting Review, 82(4), 963-1008.

Leftwich, Watts, \& Zimmerman (1981). Voluntary Corporate Disclosure: The Case of Interim Reporting. Journal of Accounting Research, 19(ArticleType: research-article / Issue Title: Studies on Standardization of Accounting Practices: An Assessment of Alternative Institutional Arrangements / Full publication date: 1981 / Copyright (C) 1981 Accounting Research Center, Booth School of Business, University of Chicago), 50-77.

Li, Lim, \& Wang (2007). Internal and external influences on IT control governance. International Journal of Accounting Information Systems, 8(4), 225-239.

Li, Peters, Richardson, \& Weidenmier Watson (2012). The Consequences of Information Technology Control Weaknesses on Management Information Systems: The Case of Sarbanes_Oxley Internal Control Reports. MIS Quarterly, 36(1), 179-204.

Liang, Chiu, Wu, \& Straub (2011). The Impact of IT Governance on Organizational Performance. Paper presented at the AMCIS 2011 Proceedings - All Submissions. Paper 268.http://aisel.aisnet.org/amcis2011_submissions/268.

Lim, Matolcsy, \& Chow (2007). The Association between Board Composition and Different Types of Voluntary Disclosure. European Accounting Review, 16(3), 555-583.

Lim, Matolcsy, \& Chow (2007). The Association between Board Composition and Different Types of Voluntary Disclosure. European Accounting Review, 16(3), 555 - 583.

Mähring (2006). The Role of the Board of Directors in IT Governance: A Review and Agenda for Research. Paper presented at the Twelfth Americas Conference on Information Systems, Acapulco, Mexico August 2006. Association of Information Systems.

Makhija, \& Patton (2004). The Impact of Firm Ownership Structure on Voluntary Disclosure: Empirical Evidence from Czech Annual Reports. The Journal of Business, 77(3), 457-491.

Martin-Oliver, \& Salas-Fumas (2012). IT assets, organization capital and market power: Contributions to business value. Decision Support Systems, 52(3), 612-623.

Mata, Fuerst, \& Barney (1995). Information Technology and Sustained Competitive Advantage: A ResourceBased Analysis. MIS Quarterly, 19(4), 487-505.

Mauldin, \& Richtermeyer (2004). An analysis of ERP annual report disclosures. International Journal of Accounting Information Systems, 5(4), 395-416.

McFarlane (2005). Management memo: A model for CIO success, CIO Canada. (30 June, 2005). Retrieved from http://www.itworldcanada.com/news/management-memo-a-model-for-cio-success/111646

Merhout, \& Havelka (2008). Information Technology Auditing: A Value-Added IT Governance Partnership between IT Management and Audit. Communications of AIS, 23(Article 26), 463-482.

Millar, Eldomiaty, Choi, \& Hilton (2005). Corporate Governance and Institutional Transparency in Emerging Markets. Journal of Business Ethics, 59(1), 163-174.

Narayanan, Pinches, Kelm, \& Lander (2000). The influence of voluntarily disclosed qualitative information. Strategic Management Journal, 21(7), 707-722. 
Nolan, \& McFarlan (2005). Information technology and Board of Directors. Harvard Business Review, 83(October), 96-106.

OECD (2004). OECD Principles of Corporate Governance.Paris: Organisation for Economic Cooperation and Development.

Pacheco-de-Almeida, \& Zemsky (2012). Some like it free: Innovators' Strategic use of Disclosure to slow down Competition. Strategic Management Journal, 33(7), 773-793.

Papke, \& Wooldridge (1996). Econometric methods for fractional response variables with an application to 401(k) plan participation rates. Journal of Applied Econometrics, 11(6), 619-632.

Papke, \& Wooldridge (2008). Panel data methods for fractional response variables with an application to test pass rates. Journal of Econometrics, 145(1-2), 121-133.

Parent, \& Reich (2009). Governing Information Technology Risk. California Management Review, 51(3), 134-152.

Patel, \& Dallas (2002). Transparency and Disclosure: Overview of Methodology and Study Results - United States. Retrieved May 18, 2009 from http://ssrn.com/abstract $=422800$

Patelli, \& Prencipe (2007). The Relationship between Voluntary Disclosure and Independent Directors in the Presence of a Dominant Shareholder. European Accounting Review, 16, 5-33.

PCAOB (2007). Auditing Standard No. 5: An Audit of Internal Control over Financial Reporting That Is Integrated with an Audit of Financial Statements,Public Company Auditing Oversight Board, New York.

Peterson (2004). Crafting Information Technology Governance. Information Systems Management, $21(4), 7-$ 22.

Prasad, Heales, \& Green (2009). Towards a Deeper Understanding of Information Technology Governance Effectiveness: A Capabilities-based Approach Paper presented at the International Conference on Information Systems, Arizona.

Premuroso, \& Bhattacharya (2007). Is There a Relationship between Firm Performance, Corporate Governance, and a Firm's Decision to Form a Technology Committee? Corporate Governance: An International Review, 15(6), 1260-1276.

Premuroso, \& Bhattacharya (2007). Is There a Relationship between Firm Performance, Corporate Governance,and a Firm's Decision to Form a Technology Committee? Corporate governance, 15 (6), 1260-1276.

Raghupathi (2007). Corpoarte Governance of IT: A framework for development. Communications of the ACM, 50(8), 94-99.

Ranganathan, \& Jha (2008). Do CIOs Matter? Assessing the Value of CIO Presence in Top Management Teams. Paper presented at the International Conference on Information Systems (ICIS), International Conference on Information Systems, Paris, France December 2008. Association of Information Systems.

Read (2004). Discussion of director responsibility for IT governance. International Journal of Accounting Information Systems, 5(2), 105-107.

Reeb, \& Zhao (2010). Director Capital and Corporate Disclosure Quality. SSRN eLibrary.

Reznik (2007). Back to Business with IT Governance. The Journal of Corporate Accounting \& Finance(September/October ), 77-84.

Ridley, Young, \& Carroll (2008). Studies to Evaluate COBIT's Contribution to Organisations: Opportunities from the Literature, 2003-06. Australian accounting review, 18(4), 334-342.

Rosenstein, \& Wyatt (1990). Outside directors, board independence, and shareholder wealth. Journal of Financial Economics, 26(2), 175-191.

Samaha, Dahawy, Abdel-Meguid, \& Abdallah (2012). Propensity and comprehensiveness of corporate internet reporting in Egypt: Do board composition and ownership structure matter? International Journal of Accounting and Information Management, 20(2), 142-170.

Sambamurthy, Bharadwaj, \& Grover (2003). Shaping Agility through Digital Options: Reconceptualizing the Role of Information Technology in Contemporary Firms. MIS Quarterly, 27(2), 237-236.

Sambamurthy, Venkataraman, \& Desanctis (1993). The design of information technology planning systems for varying organizational contexts. European Journal of Information Systems 2(1), 23-35.

Sambamurthy, \& Zmud (1999). Arrangements for Information Technology governance:A Theory of Multiple Contingencies. MIS Quarterly, 23(2), 261-291.

Schein (1992). The role of the CEO in the management of change: The case of information technology: In T.A. Kochan and M. Useem (Eds.), Transforming Organizations. Oxford: Oxford University Press.

Shleifer, \& Vishny (1997). A survey on corporate governance. Journal of Finance, 52(2), 737-783

Simonsson, Johnson, \& Ekstedt (2010). The Effect of IT Governance Maturity on IT Governance Performance. Information Systems Management, 27(1), 10-24. 
Sohal, \& Fitzpatrick (2002). IT governance and management in large Australian organisations. International Journal of Production Economics, 75(1-2), 97-112.

Spafford (2008). The Governance of Green IT: The Role of Processes in Reducing Data Center Energy Requirements: IT Governance Publishing Ltd.

Takemura, Ukai, \& Nagaoka (2005). Disclosure and Circumstances Concerning Information System Assets Economic Analysis of Information System Investment in Banking Industry (pp. 107-125): Springer Tokyo.

Trites (2004). Director responsibility for IT governance. International Journal of Accounting Information Systems, 5(2), 88-99.

Tuttle, \& Vandervelde (2007). An empirical examination of CobiT as an internal control framework for information technology. International Journal of Accounting Information Systems, 8(4), 240-263.

UNCTAD (2006). Guidance on good practices in corporate governance disclosure. Geneva: United Nations.

US Commerce (2003). Digital Economy 2003. Washington, USA:US Dept of Commerce.

Van Grembergen, \& De Haes (2004). IT governance and its mechanisms. Information systems control journal, 1, 1-7.

Van Grembergen, \& De Haes (2009). Enterprise Governance of Information Technology :Achieving Strategic Alignment and Value: Springer US.

Vanstraelen, Zarzeski, \& Robb (2003). Corporate nonfinancial disclosure practices and financial analyst forecast ability across three European countries. Journal of International Financial Management \& Accounting, 14(3), 249-279.

Webb, Pollard, \& Ridley (2006). Attempting to Define IT Governance: Wisdom or Folly? Paper presented at the 39th Hawaii International Conference on System Sciences, Kauai, Hawaii January 2006. IEEE.

Weber (1985). Basic content analysis: Beverly Hills: Sage Publications, CA.

Weill, \& Ross (2004). IT Governance, How Top Performers Manage IT Decision Rights for Superior Results. Massachusetts Harvard Business School Press Boston.

Weill, Woerner, Aral, \& Johnson (2007). Becoming more IT savvy and why it matters. CISR Research Briefing, VII(1D).

Wilkin, \& Chenhall (2010). A Review of IT Governance:A Taxonomy to Inform Accounting Information Systems. Journal of Information Systems, 24(2), 107-146.

Willson, \& Pollard (2009). Exploring IT Governance in Theory and Practice in a Large Multi-National Organisation in Australia. Information Systems Management, 26(2), 98-109.

Wiseman (1982). An evaluation of environmental disclosures made in corporate annual reports. . Accounting, Organizations and Society, 7(1), 553-563.

Wonseok, Michael, \& Joung (2006). The Market's Perception of the Transactional Risks of Information Technology Outsourcing Announcements. Journal of Management Information Systems 22(4), 271-303.

Xiao, Yang, \& Chow (2004). The determinants and characteristics of voluntary Internet-based disclosures by listed Chinese companies. Journal of Accounting and Public Policy 23, 191-225.

Xiao, \& Yuan (2007). Ownership structure, board composition and corporate voluntary disclosure: Evidence from listed companies in China. Managerial Auditing Journal, 22(6), 604-619.

Xue, Liang, \& Boulton (2008). Information technology governance in information technology investment decision processes: The impact of investment characteristics, external environment, and internal context. MIS Quarterly, 32(1), 67-96.

Xue, Ray, \& Gu (2011). Environmental Uncertainty and IT Infrastructure Governance: A Curvilinear Relationship. Information Systems Research, 22(2), 389-399.

Zhu, Kraemer, Xu, \& Dedrick (2004). Information technology payoff in e-business environments: An international perspective on value creation in the financial services industry. Journal of Management Information Systems, 21(1), 17-54.

Zmud, Shaft, Zheng, \& Croes (2010). Systematic Differences in Firm's Information Technology Signaling: Implications for Research Design. Journal of the Association for Information Systems, 11(3), 149181.

Zuboff (1988). In the age ofthe smart machine: Basic Book, New York. 



\title{
APPENDIX A: IT GOVERNANCE DISCLOSURE FRAMEWORK
}

\author{
IT Governance Disclosure \\ Items \\ Description \\ Relevant Literature
}

(C1) IT Strategic Alignment (ITSA)

1 IT expert on the board

2

IT expert with experience on the board

3

A CIO or an equivalent position in the firm

$4 \quad$ IT committee

IT risk is part of audit

5 committee or risk committee

6

IT is part of audit committee

$7 \quad$ IT steering committee

8 IT planning committee

9 Technology committee

10

IT committee at an executive level
One or more board of directors who is/are independent or non-independent with sufficient knowledge regarding IT and information assets

One or more board of directors who is/are with sufficient knowledge as well as work experience with regard to IT and information assets

Firm has a special $\mathrm{CIO}$ or an equivalent position with respect to IT and information assets at an executive level

A committee looking after IT and information assets at the board level

IT and information assets related risk are on the agenda of the Audit or Risk committee

IT and information assets auditing is part of the audit committee at the board level

Firm has an IT steering committee which monitors IT management, IT spending, and related cost allocations

Firm has an IT planning committee which looks after strategic planning and investment decisions on IT and information assets

A special committee which looks after IT and related technology architecture, projects, and governance issue at an executive level

In some countries there is a two-tier structure of corporate governance, in this situation an IT committee may be formed at an executive level. This committee reports to the supervi-
(De Haes \& Van

Grembergen, 2008; ITGI, 2003)

(ITGI, 2003; Nolan \&

McFarlan, 2005)

(De Haes \& Van Grembergen, 2008;

Peterson, 2004)

(De Haes \& Van

Grembergen, 2008; Nolan \&

McFarlan, 2005)

(De Haes \& Van

Grembergen, 2008; Hadden

\& Hermanson, 2003)

(Jordan \& Silcock, 2005;

Nolan \& McFarlan, 2005)

(Karimi, Bhattacherjee,

Gupta, \& Somers, 2000;

Peterson, 2004; Van

Grembergen \& De Haes,

2004)

(Sambamurthy,

Venkataraman, \& Desanctis, 1993; Trites, 2004)

(Premuroso \& Bhattacharya, 2007)

(Nolan \& McFarlan, 2005) 


\begin{tabular}{|c|c|c|}
\hline \multirow[t]{2}{*}{$\begin{array}{l}\text { IT Governance Disclosure } \\
\text { Items }\end{array}$} & Description & Relevant Literature \\
\hline & sory board & \\
\hline $\begin{array}{l}\mathrm{CIO} \text { or equivalent is on the } \\
\text { board }\end{array}$ & $\begin{array}{l}\text { A CIO or an equivalent position is represent- } \\
\text { ed at the board level committee }\end{array}$ & $\begin{array}{l}\text { (De Haes \& Van } \\
\text { Grembergen, 2008; Van } \\
\text { Grembergen \& De Haes, } \\
\text { 2004) }\end{array}$ \\
\hline
\end{tabular}

\section{(C2): IT Value Delivery (ITVD)}

IT governance frame-

1 work/standard: ITIL/COBIT/ISO etc.

2

IT as an issue in the board meeting

3 Suggestion/decision/advise by the board on IT

Special report/section on

4 IT/ IT projects in annual report

5 IT mentioned as a strategic business issue

$6 \quad$ IT projected as strength

7 IT projected as opportunity

8 Project updates or comments

IT is explicitly mentioned

9 for achieving specific business objectives

10

Comments/Updates on IT performance

11 IT training

12 Green IT

13 Direction and status about
These are best practices and frameworks for IT governance. The firm has adopted or mentioned to adopt any IT governance framework

IT and information assets issues are explicitly discussed at the various board level meeting

IT and related technology decisions, suggestions at the board level

A special report or a section dedicated to provide information about IT and information assets

IT is mentioned as a strategic business issue to accomplish the business mission and goals

IT and information assets are mentioned as the organizational strength to achieve the business objectives, goals etc.

IT and information assets are referred as the key assets to achieve the future opportunities

Updates or comment about on-going and/or finished (successfully or unsuccessfully) IT and related projects

IT has been deployed to achieve one or more specific business objective

There is/are comments about good or bad performance of IT

Information on IT and related training program for human resource

Efficient and environment friendly use of is termed as Green IT. A firm has reported on such initiative

Information regarding in-sourcing or out-
(De Haes \& Van

Grembergen, 2008; ITGI, 2003)

(Huff, et al., 2006; Nolan \& McFarlan, 2005; Reznik, 2007)

(Nolan \& McFarlan, 2005; Trites, 2004)

Based on the pilot study

(ITGI, 2003; Nolan \& McFarlan, 2005)

Based on the pilot study

Based on the pilot study

(De Haes \& Van Grembergen, 2008; Mauldin \& Richtermeyer, 2004)

Based on the pilot study

(De Haes \& Van Grembergen, 2008; ITGI, 2003; Trites, 2004)

(Trites, 2004; Van Grembergen \& De Haes, 2004)

(Spafford, 2008)

(ITGI, 2005; Wonseok, 


\begin{tabular}{ccc}
\hline $\begin{array}{l}\text { IT Governance Disclosure } \\
\text { Items }\end{array}$ & Description & Relevant Literature \\
\hline $\begin{array}{l}\text { IT outsourcing and in- } \\
\text { sourcing }\end{array}$ & sourcing of IT & Michael, \& Joung, 2006) \\
\hline
\end{tabular}

\section{(C3): IT Risk Management (ITRM)}

1 IT is referred under the operational risk

2 Special IT risk management program

3 Use of IT for regulation and compliance

4 IT/ Electronic Data Processing (EDP) audit

5

Information and security policy/plan (IT security)

The role of IT in account-

6 ing and the reporting standards (IAS)

7 Operations continuity plan
IT is considered as a potential risk to successful business functioning and being treated as an operational risk

Firm has a special program to mitigate IT and related technology risks

IT is used to address the regulations and compliance requirements by the legal institutions

Firm has explicitly reported with regard to IT audit

Firm has a clear information and security policy for its stakeholders (e.g. customers, employee)

IT support for the accounting and to address certain framework (e.g. Basel II)

IT and related technology continuity plans are mentioned in case of disaster
(Jordan \& Silcock, 2005)

(De Haes \& Van

Grembergen, 2008; Jordan \& Silcock, 2005; Merhout \& Havelka, 2008)

(Jordan \& Silcock, 2005; Li, Lim, \& Wang, 2007; Trites, 2004)

(Li, et al., 2007; Merhout \& Havelka, 2008; Trites, 2004)

(Jordan \& Silcock, 2005;

Trites, 2004)

(Damianides, 2005; Grant, Miller, \& Alali, 2008;

Hardy, 2006)

(Jordan \& Silcock, 2005)

\section{(C4): IT Performance Measurement (ITPM)}

1 Explicit information on IT expenditure

2 IT budget

3 IT hardware cost

4 IT software cost

5 Explicit IT manpower cost is mentioned

6 IT expenses are mentioned under administrative cost

7 IT related assets are mentioned under intangible
Financial and Non-financial statements containing information on the overall IT expenditure

Financial section of the document has disclosed the budget on IT and information assets

(De Haes \& Van Grembergen, 2008;

Takemura, Ukai, \&

Nagaoka, 2005)

(De Haes \& Van

Grembergen, 2008;

Takemura, et al., 2005)

Specific IT hardware cost is mentioned under the IT expenditure

Specific IT software cost is mentioned under the IT expenditure

Specific IT man power cost is mentioned under the IT expenditure

IT and information assets related expenses are mentioned under the administrative cost

IT and related asset are referred as intangible assets and financial are provided as intangi-
(Takemura, et al., 2005)

(Takemura, et al., 2005)

Based on pilot study

Based on pilot study

Based on pilot study 


\begin{tabular}{|c|c|c|c|}
\hline \multicolumn{2}{|c|}{$\begin{array}{l}\text { IT Governance Disclosure } \\
\text { Items }\end{array}$} & \multirow{2}{*}{$\begin{array}{l}\text { Description } \\
\text { ble assets }\end{array}$} & \multirow[t]{2}{*}{ Relevant Literature } \\
\hline & assets & & \\
\hline 8 & $\begin{array}{l}\text { Direct cost on IT is men- } \\
\text { tioned in currency or } \\
\text { percentage }\end{array}$ & $\begin{array}{l}\text { The information on IT spending is given in } \\
\text { the percentage of the total revenue or in other } \\
\text { accounting ratio }\end{array}$ & Based on pilot study \\
\hline
\end{tabular}




\title{
APPENDIX B: EXAMPLES OF IT GOVERNANCE DISCLOSURE
}

\author{
(For Chapter Two and Three)
}

\section{Information Technology Committee}

The Information Technology Committee reports to the Audit Committee

regarding its responsibilities related to the Company's information technology infrastructure. The Information Technology Committee has oversight responsibility related to the quality and integrity of the Company's information technology functions. This Committee is composed entirely of outside directors who are not officers of the Company. The current members of the Information Technology Committee are Messrs. Podl (Chairman), Castellano, Coleman,Kayman and Ms. McKissack.

Bank Name: Private Bancorp, Inc

Report: Proxy statement Schedule 14A for Securities and Exchange Commission

Year: 2007

\section{IT Steering Committee}

Primary responsibilities of the IT Steering Committee are the following:

Evaluation of short-term and medium-term plans of Information Technology (IT) with regards to business strategy

Evaluation of Risk Analysis \& Management related to IT systems

Evaluation and approval of large hardware and software supplies procurement

Supervision of big projects and IT budget Priorities definition Evaluation of policies, standards and procedures

Supervision and approval of third party collaborations.

Bank Name: Emporiki Bank

Report: Corporate Social Responsibly Report

Year: 2007

IT governance framework

We continued the comIT strategy programme intensified under comvalue. The programme aims to redevelop and standardise the IT architecture and improve internal processes. Advances included the further development of daily end processing and online functions on a uniform Java technology basis as well as the rapid incorporation of new applications in the existing website offering. We achieved our first milestone with the launch of online subscription rights trading. With regard to process optimisation, we are guided by the international CMMI (Capability Maturity Model Integration) standards to assess the degree of maturity of the application development, as well as ITIL (IT Infrastructure Library) to standardize core processes in IT Service Management.

Bank Name: Comdirect Bank 
Report: Annual report

Year: 2007

IT performance

New award for the e-Banking service of EFG Eurobank from Global Finance magazine: For the 3rd time, the internationally known magazine "Global Finance", selected Eurobank EFG as the "Best Consumer Internet Bank in Greece" for the year 2007.Among others, winners were selected according to the following criteria:

Strengths of strategy for developing and servicing online customers

Breadth of product offerings

Evidence of tangible benefits gained from internet initiatives

Web site design and functionality of www.eurobank.gr

Highlighting the importance of Internet banking, Global Finance noted that "In less than a decade, the Internet has transformed the way many consumers and most businesses bank". This new award demonstrates the Bank's successful strategy for growth, continuous improvement and development of its alternative channels, in order to maintain its innovative character and keep customer service at high levels. This successful strategy has resulted in continuous customer attraction and satisfaction, accompanied by several distinctions from technology magazines in Greece and abroad (PCMagazine, PCWorld, RAM, Global Finance)

Bank Name: EFG Eurobank

Report: Press release

Year: 2007

IT Systems Security

Accordingly, the Bank has developed an IT Systems Security Policy, which applies to all its systems, as well as other specific policies, such as:

Organizational Structure: aiming at allocating responsibilities and designating duties to the heads of corporate units.

Asset Classification: aiming at recording all sensitive data and maintaining appropriate records at each corporate unit. Any information stored in computers is deemed to form part of the Bank's IT assets and is classified on the basis of its security requirements.

Physical and Environmental Security: including measures for securing and protecting all electronic and other equipment of the Bank from third parties, as well as from power supply and cooling systems malfunction.

Communications and Operations Management: aiming at systematically monitoring the capacity and processing power of IT systems, so as to upgrade them appropriately.

Systems Development and Maintenance: aiming at protecting IT systems through appropriate encryption methods. In addition, any new system prior to its installation is subject to strict adequacy and security controls.

Business Continuity Management: aiming at protecting the Bank from unforeseen or disastrous events, so that each unit can continue to operate unobstructed. In order to deal with problems more efficiently, IT systems frequently undergo testing.

Access Control: this policy enables the Bank to restrict unauthorized access to its systems.

Firm name: National Bank of Greece

Report: Corporate Social Responsibly Report

Year: 2007

IT Budget 
At the end of 2007, a multi-business area project to improve the transparency and management of the central IT budgets was successfully concluded for the entire Group. Among other things, the levers for influencing IT costs were identified and IT cost reporting was comprehensively optimized. As part of this project, the cost level was permanently reduced by around $€ 30.9$ million p.a. $€ 28.9$ million of this was already realized in 2007 , further savings of at least $€ 2.0$ million are expected for 2008 .

Bank Name: Landesbank Berlin

Report: Annual report

Year: 2007

\section{Examples of IT governance disclosure (For Chapter Four)}

Special section on IT

Example 1:

In the future, the units supporting the ICT Strategies output will: develop and implement the whole-ofGovernment ICT strategy ensure that Queensland maximises benefits from the Australian Government's rollout of an open access, high-speed, fibre-based national broadband network implement whole-of-Government ICT methodologies and frameworks to enable agencies to maximise their ICT investments to deliver business outcomes progress technology consolidation through the implementation of new enterprise and management tools to help consolidate agencies' data centres networks and infrastructure (servers and storage) continue the development of the Queensland Government Enterprise Architecture to support ICT decision making across the Queensland Government and provide a better foundation for cross-agency initiatives ensure that departmental investment in ICT-enabled service delivery maximises value for money and avoids duplication deliver savings and benefits through sector-wide procurement arrangements for common use items such as telecommunications and software.

Organization: Departement of Public Works, Queensland Government, Australia

Report: Annual report,2008-09

Example 2:

VP's IT systems handle billions of Danish kroner worth of securities on a daily basis. Accordingly, reliable and stable operation is absolutely vital. VP has built up a great many procedures and competences to secure this. As part of this work, VP has developed a disaster contingency plan to ensure that all business systems can be restarted in less than one hour without the loss of data. VP thus fully meets the international requirements for systemically significant financial infrastructures stipulated by the European supervisory authorities and central banks. VP tests its disaster contingency plan at least once a year using a different disaster scenario each time.

Once again, VP's IT operations were reliable and stable in 2008. The IT systems are constantly monitored by internal and external system auditors who report directly to VP's Board of Directors. In addition to a range of completely new initiatives in 2008 relating to new business systems, as well as systems to further improve the monitoring and control of stability and reliability, VP has in place an ongoing programme of maintenance for existing systems and in 2008 completed the major modernisation of one of the oldest system areas. VP will continue to ensure that it has a modern, efficient system environment capable of handling the large demands made by the market.

Special risks: VP is not exposed to any particular operational risks or financial or foreign currency risks. VP's operational risks are continuously being minimised, inter alia by means of a high level of IT security, and financial or foreign exchange risks are limited.

Organization: VP SECURITIES A/S

Report: Annual report, 2008-09 
IT governance Framework:

Example 1:

[ . . . ] To consistently develop an IT-based banking business, the Bank always seeks to develop the competencies of its human resources within this particular area. This commitment was achieved through various training programs that are directly related to the development of skills and knowledge in information technology. Training provided by the Bank througout 2008 includes IT Risk Management, IT Governance \& COBIT, CISCO Certified Network Adminstrator (CCNA), AS/400 Basic Programming and Core Banking System training.

Organization: PT Bank BUMIPUTERA Indonesia Tbk

Report: Annual report, 2008-09

Example 2:

For Information Technology (IT) to function effectively, numerous linked processes have to be identified and managed. The Information Technology Infrastructure Library (ITIL/ISO 20000) defines operational processes that, once implemented, will provide ongoing control, greater efficiency and operational consistency; ISO 20000 is emerging as an EHR operational standard. [ . . . ] For Information Technology (IT) to function effectively, numerous linked processes have to be identified and managed. The Information Technology Infrastructure Library (ITIL/ISO 20000) defines operational processes that, once implemented, will provide ongoing control, greater efficiency and operational consistency; ISO 20000 is emerging as an EHR operational standard. Fujitsu Consulting Canada provided independent assessment of Alberta Health Services ITIL Maturity. Results used the itSMF ITIL Process Maturity Framework.

Organization: Alberta Health Services, Canada

Report: Annual report, 2008-09 


\section{APPENDIX C: COBIT DOMAINS AND IT PROCESSES}

\section{COBIT domains and IT processes (ITGI, 2007):}

\begin{tabular}{|c|c|c|}
\hline Domain & & Process ID/Description \\
\hline \multirow{10}{*}{ Plan \& Organize (PO) } & PO1 & Define a strategic IT plan \\
\hline & $\mathrm{PO} 2$ & Define the information architecture \\
\hline & PO3 & Determine technological direction \\
\hline & $\mathrm{PO} 4$ & Define the IT organization and its relationships \\
\hline & PO5 & Manage IT investments \\
\hline & PO6 & Communicate management aims and direction \\
\hline & PO7 & Manage human resources \\
\hline & PO8 & Manage quality \\
\hline & PO9 & Assess risks \\
\hline & PO10 & Manage projects \\
\hline \multirow{7}{*}{ Acquire \& Implement (AI) } & AI1 & Identify automated solutions \\
\hline & AI2 & Acquire and maintain application software \\
\hline & $\mathrm{AI} 3$ & Acquire and maintain technology infrastructure \\
\hline & AI4 & Enable operation and use \\
\hline & AI5 & Procure IT resources \\
\hline & AI6 & Manage changes \\
\hline & AI7 & Install and accredit solutions and changes \\
\hline \multirow{13}{*}{ Deliver \& Support (DS) } & DS1 & Define and manage service levels \\
\hline & DS2 & Manage third-party services \\
\hline & DS3 & Manage performance and capacity \\
\hline & DS4 & Ensure continuous service \\
\hline & DS5 & Ensure systems security \\
\hline & DS6 & Identify and allocate costs \\
\hline & DS7 & Educate and train users \\
\hline & DS8 & Manage service desk and incidents \\
\hline & DS9 & Manage the configuration \\
\hline & DS10 & Manage problems \\
\hline & DS11 & Manage data \\
\hline & DS12 & Manage the physical environment \\
\hline & DS13 & Manage operations \\
\hline \multirow{4}{*}{ Measure \& Evaluate (ME) } & ME1 & Monitor and evaluate IT performance \\
\hline & ME2 & Monitor and evaluate internal control \\
\hline & ME3 & Ensure regulatory compliance \\
\hline & ME4 & Provide IT governance \\
\hline
\end{tabular}





\section{APPENDIX D: COBIT FRAMEWORK SURVEY}

\section{Part 1: Company Information}

Please provide some background on your company's profile and on your function within the company. This information is especially interesting for the researchers in order to better understand and interpret the answers.

About your company:

In what sector is the company you work for active?

$\begin{array}{ll}\square \text { Financial/Banking } & \square \text { Government-National/State/Local } \\ \square \text { Telecom/Communications } & \square \text { Insurance } \\ \square \text { Technology Services/Consulting } & \square \text { Mining/Construction/Petroleum } \\ \square \text { Public Accounting } & \square \text { Manufacturing/Engineering } \\ \square \text { Agriculture } & \square \text { Transportation } \\ \square \text { Utilities } & \square \text { Pharmaceutical } \\ \square \text { Aerospace } & \square \text { Legal/Law/Real Estate } \\ \square \text { Advertising/Marketing/Media } & \square \text { Retail/Wholesale/Distribution } \square \text { Health Care/Medical } \\ \square \text { Education/Student } & \square \text { Other, please specify : }\end{array}$

What is the size of the company you work for?
$\square$ Fewer than 50 employees
$\square 500-1,499$ employees
$\square$ 10,000 - 14,999 employees
$\square 50$ - 149 employees
$\square$ 1,500-4,999 employees
$\square 15,000$ or more employees
$\square 150-499$ employees
$\square 5,000-9,999$ employees

In what Country is your company based?

About yourself: What is your function within the company you work for?
Is your function based
$\square$ in the IT department
$\square$ in a business department 
Part 2 COBIT Framework: Please find below a list of (generic) IT processes. We want you to indicate for each process how well it is implemented into the company you work for, by giving a score between 1 (not implemented) and 5 (fully implemented). In addendum you will find for each process a list of related activities that typically characterise the execution of this process.

\begin{tabular}{llllll}
\hline IT Process & $\mathbf{1}$ & $\mathbf{2}$ & $\mathbf{3}$ & $\mathbf{4}$ & $\mathbf{5}$ \\
\hline PO1 Define a strategic IT plan. & $\bigcirc$ & $\bigcirc$ & $\bigcirc$ & $\bigcirc$ & $\bigcirc$ \\
PO2 Define the information architecture. & $\bigcirc$ & $\bigcirc$ & $\bigcirc$ & $\bigcirc$ & $\bigcirc$ \\
PO3 Determine technological direction. & $\bigcirc$ & $\bigcirc$ & $\bigcirc$ & $\bigcirc$ & $\bigcirc$ \\
PO4 Define the IT processes, & & & & \\
organisation and relationships. & $\bigcirc$ & $\bigcirc$ & $\bigcirc$ & $\bigcirc$ & $\bigcirc$ \\
PO5 Manage the IT investment. & $\bigcirc$ & $\bigcirc$ & $\bigcirc$ & $\bigcirc$ & $\bigcirc$
\end{tabular}

PO6 Communicate management aims

and direction.

PO7 Manage IT human resources.

PO8 Manage quality.

PO9 Assess and manage IT risks.

PO10 Manage projects.

AI1 Identify automated solutions.

AI2 Acquire and maintain application software.

AI3 Acquire and maintain technology

infrastructure.

AI4 Enable operation and use.

AI5 Procure IT resources.

$\begin{array}{lllll}0 & 0 & 0 & 0\end{array}$

AI6 Manage changes.

AI7 Install and accredit solutions and changes.

$0 \quad 0$

$0 \quad 0 \quad 0$

DS1 Define and manage service levels.

DS2 Manage third-party services.

DS3 Manage performance and capacity.

DS4 Ensure continuous service.

$0 \quad 0$

$0 \quad 0$

$\begin{array}{lllll}0 & 0 & 0 & 0\end{array}$

DS5 Ensure systems security.

DS6 Identify and allocate costs.

$0 \quad 0$

0

○

$0 \quad 0 \quad 0$

DS7 Educate and train users.

DS8 Manage service desk and incidents.

DS9 Manage the configuration.

DS10 Manage problems.

DS11 Manage data.

DS12 Manage the physical environment.

O 0

000

○

$\begin{array}{lllll}0 & 0 & 0 & 0 & 0\end{array}$




\section{SAMENVATTING (SUMMARY IN DUTCH)}

Voor het bereiken van hun doelstellingen zijn organisaties in steeds sterkere mate afhankelijk van informatietechnologie (IT). In de voorbije decennia is er dan ook veel empirisch onderzoek verricht naar de impact van IT investeringen op de winstgevendheid van ondernemingen. Dit type onderzoek heeft laten zien dat het rendement op IT investeringen sterk verschilt van organisatie tot organisatie.

Er zijn verschillende factoren die kunnen verklaren waarom er variatie is in het rendement op IT investeringen. Een goed ingericht IT governance systeem een onderdeel van het bredere begrip corporate governance - wordt gezien als een van de sleutelfactoren in deze verklaring. In het kader van corporate governance worden eisen gesteld aan de beheersing van bedrijfsprocessen. IT governance richt zich daarbij specifiek op het besturen en beheersen van IT-gebruik binnen organisaties en het afleggen van verantwoording daarover. Onderzoek naar IT governance concentreert zich tot nu toe op vier thema's: de allocatie van besluitvormingsrechten in organisaties, het beheersen van IT risico's, het meten van het rendement op IT investeringen en de afstemming van de IT strategie op de ondernemingsstrategie. Er is echter weinig onderzoek verricht naar de transparantie van IT governance en de verslaggeving over IT governance.

Dit proefschrift bundelt drie empirische studies over de determinanten van IT governance verslaggeving van ondernemingen. De eerste studie onderzoekt hoe organisaties belanghebbenden informeren over IT governance. Met behulp van content-analyse wordt een breed scala aan openbare verslagen en rapporten geanalyseerd. De studie richt zich op de bankensector, aangezien dit een bedrijfstak is die sterk afhankelijk is van de inzet van IT. Het jaarverslag blijkt het populairste medium om informatie over IT governance te rapporteren. Tegen mijn verwachtingen in, blijken Europese banken meer informatie over IT governance te verstrekken dan Amerikaanse banken. De verklaring hiervoor is wellicht dat Amerikaanse banken zich simpelweg conformeren aan de regelgeving op dit terrein en niet meer rapporteren dan hetgeen wettelijk is voorgeschreven. Tot slot toont de eerste studie in dit proefschrift ook aan dat organisaties die een kwalitatief hoogwaardig corporate governance systeem hebben, meer informatie verschaffen over IT investeringen.

De tweede studie onderzoekt de invloed van kenmerken van de Raad van Commissarissen $(\mathrm{RvC})$ en de eigendomsstructuur van de onderneming op de verslaggeving over IT governance. De empirische analyse laat zien dat onder- 
nemingsgrootte een belangrijke determinant is van IT governance rapportage. Daarnaast blijkt ook geconcentreerd aandelenbezit - waarbij sommige partijen meer dan 5\% van de uitstaande aandelen in bezit hebben - een positieve invloed uit te oefenen op de informatieverstrekking over IT governance. In tegenstelling tot mijn verwachtingen blijkt het aandeel van onafhankelijke commissarissen in de $\mathrm{RvC}$ niet van invloed op de verslaggeving over IT governance.

Het laatste empirische hoofdstuk van dit proefschrift onderzoekt de relatie tussen de volwassenheid van IT governance en de rol van IT op industrieniveau. Organisaties die gebruik maken van 'best practices' op het terrein van IT governance zullen daarmee niet alleen de effectiviteit en efficiëntie van hun ITgerelateerde bedrijfsprocessen verbeteren, maar zullen ook in staat zijn om meer informatie over IT governance te verschaffen. Daarom onderzoek ik de hypothese dat organisaties die geavanceerde IT governance technieken (bijv. het gebruik van het COBIT raamwerk) hebben geïmplementeerd, meer informatie over IT governance zullen verschaffen dan organisaties die dergelijke technieken niet of in mindere mate hanteren. Daarnaast onderzoek ik de invloed van de rol van IT op industrieniveau, waarbij drie rollen van IT onderscheiden worden: automatiseren, informatiseren en transformeren. De empirische resultaten laten zien dat de volwassenheid van IT governance processen inderdaad positief gerelateerd is aan de verslaggeving over IT governance. Daarnaast blijkt dat ondernemingen uit die industriesectoren waar IT wordt ingezet om te informeren of transformeren, meer informatie over IT governance verschaffen dan ondernemingen uit sectoren waar IT slechts een automatiseringsmiddel is.

Samengevat levert dit proefschrift twee wezenlijke bijdragen aan de onderzoeksliteratuur op het terrein van IT governance. Ten eerste wordt in dit proefschrift een meetinstrument ontwikkeld waarmee de IT governance verslaggeving van organisaties geïnventariseerd kunnen worden. Dit instrument kan vanzelfsprekend hergebruikt worden in vervolgonderzoek, maar ook in de praktijk door IT managers voor benchmarkdoeleinden worden gebruikt. Daarnaast brengt dit proefschrift enkele determinanten van verslaggevingskeuzes in kaart. Zo levert dit proefschrift een bijdrage aan de verklaring van het feit dat de mate van verslaggeving over IT governance verschilt tussen organisaties. Toekomstig onderzoek kan de economische consequenties van deze verschillen in IT governance verslaggeving in kaart brengen. 


\section{CURRICULUM VITAE}

Anant Joshi was born on September 26, 1977 in Akola (MS), India. He holds a master's degree in Industrial Management (cum laude) from Katholieke Universiteit Leuven, Belgium and a bachelor's degree in mechanical engineering from Government College of Engineering Amravati, India. After his bachelor's study, Anant worked as a trainee software engineer at Mahindra British Telecom Ltd. and as an associate executive at Rolta India Ltd. In September 2007, Anant joined the Department of Accounting and Information Management as a $\mathrm{PhD}$ candidate.

Parts of this dissertation have been presented at various conferences including the doctoral consortium of Pacific Asia Conference on Information Systems (PACIS) at Hyderabad, India (2009), the doctoral consortium of International Conference on Information Systems (ICIS) at Saint Louis, USA (2010), the 34th Annual Congress of the European Accounting Association (EAA) at Rome, Italy (2011), and the 36th EAA at Paris, France (2013). His paper - Determinants of IT Governance Transparency: The Influence of Internal and External Corporate Governance Mechanisms received the best paper award at the 4th doctoral Colloquium of Indian Institute of Management Ahmadabad, India (2011).

As of September 2012, Anant is working as a lecturer at the Department of Organization and Strategy at Maastricht University. 